\title{
A comparison of different antibiotic regimens for the treatment of infective endocarditis (Review)
}

Martí-Carvajal AJ, Dayer M, Conterno LO, Gonzalez Garay AG, Martí-Amarista CE

Martí-Carvajal AJ, Dayer M, Conterno LO, Gonzalez Garay AG, Martí-Amarista CE.

A comparison of different antibiotic regimens for the treatment of infective endocarditis.

Cochrane Database of Systematic Reviews 2020, Issue 5. Art. No.: CD009880.

DOI: 10.1002/14651858.CD009880.pub3.

www.cochranelibrary.com 
TABLE OF CONTENTS

HEADER 1

ABSTRACT

PLAIN LANGUAGE SUMMARY

SUMMARY OF FINDINGS

BACKGROUND

OBJECTIVES

METHODS

RESULTS

Figure 1.

Figure 2.

Figure 3.

DISCUSSION

AUTHORS' CONCLUSIONS

ACKNOWLEDGEMENTS

REFERENCES

CHARACTERISTICS OF STUDIES

APPENDICES

WHAT'S NEW

HISTORY

CONTRIBUTIONS OF AUTHORS

DECLARATIONS OF INTEREST

SOURCES OF SUPPORT

DIFFERENCES BETWEEN PROTOCOL AND REVIEW

INDEX TERMS 
[Intervention Review]

\section{A comparison of different antibiotic regimens for the treatment of infective endocarditis}

Arturo J Martí-Carvajal1,2, Mark Dayer ${ }^{3}$, Lucieni O Conterno4 , Alejandro G Gonzalez Garay 5 , Cristina Elena Martí-Amarista6

1Facultad de Ciencias de la Salud Eugenio Espejo, Universidad UTE (Cochrane Ecuador), Quito, Ecuador. 2School of Medicine, Universidad Francisco de Vitoria (Cochrane Madrid), Madrid, Spain. ${ }^{3}$ Department of Cardiology, Taunton and Somerset NHS Trust, Taunton, UK. ${ }^{4}$ Medical School, Department of Internal Medicine, Infectious Diseases Division, State University of Campinas (UNICAMP), Campinas, Brazil. ${ }^{5}$ Methodology Research Unit, Instituto Nacional de Pediatría, Mexico City, Mexico. ${ }^{6}$ Department of Family Medicine, Northwell Health Southside Hospital, Bay Shore, New York, USA

Contact address: Arturo J Martí-Carvajal, arturo.marti.carvajal@gmail.com.

Editorial group: Cochrane Heart Group.

Publication status and date: New search for studies and content updated (no change to conclusions), published in Issue 5, 2020.

Citation: Martí-Carvajal AJ, Dayer M, Conterno LO, Gonzalez Garay AG, Martí-Amarista CE. A comparison of different antibiotic regimens for the treatment of infective endocarditis. Cochrane Database of Systematic Reviews 2020, Issue 5. Art. No.: CD009880. DOI: 10.1002/14651858.CD009880.pub3.

Copyright ( 2020 The Cochrane Collaboration. Published by John Wiley \& Sons, Ltd.

\section{A B S T R A C T}

\section{Background}

Infective endocarditis is a microbial infection of the endocardial surface of the heart. Antibiotics are the cornerstone of treatment, but due to the differences in presentation, populations affected, and the wide variety of micro-organisms that can be responsible, their use is not standardised. This is an update of a review previously published in 2016.

\section{Objectives}

To assess the existing evidence about the clinical benefits and harms of different antibiotics regimens used to treat people with infective endocarditis.

\section{Search methods}

We searched the Cochrane Central Register of Controlled Trials (CENTRAL), MEDLINE, Embase Classic and Embase, LILACS, CINAHL, and the Conference Proceedings Citation Index - Science on 6 January 2020. We also searched three trials registers and handsearched the reference lists of included papers. We applied no language restrictions.

\section{Selection criteria}

We included randomised controlled trials (RCTs) assessing the effects of antibiotic regimens for treating definitive infective endocarditis diagnosed according to modified Duke's criteria. We considered all-cause mortality, cure rates, and adverse events as the primary outcomes. We excluded people with possible infective endocarditis and pregnant women.

\section{Data collection and analysis}

Two review authors independently performed study selection, 'Risk of bias' assessment, and data extraction in duplicate. We constructed 'Summary of findings' tables and used GRADE methodology to assess the quality of the evidence. We described the included studies narratively. 


\section{Main results}

Six small RCTs involving 1143 allocated/632 analysed participants met the inclusion criteria of this first update. The included trials had a high risk of bias. Three trials were sponsored by drug companies. Due to heterogeneity in outcome definitions and different antibiotics used data could not be pooled.

The included trials compared miscellaneous antibiotic schedules having uncertain effects for all of the prespecified outcomes in this review. Evidence was either low or very low quality due to high risk of bias and very low number of events and small sample size.

The results for all-cause mortality were as follows: one trial compared quinolone (levofloxacin) plus standard treatment (antistaphylococcal penicillin (cloxacillin or dicloxacillin), aminoglycoside (tobramycin or netilmicin), and rifampicin) versus standard treatment alone and reported 8/31 (26\%) with levofloxacin plus standard treatment versus 9/39 (23\%) with standard treatment alone; risk ratio (RR) $1.12,95 \%$ confidence interval $(\mathrm{Cl}) 0.49$ to 2.56 . One trial compared fosfomycin plus imipenem $3 / 4$ ( $75 \%$ ) versus vancomycin 0/4 (0\%) (RR 7.00, 95\% Cl 0.47 to 103.27), and one trial compared partial oral treatment 7/201 (3.5\%) versus conventional intravenous treatment $13 / 199(6.53 \%)$ (RR $0.53,95 \% \mathrm{Cl} 0.22$ to 1.31$)$.

The results for rates of cure with or without surgery were as follows: one trial compared daptomycin versus low-dose gentamicin plus an antistaphylococcal penicillin (nafcillin, oxacillin, or flucloxacillin) or vancomycin and reported 9/28 (32.1\%) with daptomycin versus 9/25 (36\%) with low-dose gentamicin plus antistaphylococcal penicillin or vancomycin; $\mathrm{RR} 0.89,95 \% \mathrm{Cl} 0.42$ to 1.89 . One trial compared glycopeptide (vancomycin or teicoplanin) plus gentamicin with cloxacillin plus gentamicin (13/23 (56\%) versus 11/11 (100\%); RR 0.59, 95\% $\mathrm{Cl} 0.40$ to 0.85$)$. One trial compared ceftriaxone plus gentamicin versus ceftriaxone alone (15/34 (44\%) versus $21 / 33$ (64\%); RR $0.69,95 \%$ $\mathrm{Cl} 0.44$ to 1.10$)$, and one trial compared fosfomycin plus imipenem versus vancomycin (1/4 (25\%) versus $2 / 4$ (50\%); RR $0.50,95 \% \mathrm{Cl} 0.07$ to 3.55$)$.

The included trials reported adverse events, the need for cardiac surgical interventions, and rates of uncontrolled infection, congestive heart failure, relapse of endocarditis, and septic emboli, and found no conclusive differences between groups (very low-quality evidence). No trials assessed quality of life.

\section{Authors' conclusions}

This first update confirms the findings of the original version of the review. Limited and low to very low-quality evidence suggests that the comparative effects of different antibiotic regimens in terms of cure rates or other relevant clinical outcomes are uncertain. The conclusions of this updated Cochrane Review were based on few RCTs with a high risk of bias. Accordingly, current evidence does not support or reject any regimen of antibiotic therapy for the treatment of infective endocarditis.

\section{PLAIN LANGUAGE SUMMARY}

\section{Antibiotic therapy for the treatment of infective endocarditis}

\section{Review question}

We aimed to assess the existing evidence about the clinical benefits and harms of different antibiotics regimens used to treat people with infective endocarditis.

\section{Background}

Infective endocarditis is an infection of the inner lining of the heart. It is a serious infection that is frequently fatal, and cardiac surgery is often required. Antibiotics are medicines that treat infections and are the cornerstone of treatment for infective endocarditis. Treatment of patients with infective endocarditis is nosocomial (in-hospital). Despite this, there are surprising differences between guidelines in their recommendations for antibiotic therapy. Furthermore, due to the dose and length of time that antibiotics must be given for, the antibiotics can have serious side effects, such as kidney and ear damage, and cause allergic reactions.

\section{Study characteristics}

We identified only six randomised controlled trials (studies in which participants are assigned to one of two or more treatment groups using a random method) that compared different antibiotic regimens, which included a limited number of participants. Each trial investigated different types and doses of antibiotics. The included studies were published between 1998 and 2019 and were conducted in the USA, Spain, Finland, and Denmark. The evidence is up-to-date as of 6 January 2020.

\section{Key results}

This first update confirms the findings of the original version of the review. Limited and low to very low-quality evidence suggests that the comparative effects of different antibiotic regimens in terms of cure rates or other relevant clinical outcomes are uncertain. The conclusions of this updated Cochrane Review were based on few randomised controlled trials with a high risk of bias. Accordingly, the current evidence does not support or reject any regimen of antibiotic therapy for the treatment of infective endocarditis. 


\section{Quality of evidence}

The confidence in the results of this review is low to very low. The included studies had limitations in the way they were designed and performed, and three studies were sponsored by the manufacturer of the medicine that was assessed. Moreover, the limited number of people included in the studies led to uncertain results. Larger studies are required to provide more information about the best antibiotic regimens to treat people with infective endocarditis. 


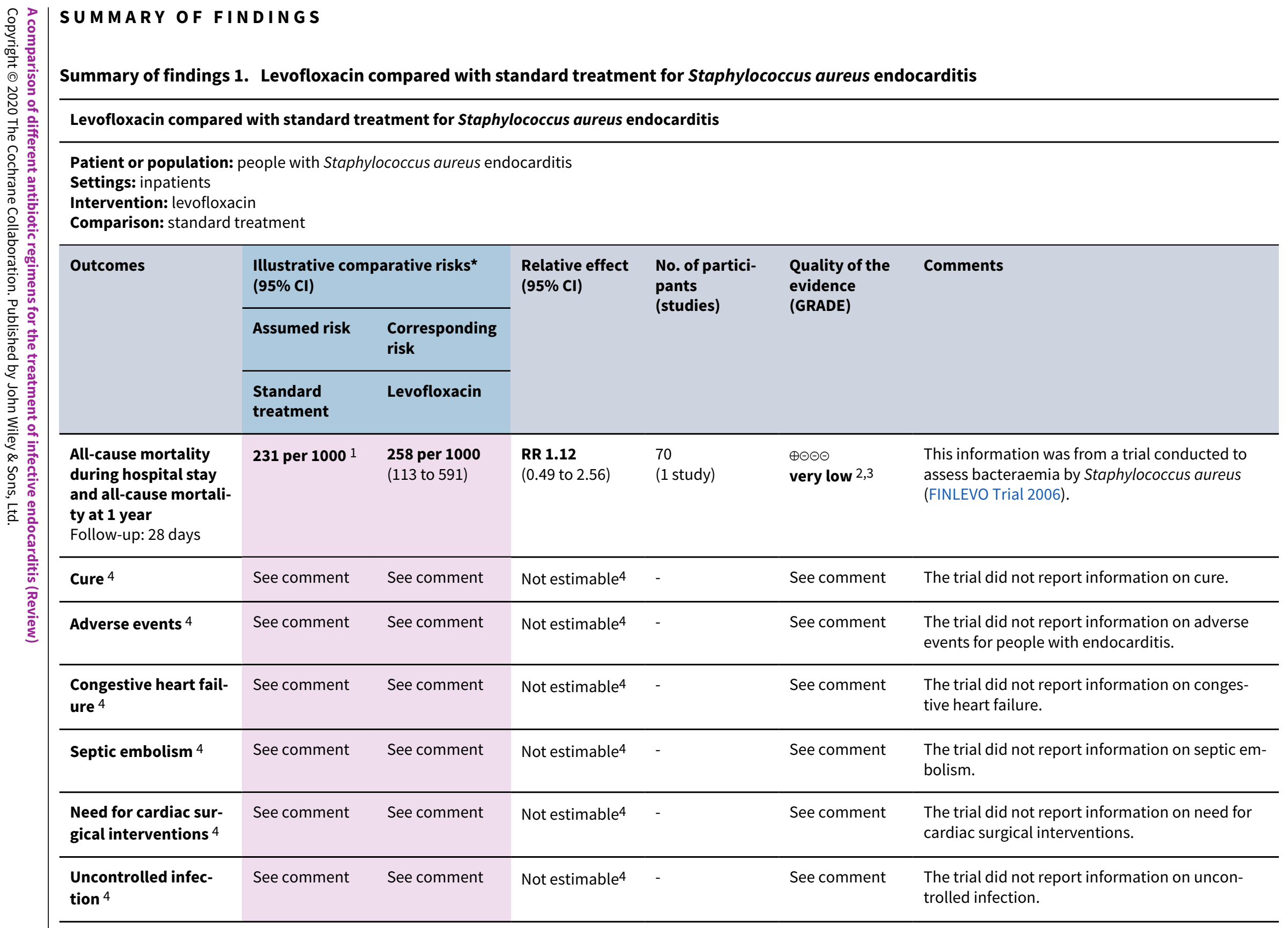

Comparison: standard treatment 
*The basis for the assumed risk (e.g. the median control group risk across studies) is provided in footnotes. The corresponding risk (and its $95 \%$ confidence interval) is based on the assumed risk in the comparison group and the relative effect of the intervention (and its $95 \% \mathrm{Cl}$ ).

Cl: confidence interval; RR: risk ratio

\section{GRADE Working Group grades of evidence}

High quality: Further research is very unlikely to change our confidence in the estimate of effect.

Moderate quality: Further research is likely to have an important impact on our confidence in the estimate of effect and may change the estimate.

Low quality: Further research is very likely to have an important impact on our confidence in the estimate of effect and is likely to change the estimate.

Very low quality: We are very uncertain about the estimate.

1Assumed risk was estimated using control risk group.

2Downgraded by one level for risk of bias. Limitations in the trial design and execution.

${ }^{3}$ Downgraded by two levels for imprecision due to small sample and very low number of events with an impact on the precision of effect estimates.

${ }^{4}$ Data on this outcome were not supplied for participants with endocarditis.

Summary of findings 2. Lipopeptide antibiotic (daptomycin) versus aminoglycoside (low-dose gentamicin) plus antistaphylococcal penicillin (nafcillin, oxacillin, or flucloxacillin) or glycopeptide antibiotic (vancomycin) for Staphylococcus aureus endocarditis

Lipopeptide antibiotic (daptomycin) versus aminoglycoside (low-dose gentamicin) plus antistaphylococcal penicillin (nafcillin, oxacillin, or flucloxacillin) or glycopeptide antibiotic (vancomycin) for Staphylococcus aureus endocarditis

Patient or population: people with endocarditis caused by Staphylococcus aureus

Settings: inpatients

Intervention: lipopeptide antibiotic (daptomycin)

Comparison: aminoglycoside (low-dose gentamicin) + antistaphylococcal penicillin (nafcillin, oxacillin, or flucloxacillin) or glycopeptide antibiotic (vancomycin)

\begin{tabular}{|c|c|c|c|c|c|c|}
\hline \multirow[t]{3}{*}{ Outcomes } & \multicolumn{2}{|c|}{$\begin{array}{l}\text { Illustrative comparative risks }{ }^{\star} \\
(95 \% \mathrm{Cl})\end{array}$} & \multirow[t]{3}{*}{$\begin{array}{l}\text { Relative effect } \\
(95 \% \mathrm{Cl})\end{array}$} & \multirow{3}{*}{$\begin{array}{l}\text { No. of partici- } \\
\text { pants } \\
\text { (studies) }\end{array}$} & \multirow{3}{*}{$\begin{array}{l}\text { Quality of the } \\
\text { evidence } \\
\text { (GRADE) }\end{array}$} & \multirow[t]{3}{*}{ Comments } \\
\hline & Assumed risk & $\begin{array}{l}\text { Corresponding } \\
\text { risk }\end{array}$ & & & & \\
\hline & $\begin{array}{l}\text { Low-dose } \\
\text { aminoglycoside } \\
\text { + antistaphylo- } \\
\text { coccal penicillin } \\
\text { or vancomycin }\end{array}$ & Daptomycin & & & & \\
\hline $\begin{array}{l}\text { All-cause mortality } \\
\text { during hospital stay }\end{array}$ & See comment & See comment & Not estimable & - & See comment & $\begin{array}{l}\text { The trial did not report information on all-cause } \\
\text { mortality. }\end{array}$ \\
\hline
\end{tabular}




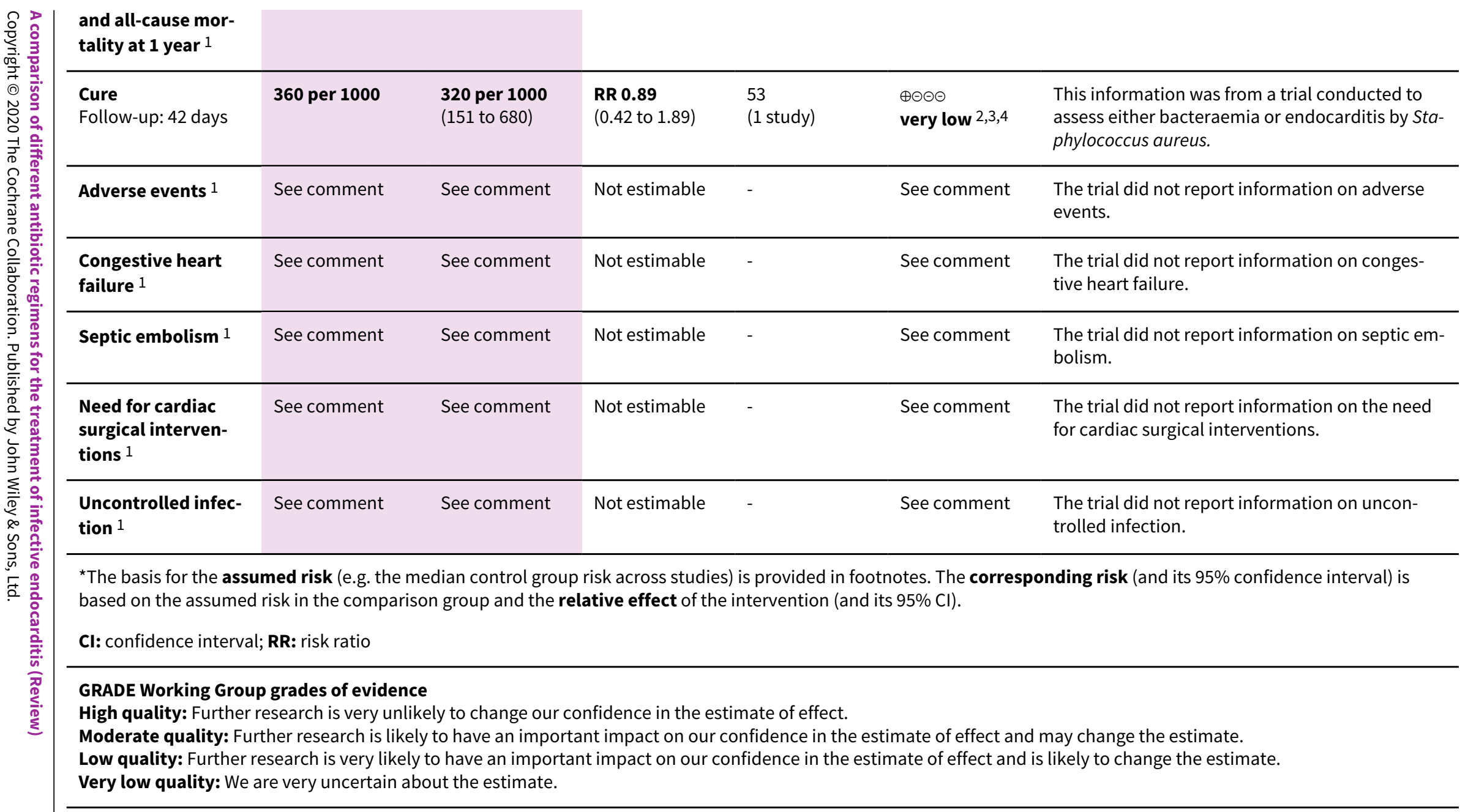

1Data on this outcome were not supplied for participants with endocarditis.

2Downgraded one level for risk of bias. Limitations in the trial design and execution.

${ }^{3}$ Downgraded two levels for imprecision due to small sample and very low number of events with an impact on the precision of effect estimates.

${ }^{4}$ Assumed risk was estimated using control risk group. 


\begin{tabular}{|c|c|c|c|c|c|c|}
\hline \multicolumn{7}{|c|}{$\begin{array}{l}\text { Summary of findings 3. Glycopeptide (vancomycin or teicoplanin) plus aminoglycoside (gentamicin) compared with beta-lactam (cloxacillin) plus } \\
\text { aminoglycoside (gentamicin) for Staphylococcus aureus endocarditis in drug abusers }\end{array}$} \\
\hline \multicolumn{7}{|c|}{$\begin{array}{l}\text { Glycopeptides (vancomycin or teicoplanin) plus aminoglycoside (gentamicin) compared with beta-lactam (cloxacillin) plus aminoglycoside (gentamicin) for Sta- } \\
\text { phylococcus aureus endocarditis in drug abusers }\end{array}$} \\
\hline \multicolumn{7}{|c|}{$\begin{array}{l}\text { Patient or population: people with endocarditis due to Staphylococcus aureus in drug abusers } \\
\text { Settings: inpatients } \\
\text { Intervention: glycopeptide (vancomycin or teicoplanin) + aminoglycoside (gentamicin) } \\
\text { Comparison: beta-lactam (cloxacillin) + aminoglycoside (gentamicin) }\end{array}$} \\
\hline \multirow[t]{3}{*}{ Outcomes } & \multicolumn{2}{|c|}{$\begin{array}{l}\text { Illustrative comparative risks* } \\
(95 \% \mathrm{CI})\end{array}$} & \multirow[t]{3}{*}{$\begin{array}{l}\text { Relative effect } \\
(95 \% \mathrm{Cl})\end{array}$} & \multirow{3}{*}{$\begin{array}{l}\text { No. of partici- } \\
\text { pants } \\
\text { (studies) }\end{array}$} & \multirow{3}{*}{$\begin{array}{l}\text { Quality of the } \\
\text { evidence } \\
\text { (GRADE) }\end{array}$} & \multirow[t]{3}{*}{ Comments } \\
\hline & Assumed risk & $\begin{array}{l}\text { Corresponding } \\
\text { risk }\end{array}$ & & & & \\
\hline & $\begin{array}{l}\text { Beta-lactam } \\
+ \text { aminoglyco- } \\
\text { side }\end{array}$ & $\begin{array}{l}\text { Glycopeptides } \\
+ \text { aminoglyco- } \\
\text { side }\end{array}$ & & & & \\
\hline $\begin{array}{l}\text { All-cause mortality } \\
\text { during hospital stay } \\
\text { and all-cause mor- } \\
\text { tality at } 1 \text { year }\end{array}$ & See comment & See comment & Not estimable & - & See comment & $\begin{array}{l}\text { The trial did not report information on all-cause } \\
\text { mortality. }\end{array}$ \\
\hline $\begin{array}{l}\text { Cure } \\
\text { Follow-up: } 12 \text { weeks }\end{array}$ & 1000 per 1000 & $\begin{array}{l}590 \text { per } 1000 \\
(400 \text { to } 850)\end{array}$ & $\begin{array}{l}\text { RR } 0.59 \\
(0.40 \text { to } 0.85)\end{array}$ & $\begin{array}{l}34 \\
\text { (1 study) }\end{array}$ & $\begin{array}{l}\oplus \oplus \odot \odot \\
\text { low } 1,2,3\end{array}$ & $\begin{array}{l}\text { This trial included } 246 \text { participants with either bac- } \\
\text { teraemia or infective endocarditis. Therefore, } 34 \\
\text { participants means only } 13.82 \% \text { of the total sam- } \\
\text { ple size. }\end{array}$ \\
\hline $\begin{array}{l}\text { Adverse events } \\
\text { Follow-up: } 12 \text { weeks }\end{array}$ & See comment & See comment & $\begin{array}{l}\text { RR } 5.5 \\
\text { (0.33 to } 91.44)\end{array}$ & $\begin{array}{l}34 \\
\text { (1 study) }\end{array}$ & $\begin{array}{l}\oplus \ominus \ominus \ominus \\
\text { very low } 1,2\end{array}$ & $\begin{array}{l}\text { There were no reported adverse events in the con- } \\
\text { trol group. }\end{array}$ \\
\hline $\begin{array}{l}\text { Congestive heart } \\
\text { failure }\end{array}$ & See comment & See comment & Not estimable & - & See comment & $\begin{array}{l}\text { The trial did not report information on congestive } \\
\text { heart failure. }\end{array}$ \\
\hline Septic embolism & See comment & See comment & Not estimable & - & See comment & $\begin{array}{l}\text { The trial did not report information on septic em- } \\
\text { bolism. }\end{array}$ \\
\hline $\begin{array}{l}\text { Need for cardiac } \\
\text { surgical interven- } \\
\text { tions }\end{array}$ & See comment & See comment & Not estimable & - & See comment & $\begin{array}{l}\text { The trial did not report information on the need for } \\
\text { cardiac surgical interventions. }\end{array}$ \\
\hline
\end{tabular}

Comparison: beta-lactam (cloxacillin) + aminoglycoside (gentamicin) 


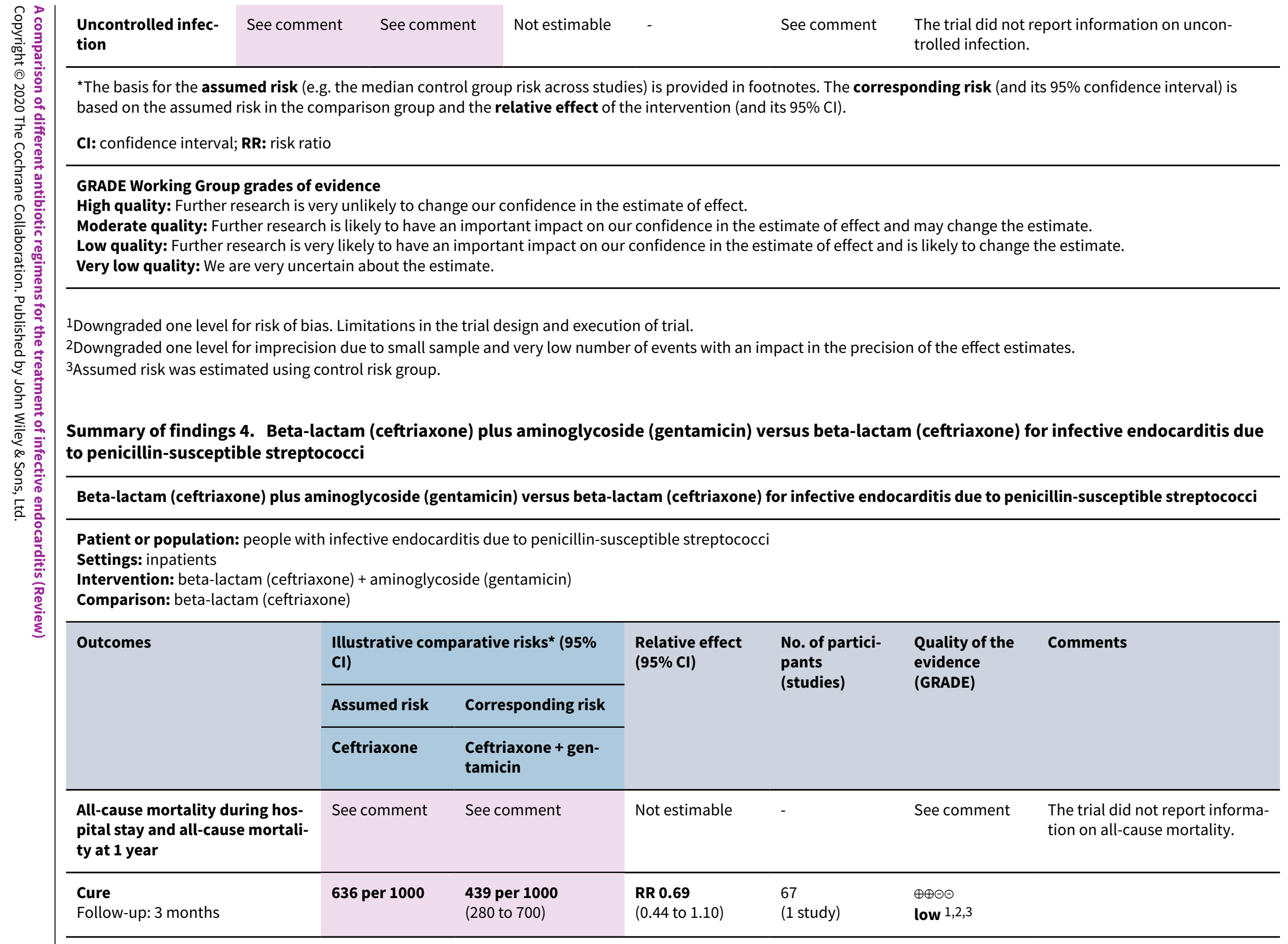




\begin{tabular}{|c|c|c|c|c|c|c|}
\hline $\begin{array}{l}\text { Adverse events } \\
\text { Follow-up: } 3 \text { months }\end{array}$ & 152 per 1000 & $\begin{array}{l}88 \text { per } 1000 \\
(23 \text { to } 339)\end{array}$ & $\begin{array}{l}\text { RR } \mathbf{0 . 5 8} \\
\text { (0.15 to } 2.24)\end{array}$ & $\begin{array}{l}67 \\
\text { (1 study) }\end{array}$ & $\begin{array}{l}\oplus \ominus \ominus \ominus \\
\text { very low } 1,2,3\end{array}$ & $\begin{array}{l}\text { The trial authors considered all } \\
\text { adverse events to be related to } \\
\text { the study drugs. }\end{array}$ \\
\hline Congestive heart failure & See comment & See comment & Not estimable & - & See comment & $\begin{array}{l}\text { The trial did not report informa- } \\
\text { tion on congestive heart failure. }\end{array}$ \\
\hline Septic embolism & See comment & See comment & Not estimable & - & See comment & $\begin{array}{l}\text { The trial did not report informa- } \\
\text { tion on septic embolism. }\end{array}$ \\
\hline $\begin{array}{l}\text { Need for cardiac surgical inter- } \\
\text { ventions } \\
\text { Follow-up: } 30 \text { months }\end{array}$ & 152 per 1000 & $\begin{array}{l}265 \text { per } 1000 \\
\text { (98 to } 708)\end{array}$ & $\begin{array}{l}\text { RR } 1.75 \\
(0.65 \text { to } 4.67)\end{array}$ & $\begin{array}{l}67 \\
\text { (1 study) }\end{array}$ & $\begin{array}{l}\oplus \ominus \ominus \ominus \\
\text { very low 1,2,3 }\end{array}$ & \\
\hline $\begin{array}{l}\text { Uncontrolled infection } \\
\text { Follow-up: } 30 \text { months }\end{array}$ & 30 per 1000 & $\begin{array}{l}29 \text { per } 1000 \\
(2 \text { to } 451)\end{array}$ & $\begin{array}{l}\text { RR } 0.97 \\
\text { (0.06 to } 14.88)\end{array}$ & $\begin{array}{l}67 \\
\text { (1 study) }\end{array}$ & $\begin{array}{l}\oplus \ominus \ominus \ominus \\
\text { very low } 1,2,3\end{array}$ & \\
\hline
\end{tabular}

${ }^{*}$ The basis for the assumed risk (e.g. the median control group risk across studies) is provided in footnotes. The corresponding risk (and its $95 \%$ confidence interval) is based on the assumed risk in the comparison group and the relative effect of the intervention (and its $95 \% \mathrm{Cl}$ ).

Cl: confidence interval; RR: risk ratio

\section{GRADE Working Group grades of evidence}

High quality: Further research is very unlikely to change our confidence in the estimate of effect.

Moderate quality: Further research is likely to have an important impact on our confidence in the estimate of effect and may change the estimate.

Low quality: Further research is very likely to have an important impact on our confidence in the estimate of effect and is likely to change the estimate.

Very low quality: We are very uncertain about the estimate.

1Downgraded one level for risk of bias. Limitations in the trial design and execution.

2Downgraded one level for imprecision. Limitations due to small sample and very low number of events with an impact on the precision of effect estimates.

${ }^{3}$ Assumed risk was estimated using control risk group.

Summary of findings 5. Fosfomycin plus imipenem compared with vancomycin for infective endocarditis due to methicillin-resistant Staphylococcus aureus

Fosfomycin plus imipenem compared with vancomycin for infective endocarditis due to methicillin-resistant Staphylococcus aureus

Patient or population: people with infective endocarditis due to methicillin-resistant Staphylococcus aureus

Settings: inpatients

Intervention: fosfomycin plus imipenem

Comparison: vancomycin 


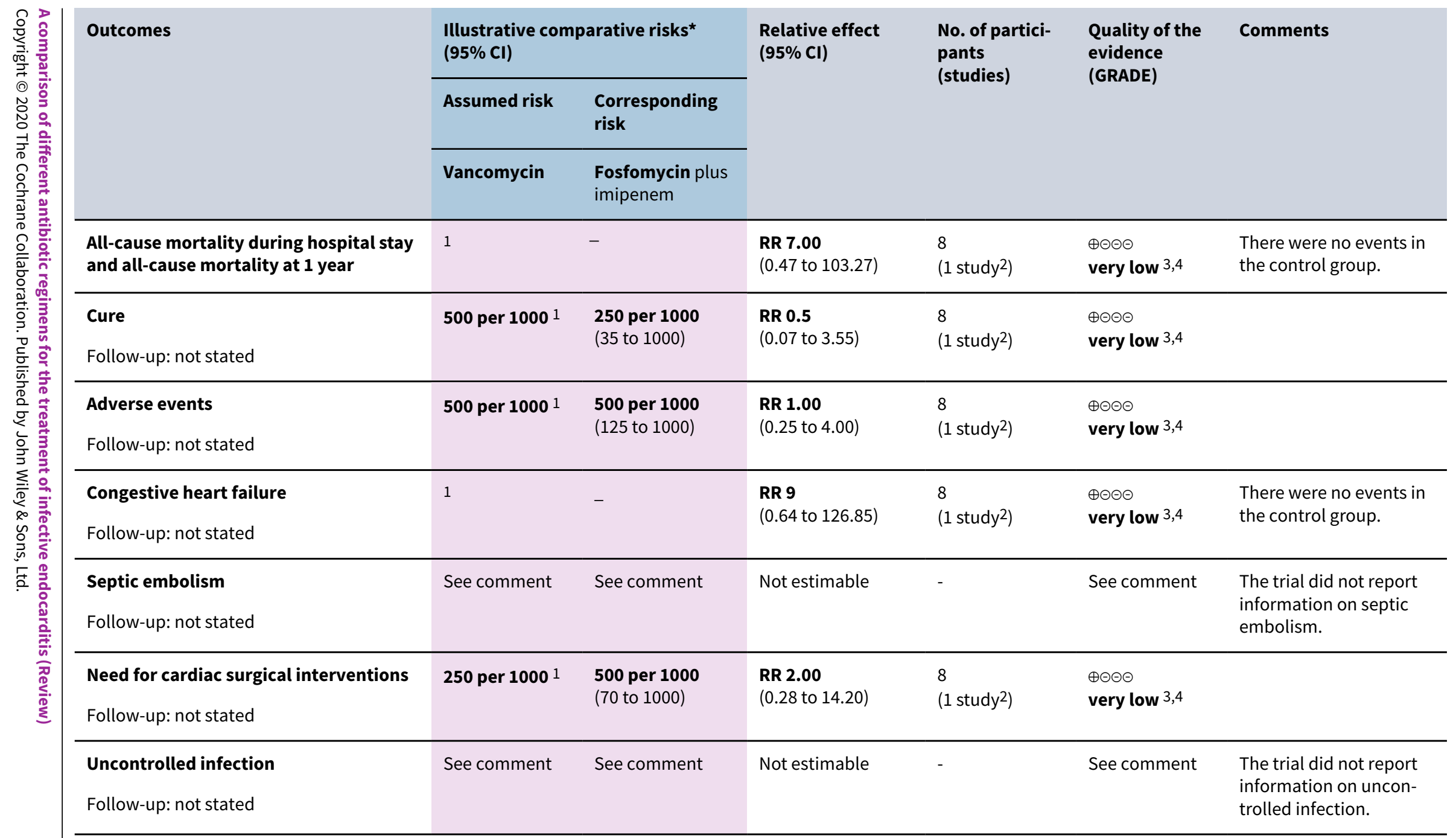

${ }^{*}$ The basis for the assumed risk (e.g. the median control group risk across studies) is provided in footnotes. The corresponding risk (and its $95 \%$ confidence interval) is based on the assumed risk in the comparison group and the relative effect of the intervention (and its $95 \% \mathrm{Cl}$ ).

Cl: confidence interval; RR: risk ratio

\section{GRADE Working Group grades of evidence}

High quality: Further research is very unlikely to change our confidence in the estimate of effect.

Moderate quality: Further research is likely to have an important impact on our confidence in the estimate of effect and may change the estimate. 


\begin{tabular}{|c|c|c|c|c|c|c|}
\hline \multicolumn{7}{|c|}{$\begin{array}{l}\text { 1Assumed risk was estimated using the control risk group. } \\
\text { 2Spanish (10 sites). } \\
\text { } 3 \text { Downgraded two levels for risk of bias. Limitations in the trial design and execution. } \\
{ }^{4} \text { Downgraded two levels for imprecision. Limitations due to small sample and very low number of events with an impact on the precision of effect estimates. } \\
\text { Summary of findings 6. Partial oral treatment compared with conventional intravenous treatment of endocarditis on the left side of the heart (on } \\
\text { native or prosthetic valves) and bacteraemia for Streptococcus, Enterococcus faecalis, Staphylococcus aureus, or coagulase-negative staphylococci }\end{array}$} \\
\hline \multicolumn{7}{|c|}{$\begin{array}{l}\text { Partial oral treatment compared with conventional intravenous treatment of endocarditis on the left side of the heart (on native or prosthetic valves) and bacter- } \\
\text { aemia for Streptococcus, Enterococcus faecalis, Staphylococcus aureus, or coagulase-negative staphylococci }\end{array}$} \\
\hline \multicolumn{7}{|c|}{$\begin{array}{l}\text { Patient or population: people with endocarditis on the left side of the heart (on native or prosthetic valves) with bacteraemia for Streptococcus, Enterococcus faecalis, Sta- } \\
\text { phylococcus aureus, or coagulase-negative staphylococci } \\
\text { Settings: either inpatients or outpatients } \\
\text { Intervention: partial oral treatment } \\
\text { Comparison: conventional intravenous treatment }\end{array}$} \\
\hline \multirow[t]{3}{*}{ Outcomes } & \multicolumn{2}{|c|}{ Illustrative comparative risks ${ }^{\star}(95 \% \mathrm{Cl})$} & \multirow{3}{*}{$\begin{array}{l}\text { Relative effect } \\
(95 \% \mathrm{Cl})\end{array}$} & \multirow{3}{*}{$\begin{array}{l}\text { No. of partici- } \\
\text { pants } \\
\text { (studies) }\end{array}$} & \multirow{3}{*}{$\begin{array}{l}\text { Quality of the } \\
\text { evidence } \\
\text { (GRADE) }\end{array}$} & \multirow[t]{3}{*}{ Comments } \\
\hline & Assumed risk & Corresponding risk & & & & \\
\hline & $\begin{array}{l}\text { Conventional in- } \\
\text { travenous treat- } \\
\text { ment }\end{array}$ & Partial oral treatment & & & & \\
\hline $\begin{array}{l}\text { All-cause mortality during hospital stay } \\
\text { and all-cause mortality at } 1 \text { year } \\
\text { Follow-up: } 6 \text { months }\end{array}$ & 65 per 10001 & $\begin{array}{l}35 \text { per } 1000 \\
(14 \text { to } 86)\end{array}$ & $\begin{array}{l}\text { RR } 0.53 \\
(0.22 \text { to } 1.31)\end{array}$ & $\begin{array}{l}400 \\
\left(1 \text { study }^{2}\right)\end{array}$ & $\begin{array}{l}\oplus \ominus \ominus \ominus \\
\text { very low } 3,4\end{array}$ & \\
\hline Cure & See comment & See comment & Not estimable & - & See comment & $\begin{array}{l}\text { The trial did not } \\
\text { report informa- } \\
\text { tion on cure. }\end{array}$ \\
\hline $\begin{array}{l}\text { Adverse events } \\
\text { Follow-up: } 6 \text { months }\end{array}$ & 60 per $1000^{1}$ & $\begin{array}{l}\mathbf{5 0} \text { per } 1000 \\
(22 \text { to } 113)\end{array}$ & $\begin{array}{l}\text { RR } \mathbf{0 . 8 3} \\
(0.36 \text { to } 1.87)\end{array}$ & $\begin{array}{l}400 \\
\text { (1 study } 2)\end{array}$ & $\begin{array}{l}\oplus \oplus \ominus \ominus \\
\text { low } 3,4\end{array}$ & \\
\hline $\begin{array}{l}\text { Congestive heart failure } \\
\text { Follow-up: } 6 \text { months }\end{array}$ & 5 per $1000^{1}$ & $\begin{array}{l}2 \text { per } 1000 \\
(0 \text { to } 40)\end{array}$ & $\begin{array}{l}\text { RR } 0.33 \\
\text { (0.01 to } 8.05 \text { ) }\end{array}$ & $\begin{array}{l}400 \\
(1 \text { study } 2)\end{array}$ & $\begin{array}{l}\oplus \ominus \ominus \ominus \\
\text { very low } 3,4\end{array}$ & \\
\hline $\begin{array}{l}\text { Need for cardiac surgical } \\
\text { interventions }\end{array}$ & 30 per 10001 & $\begin{array}{l}30 \text { per } 1000 \\
(10 \text { to } 91)\end{array}$ & $\begin{array}{l}\text { RR } 0.99 \\
\text { (0.32 to } 3.02 \text { ) }\end{array}$ & $\begin{array}{l}400 \\
(1 \text { study } 2)\end{array}$ & $\begin{array}{l}\oplus \ominus \ominus \ominus \\
\text { very low } 3,4\end{array}$ & \\
\hline
\end{tabular}

phylococcus aureus, or coagulase-negative staphylococci

Settings: either inpatients or outpatients

Intervention: partial oral treatment 


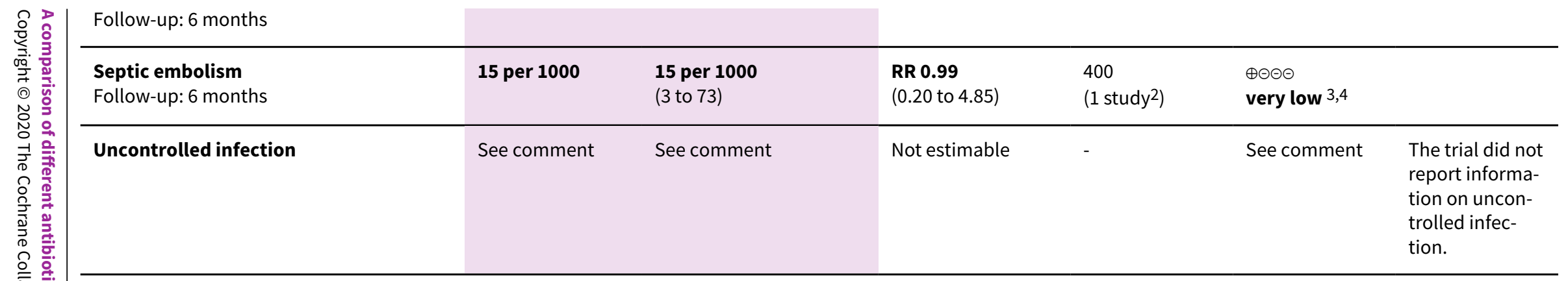

${ }^{\star}$ The basis for the assumed risk (e.g. the median control group risk across studies) is provided in footnotes. The corresponding risk (and its $95 \%$ confidence interval) is based on the assumed risk in the comparison group and the relative effect of the intervention (and its $95 \% \mathrm{Cl}$ ).

Cl: confidence interval; RR: risk ratio

\section{GRADE Working Group grades of evidence}

High quality: Further research is very unlikely to change our confidence in the estimate of effect.

Moderate quality: Further research is likely to have an important impact on our confidence in the estimate of effect and may change the estimate.

Low quality: Further research is very likely to have an important impact on our confidence in the estimate of effect and is likely to change the estimate.

Very low quality: We are very uncertain about the estimate.

${ }^{1}$ Assumed risk was estimated using control risk group.

2Danish (15 sites).

3Downgraded one level for risk of bias. Limitations on the execution of trial. It was an open trial.

${ }^{4}$ Downgraded two levels for imprecision. Limitations due to small sample and very low number of events with an impact on the precision of effect estimates. 


\section{B A C K G R O U N D}

\section{Description of the condition}

Infective endocarditis is a microbial infection of a native or prosthetic heart valve, the endocardial surface, or an indwelling cardiac device (Cahill 2016). The diagnostic criteria include the combination of clinical, echocardiographic, and microbiological data, which are known as Duke's criteria (Baddour 2015). However, it is accepted that the sensitivity of the Duke classification is not optimal, particularly for prosthetic valve infective endocarditis. Recent guidelines have suggested the use of positron emission tomography or radiolabeled leukocyte scintigraphy in order to improve diagnostic accuracy (Habib 2015; lung 2019a).

Extensive narrative reviews on infective endocarditis have been published that describe the pathophysiology, treatments, complications, and outcomes of this clinical entity (Avelana 2018; Baddour 2015; Burgos 2019; Hitzenbichler 2019; Khan 2017; Kobayashi 2019; Long 2018; Şimşek-Yavuz 2020). See Appendix 1 for types of infective endocarditis.

The incidence of infective endocarditis varies by country. Globally, the annual incidence of infective endocarditis has been estimated to be between 15 and 80 cases per million persons in populationbased studies performed in Western countries (lung 2019a; lung $2019 b)$. People with valve prostheses ( $>4$ per 1000 ) or with a history of infective endocarditis (>10 per 1000) are at a higher risk (lung 2019a). Right-sided infective endocarditis represents $5 \%$ to $10 \%$ of infective endocarditis cases (Delahaye 2019).

There are differences in the epidemiology of infective endocarditis between high- and low-income countries (Ambrosioni 2017). In high-income countries, the proportion of cases of endocarditis affecting prosthetic valves or cardiovascular implantable electronic devices has increased (Ambrosioni 2017; Cecchi 2015). Furthermore, there has been an increase in nosocomial cases and infective endocarditis caused by staphylococci and enterococci (Ambrosioni 2017; Cecchi 2015; Ursi 2019). On the other hand, in low-income countries, rheumatic heart disease remains the principal risk factor, and the most frequent causative agents are streptococci (Ambrosioni 2017).

According to the results of the European Infective Endocarditis registry, this complex clinical infectious entity remains a lifethreatening disease with a high mortality despite improvements in diagnosis and therapy (Habib 2019). Infective endocarditis is a serious disease with an in-hospital mortality of $20 \%$, a five-year mortality of $40 \%$, and significant morbidity (Selton-Suty 2019). One potential reason for increasing mortality is the long latency from the onset of symptoms to reaching a definitive diagnosis of infective endocarditis, initiating appropriate treatment and an aging population (Cresti 2017; lung 2019a; Mgbojikwe 2019). At-risk groups for developing infective endocarditis include people with valve replacements, congenital heart disease, chronic rheumatic heart disease, cardiac implantable electronic devices, nosocomial infection, HIV, diabetes mellitus, older age, cancer, poor oral hygiene, dialysis for renal impairment, and intravenous drug use (Amat-Santos 2015; Bai 2017; Beteille 2018; Burgos 2019; Egbe 2019; Elbatarny 2019; Krčméry 2019; Leahey 2019; Lin 2019; Lluri 2018; Meshaal 2018; Moriyama 2019; Muñoz-Moreno 2019; R 2018; Sadeghi 2019; Salvador 2017; Süzük 2016; Wei 2019; Yoshioka 2018). It has recently been demonstrated that the Sequential Organ
Failure Assessment (SOFA) score could be useful for appraising the severity and outcome of individuals with endocarditis (Asai 2019).

Common causative organisms of infective endocarditis include Oral (or Viridans Group) streptococci (VGS) (Vinh 2016), Staphylococcus aureus, and enterococci (Beganovic 2018; Dhotre 2018; Erdem 2019; Krčméry 2019; Kumar 2019; Ogura 2019; Salvador 2017). In particular,VGS is found in the mouth, and it is thought that dental procedures can lead to bacterial endocarditis (Dhotre 2018). Current evidence shows that the most common causative agent of infective endocarditis is S aureus (Vogkou 2016). S. aureus is an organism associated with prosthetic valves and intravenous drug use (Elbatarny 2019). Slipczuk and colleagues conducted a comprehensive review of the changes in the microbiology of infective endocarditis over the past five decades (1960s to 2000s) (Slipczuk 2013). They noted that the proportion of cases caused by staphylococcal and enterococcal infections increased, whereas the numbers due to oral VGS decreased.

Overall, enterococci are the third most common causal microorganisms of infective endocarditis, causing $5-20 \%$ of cases (Skinner 2016).

The pathogenesis of infective endocarditis is very complex and starts with endocardial injury (Chopra 2007; Thiene 2006). The prototypical lesion of infective endocarditis, the vegetation, is a mass of platelets, fibrin, microcolonies of micro-organisms, and scant inflammatory cells (Karchmer 2009). In general, the endothelial lining of the heart and its valves is resistant to infection; however, very virulent micro-organisms, such as $S$ aureus, are able to infect normal heart valves (Melehani 2016; Werdan 2014). Most often, the pathogenesis of infectious endocarditis begins with endothelial cell damage. Congenital or acquired cardiac lesions may induce continuous endocardial trauma via regurgitant flow or high-pressure jets of blood through stenotic lesions (Keynan 2013). Endothelial damage triggers thrombus formation caused by deposition of fibrin and platelets (Shannon 2010; Thurlow 2010). When transient bacteraemia occurs, bacteria can then reach these injury sites and colonise them (Keynan 2013; Widmer 2006). After colonisation, the surface is quickly covered by an additional layer of platelets and fibrin that is suitable for further colonisation, leading to progressive bacterial infection. Moreover, the injury site is further covered by a layer of exopolysaccharide that hinders the penetration of antibiotics (Daga 2011). There is proliferation of these micro-organisms and biofilm formation. Biofilm represents multilayered bacterial aggregate containing a polysaccharide and proteinaceous matrix that favours the bacteria to escape the immune system and hinders antimicrobial action (Colomer-Winter 2018; de Jong 2019; Flemming 2010; Flemming 2016; Guerra 2017; Nasser 2019; Tran 2019). After colonisation, an additional layer of platelets and fibrin cover the surface, leading to further colonisation and progressive bacterial infection and vegetation formation (Jung 2015). Vegetation is the prototypic lesion of infectious endocarditis, and is a mass of platelets, fibrin, micro-organisms, and inflammatory cells (Karchmer 2009).

The clinical features of infective endocarditis are highly variable and depend on the micro-organisms involved as well as the presence or absence of pre-existing heart disease (Song 2015; Sun 2015). The clinical presentation may be acute and rapidly progressive or subacute and chronic (Habib 2019). Fever is present in about $90 \%$ of those affected and is associated with various systemic symptoms such as loss of appetite and weight ( $\mathrm{Ba}$ 
2017; El Rafei 2016). A heart murmur is present in about $85 \%$ of people (Damasco 2019). The clinical features include neurological symptoms and signs (Champey 2016; Nascimento 2019; Sotero 2019). Infective endocarditis is a risk factor for stroke (Cantier 2019; Cao 2018; Shao 2019).

A recent meta-analysis found a better prognosis of infective endocarditis in people with mechanical valves compared with those with biological valves (Tao 2017); the clinical features of infective endocarditis are summarised in Appendix 2.

Infective endocarditis is generally thought to be lethal if left untreated, although evidence of infection may be found incidentally during valve surgery (Grisoli 2014). Successful treatment of infective endocarditis relies on microbial eradication by antimicrobial drugs; surgical intervention is sometimes needed to remove infected material and drain abscesses and reconstruct or replace damaged valves (Giacobbe 2019). However, the risk of mortality after surgical treatment of infective endocarditis is high due to several risk of factors, i.e., multivalvular affection, female sex, previous cardiac surgery, congestive heart failure, age, no blood cultures before referral, body mass index, renal failure, ischemic heart disease, inadequate response to medical treatment, prolonged aortic cross-clamp and cardiopulmonary bypass time, embolization, peri-annular extension of infection, Staphylococcus aureus infection, paravalvular abscess, vegetations $>2.2 \mathrm{~cm}$, pericardial effusion, and septic or cardiogenic shock (Jakuska 2019; Nagy 2018; Singer 2017; Varela 2019).

\section{Description of the intervention}

\section{Clinical pharmacology and microbiological spectrum}

Many antimicrobial drugs have been used alone or in combination to treat infective endocarditis (Vinh 2016). These include betalactams, aminoglycosides, glycopeptides, oxazolidinones, complex macrocyclics, and quinolones (Cunha 2015; Drees 2006; Frank 2009; Pabilona 2015). See Appendix 3 for more details.

\section{Antibiotic adverse reactions}

The major antibiotic adverse reactions associated with the main antimicrobial drugs for treating infective endocarditis are well described (Granowitz 2008). See Appendix 3 for more details.

\section{Guideline recommendations for the treatment of infective endocarditis}

According to international guidelines, treatment of infective endocarditis should use bactericidal antibiotics, administered parenterally, at high dosages, typically for prolonged periods (four to six weeks) (Baddour 2015; Habib 2019). Where possible, the choice of antibiotic should be directed at the microbial agent isolated from blood cultures, according to the sensitivity pattern identified (Baddour 2015; Habib 2019). In general, the guidelines also recommend the combination of an aminoglycoside with a cell wall inhibitor (i.e. beta-lactams and glycopeptides) for synergistic bactericidal activity, to shorten the duration of therapy (e.g. oral streptococci) and to eradicate resistant organisms (e.g. Enterococcus spp.) (Baddour 2015; Habib 2019).

The recommended doses and schedules of the main antibiotics for treating infective endocarditis are shown in Appendix 3.

\section{How the intervention might work}

Appropriate antibiotic treatment is important to control local and systemic infection, eradicate the organisms from the vegetations, and reduce the risk of complications such as septic embolisation (Baddour 2015).

\section{Why it is important to do this review}

The recommended treatment of infective endocarditis still varies between guidelines (Murphy 2019; Saraste 2019). This first update of a review previously published in 2016, Marti-Carvajal 2016, has been performed to identify and review the latest evidence. This is of great importance, as is has been reported that around the world experts in infective endocarditis management do not follow international consensus guidelines on the particular point of the use of antibiotics (Tissot-Dupont 2017).

In summary, the principal research question of this updated Cochrane Review was: 'Which antibiotic regimens are superior in treating people with infective endocarditis?'. A secondary question was: 'What are the clinical benefits and harms of those regimens?'.

\section{O B JECTIVES}

To assess the existing evidence about the clinical benefits and harms of different antibiotics regimens used to treat people with infective endocarditis.

\section{METHODS}

\section{Criteria for considering studies for this review Types of studies}

We included parallel randomised controlled trials (RCTs), randomised at the level of the participant. It is not possible to conduct a trial with another design for infective endocarditis. We included studies reported as full text, those published as abstract only, and unpublished data.

\section{Types of participants}

Adults (aged 18 years or older) with a definitive diagnosis of infective endocarditis, according to modified Duke's criteria (Durack 1994; Li 2000). This requires the presence of two major criteria, or one major and three minor criteria, or five minor criteria, or micro-organisms demonstrated by culture or histology of a vegetation, embolised vegetation, or in an intracardiac abscess, or histological evidence of active endocarditis (vegetation or intracardiac abscess) (Tam 2016).

\section{Major criteria}

- Positive blood cultures for infective endocarditis

In the absence of a primary focus, positive cultures from two separate blood cultures of one of the following typical organisms.

- Viridans group streptococci

- Streptococcus bovis

- HACEK group (Haemophilus species, Actinobacillus actinomycetes comitants, Cardiobacterium hominis, Eikenella species, Kingella kingae)

- Community-acquired S. aureus or enterococci 
OR

- Persistently positive blood cultures of a micro-organism consistent with infective endocarditis

OR

- Single blood culture for Coxiella burnetii or antiphase immunoglobulin (Ig)G antibody titre greater than 1:800

- Evidence of endocardial involvement

- New valvular regurgitation

OR

- Positive echocardiogram (oscillating intracardiac mass in the absence of an alternative anatomic explanation OR abscess OR new partial dehiscence of prosthetic valve)

\section{Minor criteria}

- Predisposing heart condition OR intravenous drug use

- Fever (at least $38.0^{\circ} \mathrm{C}$ )

- Vascular phenomena (arterial emboli, septic pulmonary infarcts, mycotic aneurysm, intracranial haemorrhage, conjunctival haemorrhage, Janeway lesions)

- Immunological phenomena (glomerulonephritis, Osler's nodes, Roth spots, positive rheumatoid factor)

- Microbiological evidence of positive blood culture not meeting major criterion but excluding single positive culture for coagulase-negative staphylococci and organisms that do not cause endocarditis OR serological evidence of active infection with organism consistent with infective endocarditis.

We excluded people with possible infective endocarditis (e.g. with one major and one minor criteria, or three minor criteria).

We excluded pregnant women with endocarditis because drugs such as tetracyclines and chloramphenicol have well-described fetal or neonatal adverse effects and should be avoided. In general, however, human studies on the safety of many antimicrobial agents in pregnancy and lactation are limited, and antimicrobial agents should be prescribed with caution (Leekha 2011).

We included trials with mixed populations, that is trials where only a subset of participants met our eligibility criteria. We obtained outcome data for the subset of interest.

\section{Types of interventions}

Antibiotic therapy (monotherapy or combinations) compared with any other active antibiotic treatment at any dose, administration route, or duration. We excluded surgical interventions.

We compared different antibiotic classes, used as single agents or in combination, as well as different durations of treatment. We compared antibiotics when used empirically and also when used against sensitive bacteria. We made the following comparisons.

- The standard antibiotics suggested by guidelines according to the sensitivity of isolated bacteria (Habib 2019).
- Streptococcus

* Penicillin (amoxicillin or ampicillin or penicillin G) or ceftriaxone for four weeks versus penicillin (amoxicillin or ampicillin or penicillin $\mathrm{G}$ ) or ceftriaxone with gentamicin or netilmicin for two weeks, or vancomycin for four weeks with gentamicin for two weeks.

- Enterococcus

* Ampicillin or amoxicillin with gentamicin for four or six weeks versus vancomycin with gentamicin for six weeks.

- Saureus

* Cloxacillin or oxacillin for four or six weeks with gentamicin for three to five days versus vancomycin for four to six weeks with gentamicin for three to five days, or cloxacillin or oxacillin for four or six weeks with gentamicin for three to five days and rifampicin for six weeks or vancomycin for four to six weeks with gentamicin three to five days and rifampicin for six weeks.

* Levofloxacin plus cloxacillin or dicloxacillin versus cloxacillin or dicloxacillin for 14 days.

- Standard antibiotics suggested by guidelines versus no standard regimen or new drugs, according to sensitivities of isolated bacteria.

- Different empirical antibiotics for treating native or prosthetic valve infective endocarditis.

\section{Types of outcome measures}

\section{Primary outcomes}

- All-cause mortality (without the time points).

- Cure, defined as: disappearance of fever, sterilisation of blood cultures, and normalisation of inflammatory markers during treatment and in the subsequent four weeks (Baddour 2015; Hoen 2006).

- Adverse events including treatment-related adverse events (TRAE) (Ioannidis 2004), at any time of the treatment. We defined TRAE as: "a response to a drug which is noxious and uninitiated and which occurs at doses normally used in man for prophylaxis, diagnosis, or therapy of disease, or for the modification of physiologic functions" (Nebeker 2004). We extracted the number of participants with at least one TRAE out of the total randomised in each study arm.

\section{Secondary outcomes}

- Incidence of septic embolism (number of participants out of the total randomised), at longest available follow-up.

- Incidence of congestive heart failure (number of participants out of the total randomised) at the first 15 days of treatment (arbitrary election).

- Quality of life (as measured by a validated scale), at longest available follow-up.

- Need for cardiac surgical interventions (valve reconstruction or valve replacement) (number of participants who underwent surgery of the total randomised), at longest available follow-up (Elmistekawy 2016).

* Indication for cardiac surgical intervention:

$\square$ haemodynamic compromise;

$\square$ persistent or uncontrolled infection (or both) despite aggressive medical therapy;

embolisation. 
- Uncontrolled infection (persisting infection, perivalvular extension), at longest available follow-up.

- Relapse of endocarditis (new onset of fever, chills, or other evidence of systemic toxicity caused by the same species within six months of the initial episode), at longest available follow-up.

Reporting one or more of the outcomes listed here in the trial was not an inclusion criterion for this review. However, when a published report did not appear to report one of our outcomes, we neither accessed the trial protocol nor contacted the trial authors to ascertain whether the outcomes were measured but not reported.

\section{Search methods for identification of studies}

\section{Electronic searches}

We searched the following electronic databases on 6 January 2020:

- the Cochrane Central Register of Controlled Trials (CENTRAL) (Issue 1 of 12, 2020) (the Cochrane Library);

- Epub Ahead of Print, In-Process \& Other Non-Indexed Citations, MEDLINE Daily and MEDLINE (Ovid, 1946 to 3 January 2020);

- Embase Classic and Embase (Ovid, 1947 to 3 January 2020);

- LILACS via Virtual Health Library (Latin American and Caribbean Health Science Information database) (BIREME, 1982 to 6 January 2020);

- CINAHL Plus with Full Text (Cumulative Index to Nursing and Allied Health Literature) (EBSCO, 1937 to 6 January 2020);

- Conference Proceedings Citation Index - Science (CPCI-S) on the Web of Science (Clarivate Analytics, 1990 to 6 January 2020).

The search strategies are shown in Appendix 4. The Cochrane sensitivity-precision maximising RCT filter was applied to MEDLINE, and for Embase, terms as recommended in the Cochrane Handbook for Systematic Reviews of Interventions were applied (Lefebvre 2011). For the other databases, except CENTRAL, an adaptation of the Cochrane RCT filter was applied.

We imposed no date or language of publication restrictions.

\section{Searching other resources}

We searched the World Health Organization (WHO) International Clinical Trials Registry Platform (apps.who.int/ trialsearch/), US National Institutes of Health Ongoing Trials Register ClinicalTrials.gov (clinicaltrials.gov), and the ISRCTN (www.isrctn.com/) for ongoing and unpublished trials on 17 March 2020.

We checked the reference lists of all included trials identified by the above methods.

\section{Data collection and analysis}

We summarised data using standard Cochrane methods (Higgins 2011). We constructed 'Summary of findings' tables and used the GRADE approach to assess the quality of included studies.

\section{Selection of studies}

Two review authors (AMC, CMA) independently screened the titles and abstracts of all studies identified as a result of the search for potential relevance, coding them as 'retrieve' (eligible or potentially eligible/unclear) or 'do not retrieve'. In case of disagreement, two review authors (AGG, MD) were asked to arbitrate. We retrieved the full-text study reports/publications, and three review authors (AMC, LOC) independently screened the full texts and identified studies for inclusion, and identified and recorded reasons for exclusion of ineligible studies. Any disagreements were resolved through discussion or by consulting a third review author (MD) if necessary. We identified and excluded duplicates and collated multiple reports of the same study so that each study, rather than each report, was the unit of interest in the review. We recorded the selection process in sufficient detail to complete a PRISMA flow diagram and 'Characteristics of excluded studies' table (Liberati 2009).

\section{Data extraction and management}

Two review authors (AMC, AGG) independently extracted data from the included trials. We extracted the following data overall.

- Participants: demographics (mean age, age range, gender, country, $\mathrm{N}$ randomised, $\mathrm{N}$ lost to follow-up, $\mathrm{N}$ analysed, severity of condition, diagnostic criteria, inclusion criteria, exclusion criteria).

- Methodological characteristics of the trial (allocation concealment, blinding, etc.). These data were extracted and included in the 'Risk of bias' assessment. We also extracted information on the design, total duration of the study, number of study centres and location, study setting, and study date for the Methods section of the Characteristics of included studies tables.

- Interventions: characteristics of infective endocarditis (anatomic site, type of affected valve), type of antibiotic and characteristics of its administration (names, alone or in combination). We also extracted data about concomitant medications and excluded medications, if this information was available.

- Outcomes: clinical outcomes, either primary or secondary, such as were reported into the included trial, including time points reported.

- Notes: funding for trial, and notable conflicts of interest of trial authors.

We discussed any discrepancies. One review author (AMC) transferred data into Review Manager 5 (Review Manager 2014). Two review authors (AMC, MD, CMA) double-checked that data were entered correctly by comparing the data presented in the systematic review with the study reports. Three review authors (LOC, AGG, CMA) spot-checked the study characteristics for accuracy against the trial report.

\section{Assessment of risk of bias in included studies}

Three review authors (AMC, LOC, AGG) independently assessed the risk of bias in pairs of each trial using a simple form, following the domain-based evaluation as described in the Cochrane Handbook for Systematic Reviews of Interventions (Higgins 2011). Any disagreements were resolved by discussion.

We assessed the following domains as low, high, or unclear risk of bias:

- generation of allocation sequence;

- allocation concealment;

- blinding (of participants, personnel, and outcome assessors);

- incomplete outcome data; 
- selective reporting

- other sources of bias.

See Appendix 5 for criteria used for assessing risk of bias.

\section{Measures of treatment effect}

We did not conduct a meta-analysis as studies used different antibiotic regimens. We will apply the following procedures in the future if possible.

For dichotomous data (incidence of septic embolism and incidence of congestive heart failure), we will present results as summary risk ratios (RRs) with $95 \%$ confidence intervals ( $\mathrm{Cls}$ ). For continuous data (quality of life), we will present results as mean difference (MD) if the studies report continuous data on the same scale and standardised mean differences (SMDs) with 95\% Cls if studies report different scales.

We presented results as RRs with $95 \% \mathrm{Cls}$ for all-cause mortality during hospital stay and all-cause mortality at one year, cure, adverse events including TRAEs, need for cardiac surgical interventions, uncontrolled infection, and relapse of endocarditis.

\section{Unit of analysis issues}

The unit of analysis was the participants with infective endocarditis. In the case of trials with more than two arms, we compared families of antibiotics, that is glycopeptides plus aminoglycoside versus beta-lactam plus aminoglycoside.

\section{Dealing with missing data}

We did not perform sensitivity analysis for per-protocol, worsecase, and best-case scenarios as no meta-analysis was performed (Hollis 1999). In the case of missing data on participants or missing statistics (such as standard deviations) in future updates, we will contact the trial authors.

\section{Assessment of heterogeneity}

We were unable to pool findings to perform meta-analysis as the studies used different antibiotic regimens. For future updates, we will use the $1^{2}$ statistic to measure statistical heterogeneity between the trials in each analysis if possible. The $\mathrm{I}^{2}$ statistic describes the percentage of total variation across trials that is due to heterogeneity rather than to sampling error (Higgins 2003). In future updates, we will visually inspect the forest plots. There is substantial uncertainty in the value of $I^{2}$ when there is only a small number of studies, in which case we will also consider the $P$ value from the $\mathrm{Chi}^{2}$ test.

\section{Assessment of reporting biases}

If in future updates we include 10 or more trials, we will attempt to assess whether the review is subject to publication bias by using a funnel plot. If we detect asymmetry, we will explore other causes (e.g. selective outcome reporting, poor methodological quality in smaller studies, true heterogeneity) (Sterne 2011).

\section{Data synthesis}

We did not conduct a meta-analysis. For future updates, if the eligible trials are sufficiently comparable in their clinical characteristics, we will summarise their findings using both fixedeffect and random-effects models. In the presence of statistical heterogeneity and the absence of small-study effects, we expect the $95 \% \mathrm{Cl}$ from the random-effects model to include the $95 \% \mathrm{Cl}$ from the fixed-effect model. In such a case, we will report only the data using the random-effects model as it appropriately conveys heterogeneity. If substantial differences are observed between both models, we will investigate this further.

\section{Subgroup analysis and investigation of heterogeneity}

We anticipate clinical heterogeneity for the following participants and intervention characteristics, therefore we will carry out the following subgroup analyses in future updates if possible.

- People at highest risk for a complicated or lethal course of infective endocarditis (people with valvular prosthesis (mechanical or biological), people who have previously had endocarditis, people with certain congenital heart defects, and heart-transplant recipients who have developed a cardiac valvulopathy).

- People aged over 60 years.

- People with culture-negative endocarditis versus people with infective endocarditis with positive blood cultures.

- Right-sided versus left-sided infective endocarditis.

- Type of infective organism.

- People with native-valve endocarditis versus people with prosthetic-valve endocarditis.

- People with community-acquired endocarditis versus healthcare-associated endocarditis or endocarditis that developed after a surgical procedure.

- Monotherapy versus combination therapy.

We plan to restrict subgroup analysis to primary outcomes only (Higgins 2011).

\section{Sensitivity analysis}

For future updates, if sufficient trials are identified and pooled, we will conduct a sensitivity analysis comparing the results using all the included trials.

- Including only RCTs with a low risk of bias (Higgins 2011). It is unlikely that we will find many trials at low risk of bias in all 'Risk of bias' domains, therefore we will choose three core domains only: generation of allocation sequence, incomplete outcome data, and selective reporting bias.

- Sensitivity analyses taking concealment of allocation and attrition into consideration.

\section{'Summary of findings' tables}

We used the principles of the GRADE system to assess the quality of the body of evidence associated with all main outcomes (allcause mortality during hospital stay and all-cause mortality at one year, cure, adverse events, TRAE, incidence of congestive heart failure, incidence of septic embolism, need for cardiac surgical intervention) (Guyatt 2008), and constructed 'Summary of findings' tables using GRADEpro GDT software (GRADEpro 2008). The GRADE approach appraises the quality of a body of evidence based on the extent to which one can be confident that an estimate of effect or association reflects the item being assessed. Evaluation of the quality of a body of evidence considers within-study risk of bias, directness of the evidence, heterogeneity in the data, precision of effect estimates, and risk of publication bias (Balshem 2011; Guyatt 
2011a; Guyatt 2011b; Guyatt 2011c; Guyatt 2011d; Guyatt 2011e; Guyatt 2011f; Guyatt 2011g; Guyatt 2011h).

One review author (AMC) constructed 'Summary of findings' tables, and another review author (AGG) assessed the quality of evidence: Summary of findings 1; Summary of findings 2; Summary of findings 3; Summary of findings 4; Summary of findings 5; Summary of findings 6 .

\section{RESULTS}

\section{Description of studies}

\section{Results of the search}

Searching from the previous review to January 2020 (latest search), we identified 415 records in the database searches and 14 records from clinical trials registers. There were 351 unique references after removal of duplicates. We excluded a further 347 references after title and abstract screening. We obtained the full texts of the remaining four references for more detailed examination. These four references were for two new RCTs (Pericas 2018; POET 2019).

This updated review includes a total of six RCTs, published between 1998 and 2019, involving 1143 participants (FINLEVO Trial 2006; Fortún 2001; Fowler 2006; Pericas 2018; POET 2019; Sexton 1998). See Figure 1 for details of study selection. 
Figure 1. Study flow diagram.

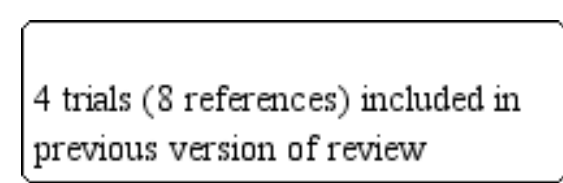

previous version of review
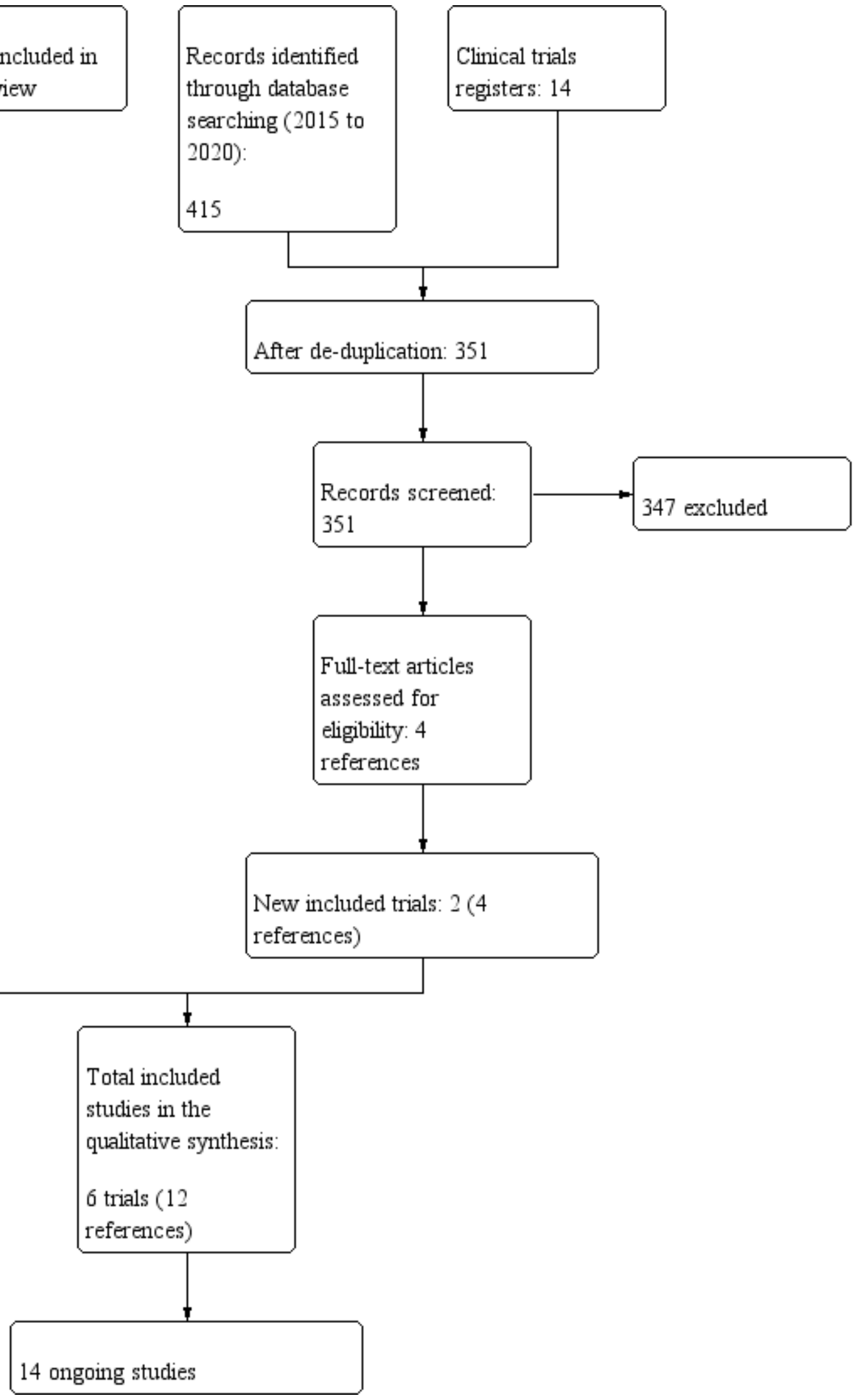
The length of follow-up ranged from 28 days to six months. The trials varied in size, characteristics of participant populations, duration, drug dosage, and experimental design. For study details see Characteristics of included studies.

\section{Included studies}

For study details see Characteristics of included studies.

\section{Interventions}

The following comparisons were evaluated in the included trials.

\section{A quinolone plus standard treatment versus standard treatment}

A quinolone, levofloxacin, at a dose of $500 \mathrm{mg}$ once daily for participants weighing less than $60 \mathrm{~kg}$ and $500 \mathrm{mg}$ twice daily for participants weighing over $60 \mathrm{~kg}$, administered both intravenously and orally, was compared with standard treatment. Standard treatment comprised cloxacillin or dicloxacillin $2 \mathrm{~g}$ every four hours, intravenously. Participants with contraindications to penicillin received cefuroxime (1.5 g every six hours, clindamycin $600 \mathrm{mg}$ every six or eight hours, or vancomycin $1 \mathrm{~g}$ twice daily). When oral treatment was indicated, cloxacillin $500 \mathrm{mg}$ every six hours, cephalexin or cefadroxil $500 \mathrm{mg}$ every six hours, or clindamycin $300 \mathrm{mg}$ every six hours was used. Doses were adjusted according renal function. Furthermore, an aminoglycoside, tobramycin or netilmicin at $1 \mathrm{mg} / \mathrm{kg}$ body weight every eight hours, and rifampicin $450 \mathrm{mg}$ once daily for participants weighing under $50 \mathrm{~kg}$ and $600 \mathrm{mg}$ once daily for participants weighing over $50 \mathrm{~kg}$, oral or intravenously was used (FINLEVO Trial 2006).

\section{A glycopeptide plus an aminoglycoside versus a beta-lactam plus an aminoglycoside}

Vancomycin $500 \mathrm{mg}$ intravenous every six hours with gentamicin $1.5 \mathrm{mg} / \mathrm{kg}$ every eight hours for two weeks, or teicoplanin $12 \mathrm{mg} /$ $\mathrm{kg}$ every 24 hours, with a loading dose of $24 \mathrm{mg} / \mathrm{kg}$ given on the first day with gentamicin $1.5 \mathrm{mg} / \mathrm{kg}$ every eight hours for two weeks was compared with cloxacillin $2 \mathrm{~g}$ intravenously every four hours with gentamicin $1.5 \mathrm{mg} / \mathrm{kg}$ every eight hours for two weeks (Fortún 2001).

\section{A lipopeptide antibiotic (daptomycin) versus either antistaphylococcal penicillins or a glycopeptide antibiotic plus an aminoglycoside}

Daptomycin $6 \mathrm{mg} / \mathrm{kg}$ intravenously once daily was compared with standard therapy with either vancomycin $1 \mathrm{~g}$ every 12 hours or nafcillin, oxacillin, or flucloxacillin $2 \mathrm{~g}$ every four hours (depending on the susceptibility of the causative strain to methicillin) plus gentamicin $1 \mathrm{mg} / \mathrm{kg}$ intravenously every eight hours for the first four days. The duration of therapy was determined by the investigators, but the median duration of therapy was 14 days for daptomycin and 15 days for standard therapy (Fowler 2006).

\section{A beta-lactam plus an aminoglycoside versus a beta-lactam alone}

Ceftriaxone $2 \mathrm{~g}$ intravenously once daily for two weeks was compared with ceftriaxone $2 \mathrm{~g}$ intravenously once daily with gentamicin $3 \mathrm{mg} / \mathrm{kg}$ (of ideal body weight) once daily for two weeks (Sexton 1998).

Two studies determined gentamicin levels (Fortún 2001; Sexton 1998), and one study determined vancomycin and teicoplanin levels (Fortún 2001). One study did not report if the antibiotic levels were determined (Fowler 2006).

\section{Fosfomycin plus imipenem versus vancomycin}

Fosfomycin $2 \mathrm{~g}$ intravenously six hourly plus imipenem $1 \mathrm{~g}$ intravenously six hourly, adjusted for renal function, was compared with vancomycin 30 to $45 \mathrm{mg} / \mathrm{kg}$ daily intravenously divided into two to three doses, ensuring trough levels $\geq 15 \mathrm{mg} / \mathrm{L}$ (Pericas 2018). If the participant developed either treatment failure or renal failure with vancomycin, he/she was switched to the fosfomycin/ imipenem group.

\section{Partial oral treatment versus conventional intravenous treatment}

After an initial period of conventional intravenous treatment, a switch to oral medication was compared to continuing with conventional intravenous treatment. This treatment strategy was based on the guidelines of the European Society of Cardiology (Habib 2015), with modifications endorsed by the Danish Society of Cardiology (Moser 2017). The composition, doses, and duration of different oral regimens are described in Appendix 6 and Appendix 7. No details were provided regarding the conventional intravenous therapy regimens (POET 2019).

\section{Participants}

The included trials involved a total of 1143 randomised participants (median 156.5; range 34 to 381 ).

Five trials reported the age of the participants, which ranged between 18 and 92 years (FINLEVO Trial 2006; Fortún 2001; Pericas 2018; POET 2019; Sexton 1998). Male participants were predominant in five trials: $60 \%$ in FINLEVO Trial 2006, $97.5 \%$ in Fortún 2001, 76\% in POET 2019, and 80\% in Sexton 1998. One trial did not report the gender of the participants (Fowler 2006). One trial showed inconsistency regarding the frequency of this variable between comparison groups (Pericas 2018).

Only two trials included people diagnosed as having definitive and probable endocarditis (FINLEVO Trial 2006; Fowler 2006). Four trials only included people with infective endocarditis (Fortún 2001; Pericas 2018; POET 2019; Sexton 1998). One trial only included right-sided endocarditis (Fortún 2001); two trials included leftsided endocarditis (POET 2019; Sexton 1998); and three trials reported data of participants irrespective of the side of the valve affected by endocarditis (FINLEVO Trial 2006; Fowler 2006; Pericas 2018).

The included trials were conducted to assess the effect of the intervention on different micro-organisms: methicillin-susceptible S aureus (Fortún 2001), S aureus (FINLEVO Trial 2006; Fowler 2006), and ceftriaxone-susceptible viridans group streptococci or $S$ bovis endocarditis (Sexton 1998). Two trials only included endocarditis affecting native valves (Fortún 2001; Sexton 1998). Two trials involved participants with either native or prosthetic valves (Fowler 2006; POET 2019). Two trials reported data from participants with $S$ aureus bacteraemia, a subset of whom had endocarditis: 70 participants in FINLEVO Trial 2006 and 52 participants in Fowler 2006.

\section{Methods}

The included trials were conducted between 1998 and 2019 and used a parallel design (FINLEVO Trial 2006; Fortún 2001; Fowler 2006; Pericas 2018; POET 2019; Sexton 1998). Five trials had two arms (FINLEVO Trial 2006; Fowler 2006; Pericas 2018; POET 2019; Sexton 1998), and one trial had three arms (Fortún 2001). There 
were five multicentre trials (FINLEVO Trial 2006; Fowler 2006; Pericas 2018; POET 2019; Sexton 1998). One trial was conducted in Finland (FINLEVO Trial 2006), one trial in Denmark (POET 2019), two trials in Spain (Fortún 2001; Pericas 2018), and two trials in the USA (Fowler 2006; Sexton 1998). The follow-up of the trials ranged between 28 days, (FINLEVO Trial 2006) and six months (POET 2019). Four trials reported a priori sample size estimation (FINLEVO Trial 2006; Fowler 2006; Pericas 2018; POET 2019). The median number of outcomes reported by any trial was six (minimum four, maximum seven). One trial included a composite outcome involving four components (POET 2019). Two trials without a priori sample size estimation assessed six outcomes each (Fortún 2001; Sexton 1998).

\section{Excluded studies}

We excluded 10 RCTs that did not meet Duke's criteria for diagnosis of infective endocarditis (Abrams 1979; Fortún 1995;
Gilbert 1991; Greenman 1984; Heldman 1996; Korzeniowski 1982; Levine 1991; Markowitz 1992; Ribera 1996; Stamboulian 1991). See Characteristics of excluded studies.

\section{Ongoing trials}

We identified 14 ongoing trials (CTRI/2008/091/000060; EUCTR 2016-003059-31; EUCTR 2017-001699-43; EudraCT 2008-008683-28; JPRN-UMIN 000032006; NCT00638157; NCT00695903; NCT02208063; NCT02701595; NCT02701608; NCT03138733; NCT03148756; NCT04222257; RBR-3p8g7n 2016). See Characteristics of ongoing studies.

\section{Risk of bias in included studies}

The risk of bias in the included trials is summarised in Figure 2 and Figure 3 , and detailed in the Characteristics of included studies table.

\section{Figure 2. Risk of bias graph: review authors' judgements about each risk of bias item presented as percentages across all included studies.}

Random sequence generation (selection bias) Allocation concealment (selection bias) Blinding of participants and personnel (performance bias): All outcomes Blinding of outcome assessment (detection bias): Cure Blinding of outcome assessment (detection bias): All-cause mortality Blinding of outcome assessment (detection bias): Adverse events Blinding of outcome assessment (detection bias): Incidence of septic embolism Blinding of outcome assessment (detection bias): Incidence of congestive heart failure Blinding of outcome assessment (detection bias): Quality of life Blinding of outcome assessment (detection bias): Need for cardiac surgical interventions Blinding of outcome assessment (detection bias): Indication of cardiac surgery Blinding of outcome assessment (detection bias): Uncontrolled infection Blinding of outcome assessment (detection bias): Relapse Incomplete outcome data (attrition bias): All outcomes Selective reporting (reporting bias) Other bias

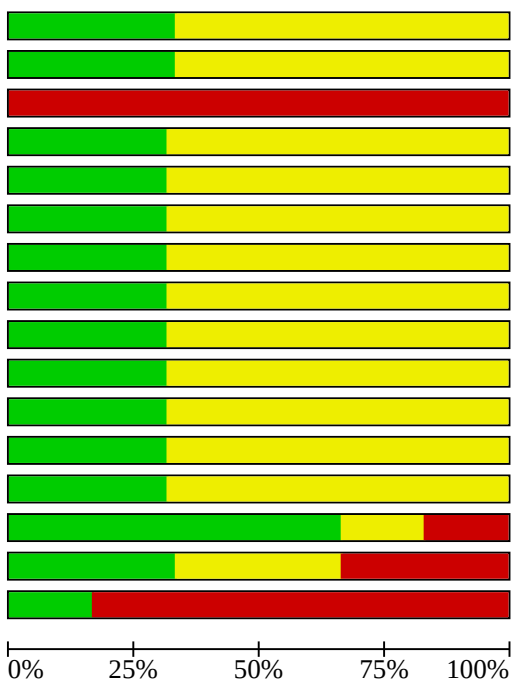
Low risk of bias 
Figure 3. Risk of bias summary: review authors' judgements about each risk of bias item for each included study.

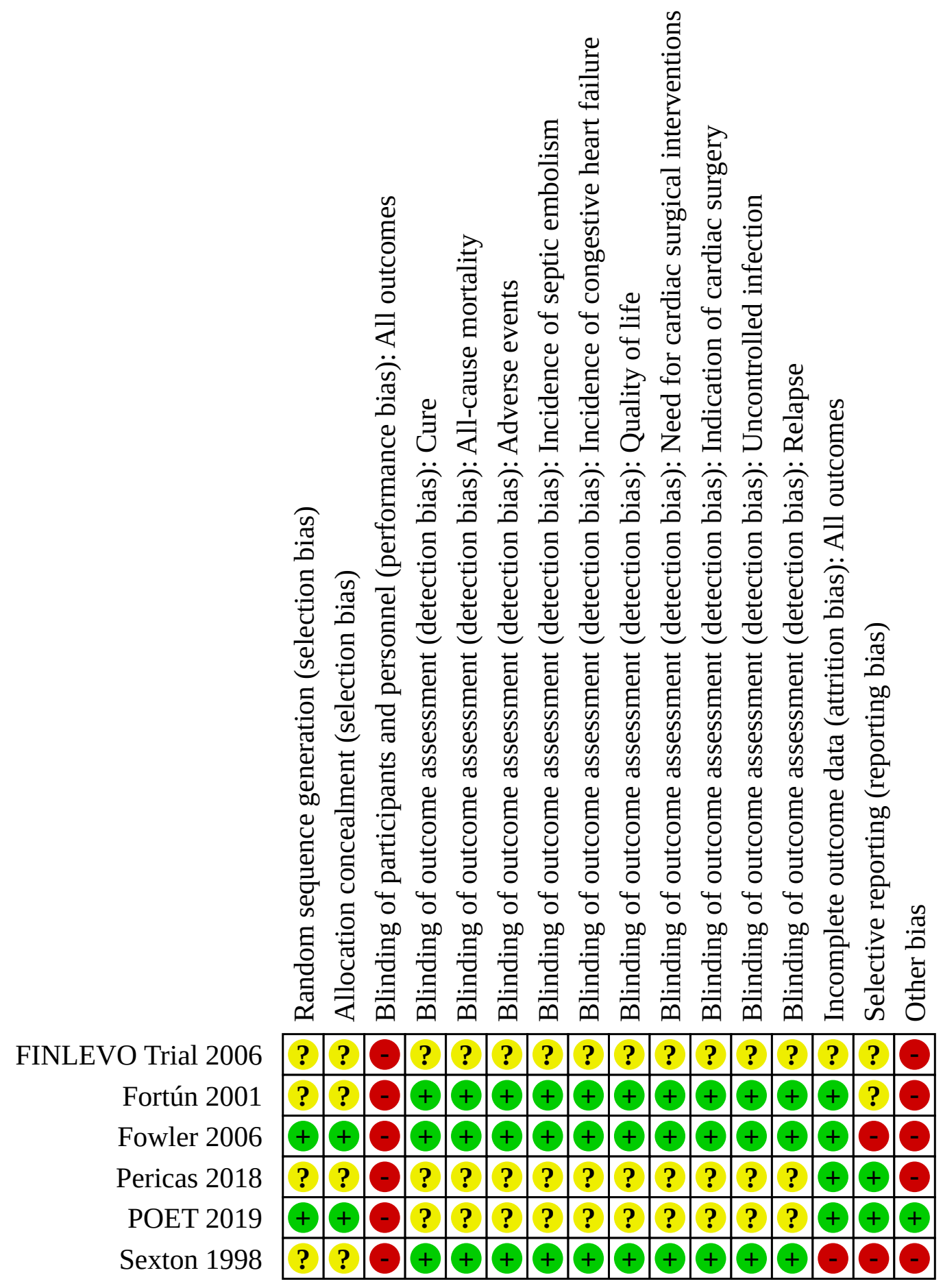

We considered all trials as at high risk of bias. 


\section{Allocation}

\section{Random sequence generation}

The risk of bias arising from the method of generation of the allocation sequence was low in two trials (Fowler 2006; POET 2019). Four trials had an unclear risk of bias (FINLEVO Trial 2006; Fortún 2001; Pericas 2018; Sexton 1998).

\section{Allocation concealment}

The risk of bias arising from the method of generation of the allocation sequence was low in two trials (Fowler 2006; POET 2019). Four trials had an unclear risk of bias (FINLEVO Trial 2006; Fortún 2001; Pericas 2018; Sexton 1998).

\section{Blinding}

The risk of bias due to lack of blinding of participants and personnel was high in all trials (FINLEVO Trial 2006; Fortún 2001; Fowler 2006; Pericas 2018; POET 2019; Sexton 1998).

\section{Blinding of outcome assessment (detection bias)}

For all-cause mortality, the risk of bias was low risk in three trials, FINLEVO Trial 2006; Fortún 2001; POET 2019, and unclear in three trials (Fowler 2006; Pericas 2018; Sexton 1998).

For cure, we rated Fortún 2001, Fowler 2006, and Sexton 1998 as at low risk of bias for blinding of outcome assessment. We rated one trial as having an unclear risk of bias (Pericas 2018). POET 2019 did not assess this outcome.

For adverse events, three trials were at low risk of bias (Fortún 2001; POET 2019; Sexton 1998), and three trials were at unclear risk of bias for blinding of outcome assessment (FINLEVO Trial 2006; Fowler 2006; Pericas 2018).

For incidence of septic embolism, one trial was at low risk of bias (POET 2019), and five trials were at unclear risk of bias (FINLEVO Trial 2006; Fortún 2001; Fowler 2006; Pericas 2018; Sexton 1998).

For incidence of heart failure, one trial was at low risk of bias (POET 2019), and five trials were at unclear risk of bias (FINLEVO Trial 2006; Fortún 2001; Fowler 2006; Pericas 2018; Sexton 1998).

No trials assessed quality of life, thus we rated all trials as at unclear risk of bias for this domain (FINLEVO Trial 2006; Fortún 2001; Fowler 2006; Pericas 2018; POET 2019; Sexton 1998).

For the need for cardiac valve reconstruction or replacement, we assessed two trials as at low risk of bias (POET 2019; Sexton 1998), and four trials as at unclear risk of bias (FINLEVO Trial 2006; Fortún 2001; Fowler 2006; Pericas 2018).

For indication of cardiac surgery due to embolisation, haemodynamic compromise, or persistent infection, two trials were at low risk of bias (POET 2019; Sexton 1998), and four trials were at unclear risk of bias (FINLEVO Trial 2006; Fortún 2001; Fowler 2006; Pericas 2018).

For uncontrolled infection, two trials had a low risk of bias (Fowler 2006; Sexton 1998), and four trials had an unclear risk of bias (FINLEVO Trial 2006; Fortún 2001; Pericas 2018; POET 2019).
For relapse, two trials had a low risk of bias (Fortún 2001; POET 2019), and four trials had an unclear risk of bias (FINLEVO Trial 2006; Fortún 2001; Pericas 2018; Sexton 1998).

\section{Incomplete outcome data}

Risk of attrition bias was low in four trials (Fortún 2001; Fowler 2006; Pericas 2018; POET 2019), high in one trial (Sexton 1998), and unclear in one trial (FINLEVO Trial 2006).

\section{Selective reporting}

Risk of selective outcome reporting bias was low in two trials (Pericas 2018; POET 2019), high in two trials (Fowler 2006; Sexton 1998), and unclear in two trials (FINLEVO Trial 2006; Fortún 2001).

\section{Other potential sources of bias}

One trial had a low risk for other potential trial (POET 2019). Risk of other bias was high in five trials due to bias in the presentation of data, and design bias (FINLEVO Trial 2006; Fortún 2001; Fowler 2006; Pericas 2018; Sexton 1998).

\section{Effects of interventions}

See: Summary of findings 1 Levofloxacin compared with standard treatment for Staphylococcus aureus endocarditis; Summary of findings 2 Lipopeptide antibiotic (daptomycin) versus aminoglycoside (low-dose gentamicin) plus antistaphylococcal penicillin (nafcillin, oxacillin, or flucloxacillin) or glycopeptide antibiotic (vancomycin) for Staphylococcus aureus endocarditis; Summary of findings 3 Glycopeptide (vancomycin or teicoplanin) plus aminoglycoside (gentamicin) compared with beta-lactam (cloxacillin) plus aminoglycoside (gentamicin) for Staphylococcus aureus endocarditis in drug abusers; Summary of findings 4 Betalactam (ceftriaxone) plus aminoglycoside (gentamicin) versus betalactam (ceftriaxone) for infective endocarditis due to penicillinsusceptible streptococci; Summary of findings $\mathbf{5}$ Fosfomycin plus imipenem compared with vancomycin for infective endocarditis due to methicillin-resistant Staphylococcus aureus; Summary of findings 6 Partial oral treatment compared with conventional intravenous treatment of endocarditis on the left side of the heart (on native or prosthetic valves) and bacteraemia for Streptococcus, Enterococcus faecalis, Staphylococcus aureus, or coagulase-negative staphylococci

Results were based on 632 participants from 1143 randomised participants. This is due to the fact that three trials were conducted in participants with S aureus bacteraemia (FINLEVO Trial 2006; Fowler 2006; Pericas 2018), which included a subset of participants with infective endocarditis, but treated a broader range of participants; we have only included the data from the participants with endocarditis. See Summary of findings 1; Summary of findings 2; Summary of findings 3; Summary of findings 4; Summary of findings 5; Summary of findings 6 .

\section{Primary outcomes}

\section{All-cause mortality}

Quinolones (levofloxacin) plus standard treatment (antistaphylococcal penicillin (cloxacillin or dicloxacillin), aminoglycoside (tobramycin or netilmicin), and rifampicin) versus standard treatment

One trial showed inconclusive evidence regarding all-cause mortality at 28 days and 3 months $(8 / 31(26 \%)$ with levofloxacin 
plus standard treatment versus 9/39 (23\%) with standard treatment alone; risk ratio (RR) 1.12, 95\% confidence interval (CI) 0.49 to 2.56 ; very low-quality evidence) (FINLEVO Trial 2006).

Glycopeptides (vancomycin or teicoplanin) plus an aminoglycoside (gentamicin) versus a beta-lactam (cloxacillin) plus an aminoglycoside (gentamicin)

One trial described no deaths at least 12 weeks after completion of therapy (Fortún 2001).

\section{Fosfomycin plus imipenem versus vancomycin}

One trial showed inconclusive evidence in terms of all-cause mortality at six months (3/4 (75\%) with fosfomycin plus imipenem versus $0 / 4$ (0\%) with vancomycin; RR $7.00,95 \% \mathrm{Cl} 0.47$ to 103.27 ; very low-quality evidence) (Pericas 2018).

\section{Partial oral treatment versus conventional intravenous treatment}

One trial showed inconclusive evidence regarding all-cause mortality at six months $(7 / 201$ (3.48\%) with partial oral treatment versus $13 / 199$ (6.53\%) with conventional intravenous treatment; RR $0.53,95 \% \mathrm{Cl} 0.22$ to 1.31 ; very low-quality evidence) (POET 2019).

\section{Cure}

Lipopeptide antibiotics (daptomycin) versus aminoglycoside (lowdose gentamicin) plus antistaphylococcal penicillins (nafcillin, oxacillin, or flucloxacillin) or glycopeptide antibiotics (vancomycin)

One trial found no conclusive evidence between the two regimens for cure $(9 / 28$ (32\%) with daptomycin versus $9 / 25$ (36\%) with lowdose gentamicin plus antistaphylococcal penicillin or vancomycin; RR $0.89,95 \% \mathrm{Cl} 0.42$ to 1.89 ; very low-quality evidence) (Fowler 2006).

Glycopeptides (vancomycin or teicoplanin) plus an aminoglycoside (gentamicin) versus a beta-lactam (cloxacillin) plus an aminoglycoside (gentamicin)

One trial showed conclusive evidence between the regimens for cure $(13 / 23(56 \%)$ with glycopeptides plus aminoglycoside versus $11 / 11(100 \%)$ beta-lactam plus an aminoglycoside; RR $0.59,95 \% \mathrm{Cl}$ 0.40 to 0.85 ; low-quality evidence) (Fortún 2001).

Beta-lactam (ceftriaxone) plus an aminoglycoside (gentamicin) versus a beta-lactam alone (ceftriaxone)

One trial found inconclusive evidence between the regimens for cure $(15 / 34(44 \%)$ with beta-lactam plus aminoglycoside versus $21 / 33(64 \%)$ with beta-lactam alone; RR $0.69,95 \% \mathrm{Cl} 0.44$ to 1.10 ; low-quality evidence) (Sexton 1998).

\section{Fosfomycin plus imipenem versus vancomycin}

One trial showed inconclusive evidence between the regimens for cure $(1 / 4(25 \%)$ with fosfomycin plus imipenem versus $2 / 4(50 \%)$ with vancomycin; $\mathrm{RR} 0.50,95 \% \mathrm{Cl} 0.07$ to 3.55 ; very low-quality evidence) (Pericas 2018).

\section{Treatment-related adverse events}

Glycopeptides (vancomycin or teicoplanin) plus an aminoglycoside (gentamicin) versus a beta-lactam plus an aminoglycoside (cloxacillin plus gentamicin)

One trial showed no conclusive evidence with regard to TRAEs (5/23 (22\%) with glycopeptides plus aminoglycoside versus $0 / 11$
(0\%) with beta-lactam plus aminoglycoside; RR 5.50, 95\% Cl 0.33 to 91.44; very low-quality evidence) (Fortún 2001).

A beta-lactam (ceftriaxone) plus an aminoglycoside (gentamicin) versus a beta-lactam alone (ceftriaxone)

One trial found inconclusive results with regard to TRAEs (3/34 $(8.8 \%)$ with beta-lactam plus aminoglycoside versus $5 / 33(15 \%)$ with a beta-lactam alone; RR $0.58,95 \% \mathrm{Cl} 0.15$ to 2.24 ; very lowquality evidence) (Sexton 1998).

\section{Fosfomycin plus imipenem versus vancomycin}

One trial showed inconclusive evidence in terms of adverse events (2/4 (50\%) with fosfomycin plus imipenem versus $2 / 4$ (50\%) with vancomycin; RR $1.00,95 \% \mathrm{Cl} 0.25$ to 4.00 ; very low-quality evidence) (Pericas 2018).

\section{Partial oral treatment versus conventional intravenous treatment}

One trial showed inconclusive evidence regarding adverse events $(10 / 201$ (4.97\%) with fosfomycin plus imipenem versus $12 / 199$ (6.03\%) with vancomycin; RR $0.83,95 \% \mathrm{Cl} 0.36$ to 1.87 ; low-quality evidence) (POET 2019).

\section{Secondary outcomes}

\section{Incidence of septic embolism}

Partial oral treatment versus conventional intravenous treatment

One trial showed inconclusive evidence regarding septic embolism (3/201 (1.49\%) with fosfomycin plus imipenem versus $3 / 199$ (1.50\%) with vancomycin; RR $0.99,95 \% \mathrm{Cl} 0.20$ to 4.85 ; very low-quality evidence) (POET 2019).

\section{Incidence of congestive heart failure}

Fosfomycin plus imipenem versus vancomycin

One trial showed inconclusive evidence in terms of congestive heart failure (4/4 (100\%) with fosfomycin plus imipenem versus $0 / 4(0 \%)$ with vancomycin; RR $9.00,95 \% \mathrm{Cl} 0.64$ to 126.85 ; very low-quality evidence) (Pericas 2018).

\section{Partial oral treatment versus conventional intravenous treatment}

One trial showed inconclusive evidence regarding congestive heart failure $(0 / 201(0 \%)$ with partial oral treatment versus $1 / 199(0.5 \%)$ with conventional intravenous treatment; RR $0.33,95 \% \mathrm{Cl} 0.01$ to 8.05; very low-quality evidence) (POET 2019).

\section{Quality of life}

No trials assessed quality of life.

\section{Need for cardiac surgical intervention (valve reconstruction or replacement) intervention}

\section{A beta-lactam (ceftriaxone) plus an aminoglycoside (gentamicin)} versus a beta-lactam (ceftriaxone) alone

One trial found inconclusive results in terms of need for a cardiac surgical intervention (9/34 (26\%) with beta-lactam plus aminoglycoside versus 5/33 (15\%) with beta-lactam alone; RR 1.75 , $95 \% \mathrm{Cl} 0.65$ to 4.67 ) (Sexton 1998). 
A beta-lactam (ceftriaxone) plus an aminoglycoside (gentamicin) versus a beta-lactam alone (ceftriaxone)

One trial reported that one participant in the control group had a pedunculated mobile vegetation at the time of surgery (Sexton 1998).

\section{Fosfomycin plus imipenem versus vancomycin}

One trial showed inconclusive evidence in terms of need for a cardiac surgical intervention (2/4 (50\%) with fosfomycin plus imipenem versus $1 / 4$ (25\%) with vancomycin; RR $2.00,95 \% \mathrm{Cl} 0.28$ to 14.20; very low-quality evidence) (Pericas 2018).

\section{Partial oral treatment versus conventional intravenous treatment}

One trial showed inconclusive evidence regarding need for a cardiac surgical intervention (6/201 (2.98\%) with partial oral treatment versus 6/199 (3.01\%) with conventional intravenous treatment; RR $0.99,95 \% \mathrm{Cl} 0.32$ to 3.02 ; very low-quality evidence) (POET 2019).

\section{Uncontrolled infection}

A beta-lactam (ceftriaxone) plus an aminoglycoside (gentamicin) versus a beta-lactam (ceftriaxone) alone

One trial found no conclusive results in terms of uncontrolled infection (1/34 $(2.9 \%)$ with a beta-lactam plus an aminoglycoside versus $1 / 33$ (3.0\%) with a beta-lactam alone; RR $0.97,95 \% \mathrm{CI} 0.06$ to 14.88; very low-quality evidence) (Sexton 1998).

\section{Relapse of endocarditis}

A beta-lactam (ceftriaxone) plus an aminoglycoside (gentamicin) versus a beta-lactam alone (ceftriaxone)

One trial reported no relapses in either group (Sexton 1998).

\section{Fosfomycin plus imipenem versus vancomycin}

One trial showed inconclusive evidence in terms of relapse of endocarditis $(0 / 4(0 \%)$ with fosfomycin plus imipenem versus $1 / 4$ (25\%) with vancomycin; RR $0.33,95 \% \mathrm{Cl} 0.02$ to 6.37 ; very lowquality evidence) (Pericas 2018).

\section{Partial oral treatment versus conventional intravenous treatment}

One trial showed inconclusive evidence regarding relapse of endocarditis (5/201 (2.48\%) with partial oral treatment versus 5/199 $(2.51 \%)$ with conventional intravenous treatment; RR 0.99, 95\% Cl 0.29 to 3.37; very low-quality evidence) (POET 2019).

\section{DISCUSSION}

\section{Summary of main results}

This updated Cochrane Review aimed to assess the clinical benefits and harms of different antibiotic regimens to treat infective endocarditis. Six small RCTs, involving 1143 randomised participants, of which 632 were analysed, met our inclusion criteria. The trials were conducted using modified Duke's criteria to diagnose infective endocarditis. We concluded that our main finding suggesting that one antibiotic regimen is not superior to another is uncertain. The included trials had a high risk of bias and were underpowered, and three trials were sponsored by drug companies.
The six included trials used different treatment schedules in terms of antibiotics used, routes of administration, and duration of treatment:

- a fluoroquinolone (levofloxacin) versus standard treatment comprised of an antistaphylococcal penicillin (cloxacillin or dicloxacillin) plus an aminoglycoside (tobramycin or netilmicin) and rifampicin (FINLEVO Trial 2006);

- a glycopeptide (vancomycin or teicoplanin) plus an aminoglycoside (gentamicin) versus a beta-lactam (cloxacillin) plus an aminoglycoside (gentamicin) (Fortún 2001);

- a lipopeptide antibiotic (daptomycin) versus an aminoglycoside (low-dose gentamicin) plus antistaphylococcal penicillins (nafcillin, oxacillin, or flucloxacillin) or glycopeptide antibiotics (vancomycin) (Fowler 2006);

- fosfomycin plus imipenem versus vancomycin (Pericas 2018);

- partial oral treatment versus conventional intravenous treatment (POET 2019); and

- a beta-lactam (ceftriaxone) plus an aminoglycoside (gentamicin) versus a beta-lactam (ceftriaxone) alone (Sexton 1998).

Four trials reported the main outcome of this Cochrane Review, all-cause in-hospital mortality and all-cause mortality at one year. These trials found no conclusive differences between treatment regimens (FINLEVO Trial 2006; Fortún 2001; Pericas 2018; POET 2019).

The included trials showed inconclusive effects with regard to cure rates, TRAEs, the need for cardiac surgical intervention, uncontrolled infection, incidence of septic emboli, congestive heart failure, and relapse of endocarditis. No trials assessed quality of life.

\section{Overall completeness and applicability of evidence}

The data from this updated Cochrane Review suggest that there is insufficient evidence to conclude that there is no difference in either clinical benefits or in the frequency of treatment-related adverse events related to the antibiotics used to treat infective endocarditis. Antistaphylococcal penicillins may be more effective than glycopeptides.

The six small trials included participants with different comorbidities and micro-organisms who received different treatment schedules in terms of antibiotic used and duration of therapy, therefore we were unable to conduct a meta-analysis.

The conclusions of this review are based on RCTs with a high risk of bias. Due to insufficient data, we were unable to draw conclusions to guide practice. Recommendations for antibiotic treatment of endocarditis in current guidelines are based on expert consensus, due to a lack of evidence from RCTs to support them (Baddour 2015; Habib 2019). Data from this review were insufficient to refute or corroborate such recommendations. These findings support what was noted by Paterson 2013, that there is a need for RCTs to define optimal treatment regimens for this serious infection.

This updated review identified six trials assessing many outcomes with small sample sizes. Consequently, it is likely that at least one type I error was made (Delorme 2016; Senn 2007). Two trials without sample size estimation included many outcomes. These trials therefore have a high risk of uncertainty of clinical significance (Mascha 2018; Sormani 2017). 


\section{Quality of the evidence}

We conducted GRADE assessments. The quality of evidence of the six included trials is shown in Summary of findings 1; Summary of findings 2; Summary of findings 3; Summary of findings 4; Summary of findings 5; Summary of findings 6 . Overall, the included trials had a high risk of bias (Figure 2; Figure 3) due to poor trial design and reporting related to failure to conceal allocation, blinding, selective outcome reporting of the six trials for the main outcomes assessed (all-cause mortality during hospital stay and all-cause mortality at one year, cure, TRAEs, incidence of septic embolism, incidence of congestive heart failure, quality of life, and need for cardiac surgical intervention). Furthermore, we downgraded the quality of the evidence for serious imprecision due to small sample sizes and low number of events.

\section{Potential biases in the review process}

The main potential bias in this review was the exclusion of 10 RCTs of antibiotic therapy for the treatment of infective endocarditis because they did not apply modified Duke's criteria for diagnosis (Durack 1994). Von Reyn's old criteria were outperformed by Duke's (Bayer 1994; Von Reyn 1981). There is sufficient longstanding evidence to support the superiority of Ducke's criteria over Von Reyn's old criteria (Durack 1994; Holland 2016; Naber 2001), although Duke's criteria are not perfect (lung 2019a; Olaison 1996). Today, Dr von Reyn's statement remains valid: "Infective endocarditis is a diagnosis that can only be confirmed unequivocally by examination of the endocardium at surgery or autopsy" (Von Reyn 1981).

In a systematic review process, there is a group of biases known as significance-chasing biases, such as publication bias and selective outcome reporting bias (Ioannidis 2010). Selective outcome reporting bias operates through suppression of information on specific outcomes and is similar to study publication bias in that 'negative' results remain unpublished (Ioannidis 2010). Regarding the risk of selective outcome reporting bias, this updated Cochrane Review found two trials with a low risk (Pericas 2018; POET 2019), two trials with a high risk (Fowler 2006; Sexton 1998), and two trials with an unclear risk (FINLEVO Trial 2006; Fortún 2001). See Figure 2; Figure 3.

\section{Agreements and disagreements with other studies or reviews}

This first update found no new systematic reviews to be discussed in this section. Consequently, our results are similar to two nonCochrane Reviews (Falagas 2006; Yung 2007). These two reviews differed in their eligibility criteria. One review only looked at the management of right-side endocarditis in intravenous drug users (Yung 2007), whereas the other review limited itself to looking specifically at the role of aminoglycosides in combination with beta-lactams to treat endocarditis (Falagas 2006). Our Cochrane Review had no restrictions on micro-organism, clinical population, or antimicrobial agent. Falagas 2006 included a pooled analysis, an approach we decided to avoid due to the heterogeneity in outcome definitions and differences in the composition of the antibiotic regimens. This heterogeneity, along with a paucity of identified trials, prevented us from performing any meta-analysis. Yung 2007 did not pool results because of clinical heterogeneity. Despite these differences, the reviews reached similar results, that is that the evidence from the included trials was insufficient to support or reject one antimicrobial regimen over another.

\section{AUTHORS' CONCLUSIONS}

\section{Implications for practice}

This first update confirms the findings of the original version of the review. Limited and very low-quality evidence suggests that the comparative effects of different antibiotic regimens in terms of cure rates or other relevant clinical outcomes are uncertain. The conclusions of this updated Cochrane Review were based on few randomised controlled trials with a high risk of bias. Accordingly, the current evidence does not support or reject any regimen of antibiotic therapy for the treatment of infective endocarditis.

\section{Implications for research}

Infectious endocarditis is a rare disease caused by different microorganisms, which vary according to the population at risk. This is an obstacle to the conduct of randomised controlled trials, and should therefore indicate a need for the co-operation of different clinical centres.

Randomised controlled trials are needed to assess the clinical benefits and harms of the use of antibiotic regimens for treating infective endocarditis. These trials should be high-quality randomised trials, with a priori calculation of sample sizes, to assess the clinical benefits and harms of antibiotics to treat infective endocarditis, as noted by Paterson 2013. The trials should be designed according to the SPIRIT (Standard Protocol Items: Recommendations for Interventional Trials) statement (Chan 2013), and reported according to the CONSORT statement for improving the quality of reporting of efficacy and harms in clinical research (Ioannidis 2004; Moher 2010). Future trials should be planned following the Foundation of Patient-Centered Outcomes Research Institute recommendations (Basch 2012; Gabriel 2012; McKinney 2012).

\section{ACKNOWLEDGEMENTS}

We acknowledge Georgia Salanti, Petros Georgoulas, Joey SW Kwong, and Ricardo Hidalgo for participating in the protocol of this Cochrane Review.

We express our gratitude to Alma Adler and Nicole Martin for supporting us during the development of the first version of this review.

We want to express our gratitude to Rosa María Finizola, Alma Arrioja, Raquel González, Karen Aguero, Alvis Castillo, and Elizabeth de Mora from Asociación Cardiovascular (ASCARDIO), Barquisimeto, Edo. Lara, Venezuela, for their valuable support during the development of the first version of this review.

We acknowledge Evangelo Boumis (peer reviewer) and Janet Yarrow (consumer reviewer) for improving the quality of the first update of this review. We are also grateful to Lisa Winer for valuable copy edits. 


\section{R E F E R E N C E S}

\section{References to studies included in this review}

FINLEVO Trial 2006 \{published data only\}

Ruotsalainen E, Järvinen A, Koivula I, Kauma H, Rintala E, Lumio J, Finlevo Study Group. Levofloxacin does not decrease mortality in Staphylococcus aureus bacteraemia when added to the standard treatment: a prospective and randomized clinical trial of 381 patients. Journal of Internal Medicine 2006;259(2):179-90. [PMID: 16420547]

\section{Fortún 2001 \{published data only\}}

Fortún J, Navas E, Martínez-Beltrán J, Pérez-Molina J, MartínDávila P, Guerrero A, et al. Short-course therapy for rightside endocarditis due to Staphylococcus aureus in drug abusers: cloxacillin versus glycopeptides in combination with gentamicin. Clinical Infectious Diseases 2001;33(1):120-5. [PMID: 11389505]

\section{Fowler 2006 \{published data only\}}

Cosgrove SE, Vigliani GA, Fowler VG Jr, Abrutyn E, Corey GR, Levine DP, et al. Initial low-dose gentamicin for Staphylococcus aureus bacteremia and endocarditis is nephrotoxic. Clinical Infectious Diseases 2009;48(6):713-21. [PMID: 19207079]

* Fowler VG Jr, Boucher HW, Corey GR, Abrutyn E, Karchmer AW, Rupp ME, et al. Daptomycin versus standard therapy for bacteremia and endocarditis caused by Staphylococcus aureus. New England Journal of Medicine 2006;355(7):653-65. [PMID: 16914701]

Kanafani Z, Boucher H, Fowler V, Cabell C, Hoen B, Miro JM, et al. Daptomycin compared to standard therapy for the treatment of native valve endocarditis. Enfermedades Infecciosas y Microbiología Clínica 2010;28(8):498-503. [PMID: 20188444]

Rehm SJ, Boucher H, Levine D, Campion M, Eisenstein BI, Vigliani GA, et al. Daptomycin versus vancomycin plus gentamicin for treatment of bacteraemia and endocarditis due to Staphylococcus aureus: subset analysis of patients infected with methicillin-resistant isolates. Journal of Antimicrobial Chemotherapy 2008;62(6):1413-21. [PMID: 18782781]

Pericas 2018 \{published data only\}

* Pericàs JM, Moreno A, Almela M, García de la Mària C, Marco F, Muñoz P, FOSIMI Investigators. Efficacy and safety of fosfomycin plus imipenem versus vancomycin for complicated bacteraemia and endocarditis due to methicillin-resistant Staphylococcus aureus: a randomized clinical trial. Clinical Microbiology and Infections 2018;24(6):673-6. [PMID: 29408610]

del Rio A, Gasch O, Moreno A, Pena C, Cuquet J, Soy D, et al. Efficacy and safety of fosfomycin plus imipenem as rescue therapy for complicated bacteremia and endocarditis due to methicillin-resistant Staphylococcus aureus: a multicenter clinical trial. Clinical Infectious Diseases 2014;59(8):1105-12. [PMID: 25048851]
POET 2019 \{published data only\}

Iversen K, Host N, Bruun NE, Elming H, Pump B, Christensen JJ, et al. Partial oral treatment of endocarditis. American Heart Journal 2013;165(2):116-22. [PMID: 23351813]

* Iversen K, Ihlemann N, Gill SU, Madsen T, Elming H, Jensen KT, et al. Partial oral versus intravenous antibiotic treatment of endocarditis. New England Journal of Medicine 2019;380(5):415-24. [PMID: 30152252]

\section{Sexton 1998 \{published data only\}}

Sexton D, Tenenbaum M, Wilson W, Steckelberg J, Tice A, Gilbert $D$, et al. Ceftriaxone once daily for four weeks vs. ceftriaxone plus gentamicin for two weeks for the treatment of penicillin susceptible Streptococcal endocarditis. Clinical Infectious Diseases 1996;4:23889.

* Sexton DJ, Tenenbaum MJ, Wilson WR, Steckelberg JM, Tice AD, Gilbert D, et al. Ceftriaxone once daily for four weeks compared with ceftriaxone plus gentamicin once daily for two weeks for treatment of endocarditis due to penicillinsusceptible streptococci. Endocarditis Treatment Consortium Group. Clinical Infectious Diseases 1998;27(6):1470-4. [PMID: 9868662]

\section{References to studies excluded from this review}

\section{Abrams 1979 \{published data only\}}

Abrams B, Sklaver A, Hoffman T, Greenman R. Single or combination therapy of staphylococcal endocarditis in intravenous drug abusers. Annals of Internal Medicine 1979;90(5):789-91. [PMID: 434682]

Fortún 1995 \{published data only\}

Fortún J, Pérez-Molina JA, Añón MT, Martínez-Beltrán J, Loza E, Guerrero A. Right-sided endocarditis caused by Staphylococcus aureus in drug abusers. Antimicrobial Agents and Chemotherapy 1995;39(2):525-8. [PMID: 7726526]

Gilbert 1991 \{published data only\}

Gilbert DN, Wood CA, Kimbrough RC. Failure of treatment with teicoplanin at 6 milligrams/kilogram/day in patients with Staphylococcus aureus intravascular infection. The Infectious Diseases Consortium of Oregon. Antimicrobial Agents and Chemotherapy 1991;35(1):79-87. [PMID: 1826594]

\section{Greenman 1984 \{published data only\}}

Greenman RL, Arcey SM, Gutterman DA, Zweig RM. Twice-daily intramuscular ceforanide therapy of Staphylococcus aureus endocarditis in parenteral drug abusers. Antimicrobial Agents and Chemotherapy 1984;25(1):16-9. [PMID: 6703681]

Heldman 1996 \{published data only\}

Heldman AW, Hartert TV, Ray SC, Daoud EG, Kowalski TE, Pompili VJ, et al. Oral antibiotic treatment of right-sided staphylococcal endocarditis in injection drug users: prospective randomized comparison with parenteral therapy. American Journal of Medicine 1996;101(1):68-76. [PMID: 8686718] 


\section{Korzeniowski 1982 \{published data only\}}

Korzeniowski O, Sande MA. Combination antimicrobial therapy for Staphylococcus aureus endocarditis in patients addicted to parenteral drugs and in nonaddicts: a prospective study. Annals of Internal Medicine 1982;97(4):496-503. [PMID: 6751182]

Levine 1991 \{published data only\}

Levine DP, Fromm BS, Reddy BR. Slow response to vancomycin or vancomycin plus rifampin in methicillin-resistant Staphylococcus aureus endocarditis. Annals of Internal Medicine 1991;115(9):674-80. [PMID: 1929035]

Markowitz 1992 \{published data only\}

Markowitz N, Quinn EL, Saravolatz LD. Trimethoprimsulfamethoxazole compared with vancomycin for the treatment of Staphylococcus aureus infection. Annals of Internal Medicine 1992;117(5):390-8. [PMID: 1503330]

Ribera 1996 \{published data only\}

Ribera E, Gomez-Jimenez J, Cortes E, del Valle O, Planes A, Gonzalez-Alujas T, et al. Effectiveness of cloxacillin with and without gentamicin in short-term therapy for right-sided Staphylococcus aureus endocarditis. A randomized, controlled trial. Annals of Internal Medicine 1996;125(12):969-74. [PMID: 8967707]

\section{Stamboulian 1991 \{published data only\}}

Stamboulian D, Bonvehi P, Arevalo C, Bologna R, Cassetti I, Scilingo V, et al. Antibiotic management of outpatients with endocarditis due to penicillin-susceptible streptococci. Reviews of Infectious Diseases 1991;13(Suppl 2):160-3. [PMID: 2017645]

\section{References to ongoing studies}

\section{CTRI/2008/091/000060 \{published data only\}}

CTRI/CTRI/2008/091/000060. A clinical trial to study the safety and efficacy of combination drug, vancomycin and ceftriaxone compared to vancomycin in mild to severe bacterial infections. who.int/trialsearch/Trial2.aspx?TrialID=CTRI/2008/091/000060 (date registered 7 May 2008).

\section{EUCTR 2016-003059-31 \{published data only\}}

EUCTR 2016-003059-31. Study to assess the efficacy, safety and pharmacokinetics of CF-301 compared with placebo in addition to standard-of-care antibiotic therapy in blood infections caused by S. aureus, including heart valve infections. who.int/ trialsearch/Trial2.aspx?TrialID=EUCTR2016-003059-31 (start date 2 November 2017).

\section{EUCTR 2017-001699-43 \{published data only\}}

EUCTR2017-001699-43. A study to assess the efficacy and safety of ceftobiprole medocaril compared to daptomycin in the treatment of Staphylococcus aureus bacteremia, including infective endocarditis. who.int/trialsearch/Trial2.aspx? TrialID=EUCTR2017-001699-43 (start date 13 December 2018).

\section{EudraCT 2008-008683-28 \{published data only\}}

EUCTR 2008-008683-28. Evaluación de la eficacia y la seguridad de la combinación de fosfomicina (F) e imipenem (I) para el tratamiento de la endocarditis infecciosa (EI) sobre válvula nativa o protésica por S. Aureus resistente a meticilina (SARM). who.int/trialsearch/Trial2.aspx?TrialID=EUCTR2008-008683-28 (start date 23 September 2009).

\section{JPRN-UMIN 000032006 \{published data only\}}

JPRN-UMIN 000032006. An open-label randomized controlled trial of ampicillin/cloxacillin and ceftriaxone for empirical treatment of infective endocarditis. who.int/trialsearch/ Trial2.aspx?TrialID=JPRN-UMIN000032006 (first received 31 March 2018).

\section{NCT00638157 \{published data only\}}

NCT00638157. Phase 4 Efficacy and safety study of cubicin ${ }^{\circledR}$ with and without combination therapy in S. aureus infective endocarditis (SAIE). clinicaltrials.gov/ct2/show/NCT00638157 (first received 18 March 2008).

\section{NCT00695903 \{published data only\}}

NCT00695903. Phase 2 study of safety, efficacy, and pharmacokinetics of higher doses of daptomycin and vancomycin in MRSA bacteremia (HDSAB). clinicaltrials.gov/ct2/ show/NCT00695903 (first received 12 June 2008).

NCT02208063 \{published data only\}

NCT02208063. A phase 3 telavancin Staphylococcus aureus (S. aureus) bacteremia trial. clinicaltrials.gov/ct2/show/ NCT02208063 (first received 4 August 2014).

\section{NCT02701595 \{published data only\}}

NCT02701595. Oral switch during treatment of left-sided endocarditis due to multi-susceptible streptococcus. clinicaltrials.gov/ct2/show/NCT02701595 (first received 8 March 2016).

\section{NCT02701608 \{published data only\}}

NCT02701608. Oral switch during treatment of left-sided endocarditis due to multi-susceptible staphylococcus. clinicaltrials.gov/ct2/show/NCT02701608 (first received 8 March 2016).

\section{NCT03138733 \{published data only\}}

NCT03138733. Ceftobiprole in the treatment of patients with Staphylococcus aureus bacteremia. clinicaltrials.gov/show/ nct03138733 (first received 3 May 2017).

\section{NCT03148756 \{published data only\}}

NCT03148756. Efficacy and safety of dalbavancin compared to standard of care antibiotic therapy for the completion of treatment of patients with complicated bacteremia or infective endocarditis. clinicaltrials.gov/show/nct03148756 (first received 11 May 2017).

\section{NCT04222257 \{published data only\}}

NCT04222257. Short-course antibiotic treatment in grampositive cocci infective endocarditis (SATIE). clinicaltrials.gov/ ct2/show/NCT04222257 (first received 9 January 2020).

RBR-3p8g7n 2016 \{published data only\}

RBR-3p8g7n. Clinical trial of telavancin versus standard intravenous therapy in the treatment of subjects with Staphylococcus aureus bacteremia including infective 
endocarditis. apps.who.int/trialsearch/Trial2.aspx? TrialID=RBR-3p8g7n (first received 3 August 2016).

\section{Additional references}

\section{Amat-Santos 2015}

Amat-Santos IJ, Ribeiro HB, Urena M, Allende R, Houde C, Bedard E, et al. Prosthetic valve endocarditis after transcatheter valve replacement: a systematic review. JACC. Cardiovascular Interventions 2015;8(2):334-46. [PMID: 25700757]

\section{Ambrosioni 2017}

Ambrosioni J, Hernandez-Meneses M, Tellez A, Pericas J, Falces $C$, Tolosana JM, et al. The changing epidemiology of infective endocarditis in the Twenty-First Century. Current Infectious Disease Reports 2017;19(5):21. [PMID: 28401448]

\section{Anderson 2008}

Anderson VR, Perry CM. Levofloxacin: a review of its use as a high-dose, short-course treatment for bacterial infection. Drugs 2008;68(4):535-65. [PMID: 18318569]

\section{Asai 2019}

Asai N, Shiota A, Ohashi W, Watanabe H, Shibata Y, Kato H, et al. The SOFA score could predict the severity and prognosis of infective endocarditis. Journal of Infection and Chemotherapy 2019;25(12):965-71. [PMID: 31320197]

\section{Avelana 2018}

Avelana PM, Aurelio M, Swieszkowski S, Nacinovich F, Kazelian L, Spenato M, et al. Infective endocarditis in Argentina. Results of the EIRA 3 study [Endocarditis infecciosa en la República Argentina. Resultados del estudio EIRA 3]. Revista Argentina de Cardiología 2018;86(1):21-9. [biblio-990513]

\section{Ba 2017}

Ba DM, Mboup MC, Zeba N, Dia K, Fall AN, Fall F, et al. Infective endocarditis in Principal Hospital of Dakar: a retrospective study of 42 cases over 10 years. Pan African Medical Journal 2017;26:40. [PMID: 28451018]

\section{Baddour 2015}

Baddour LM, Wilson WR, Bayer AS, Fowler VG Jr, Tleyjeh IM, Rybak MJ, et al. Infective endocarditis in adults: diagnosis, antimicrobial therapy, and management of complications: a scientific statement for healthcare professionals from the American Heart Association. Circulation 2015;132(15):1435-86. [PMID: 26373316]

\section{Bai 2017}

Bai AD, Agarwal A, Steinberg M, Showler A, Burry L, Tomlinson GA, et al. Clinical predictors and clinical prediction rules to estimate initial patient risk for infective endocarditis in Staphylococcus aureus bacteraemia: a systematic review and meta-analysis. Clinical Microbiology and Infection 2017;23(12):900-6. [PMID: 28487168]

\section{Balshem 2011}

Balshem H, Helfand M, Schünemann HJ, Oxman AD, Kunz R, Brozek J, et al. GRADE guidelines: 3. Rating the quality of evidence. Journal of Clinical Epidemiology 2011;64(4):401-6. [PMID: 21208779]

\section{Basch 2012}

Basch E, Aronson N, Berg A, Flum D, Gabriel S, Goodman SN, et al. Methodological standards and patient-centeredness in comparative effectiveness research: the PCORI perspective. JAMA 2012;307(15):1636-40. [PMID: 22511692]

\section{Bayer 1994}

Bayer AS, Ward JI, Ginzton LE, Shapiro SM. Evaluation of new clinical criteria for the diagnosis of infective endocarditis. American Journal of Medicine 1994;96(3):211-9. [PMID: 8154508]

\section{Beganovic 2018}

Beganovic M, Luther MK, Rice LB, Arias CA, Rybak MJ, LaPlante KL. A review of combination antimicrobial therapy for Enterococcus faecalis bloodstream infections and infective endocarditis. Clinical Infectious Diseases 2018;67(2):303-9. [PMID: 29390132]

\section{Beteille 2018}

Beteille E, Guarana M, Nucci M. Infective endocarditis in neutropenic patients with viridans streptococci bacteraemia. Clinical Microbiology and Infection 2018;24(8):916-7. [PMID: 29559393

\section{Burgos 2019}

Burgos LM, Cracco MA, Fernandez Oses P, Iribarren AC, Ronderos R, Nacinovich F. Infective endocarditis in Argentina: what have we learned in the last 25 years? [Endocardtis infecciosa en ARGENTINA: ¿Qué aprendimos en los últimos 25 años?]. Medicina 2019;79(4):257-64. [PMID: 31487244]

\section{Cahill 2016}

Cahill TJ, Prendergast BD. Infective endocarditis. Lancet 2016;387(10021):882-93. [PMID: 26341945]

\section{Cantier 2019}

Cantier M, Sabben C, Adle-Biassette H, Louedec L, Delbosc S, Desilles JP, et al. Neurologic complications of infective endocarditis: a joint model for a septic thromboembolism and inflammatory small vessel disease. Critical Care Medicine 2019;47(8):e685-92. [PMID: 31149963]

\section{Cao 2018}

Cao GF, Liu W, Bi Q. Stroke in patients with infective endocarditis: a 15-year single-center cohort study. European Neurology 2018;80(3-4):171-8. [PMID: 30485851]

\section{Cecchi 2015}

Cecchi E, Chirillo F, Castiglione A, Faggiano P, Cecconi M, Moreo A, et al. Clinical epidemiology in Italian registry of infective endocarditis (RIEI): focus on age, intravascular devices and enterococci. International Journal of Cardiology 2015;190:151-6. [PMID: 25918069]

\section{Chambers 2001a}

Chambers HF. The aminoglycosides. In: Hardman JG, Limbird LE, editors(s). Goodman \& Gilman's. The Pharmacological 
Basis of Therapeutics. 10th edition. New York: McGraw Hill, 2001:1219-38. [ISBN: 0-07-135469-7]

\section{Chambers 2001b}

Chambers HF. Protein synthesis inhibitors and miscellaneous antibacterial agents. In: Hardman JG, Limbird LE, editors(s). Goodman \& Gilman's. The Pharmacological Basis of Therapeutics. 10th edition. New York: McGraw Hill, 2001:1239-71. [ISBN: 0-07-135469-7]

\section{Champey 2016}

Champey J, Pavese P, Bouvaist H, Kastler A, Krainik A, Francois P. Value of brain MRI in infective endocarditis: a narrative literature review. European Journal of Clinical Microbiology and Infectious Diseases 2016;35(2):159-68. [PMID: 26585337]

\section{Chan 2013}

Chan AW, Tetzlaff JM, Gøtzsche PC, Altman DG, Mann H, Berlin JA, et al. SPIRIT 2013 explanation and elaboration: guidance for protocols of clinical trials. BMJ 2013;346:e7586. [PMID: 23303884]

\section{Chen 2009}

Chen LF, Kaye D. Current use for old antibacterial agents: polymyxins, rifamycins, and aminoglycosides. Infectious Disease Clinics of North America 2009;23(4):1053-75. [PMID: 19909897]

\section{Chopra 2007}

Chopra P, Gulwani H. Pathology and pathogenesis of rheumatic heart disease. Indian Journal of Pathology \& Microbiology 2007;50(4):685-97. [PMID: 18306530]

\section{Colomer-Winter 2018}

Colomer-Winter C, Gaca AO, Chuang-Smith ON, Lemos JA, Frank KL. Basal levels of (p)ppGpp differentially affect the pathogenesis of infective endocarditis in Enterococcus faecalis. Microbiology 2018;164(10):1254-65. [PMID: 30091695]

\section{Cosgrove 2009}

Cosgrove SE, Vigliani GA, Fowler VG Jr, Abrutyn E, Corey GR, Levine DP, et al. Initial low-dose gentamicin for Staphylococcus aureus bacteremia and endocarditis is nephrotoxic. Clinical Infectious Diseases 2009;48(6):713-21. [PMID: 19207079]

\section{Cresti 2017}

Cresti A, Chiavarelli M, Scalese M, Nencioni C, Valentini S, Guerrini F, et al. Epidemiological and mortality trends in infective endocarditis, a 17-year population-based prospective study. Cardiovascular Diagnosis and Therapy 2017;7(1):27-35. [PMID: 28164010]

\section{Cunha 2015}

Cunha BA, Brahmbhatt K, Raza M. Haemophilus parainfluenzae aortic prosthetic valve endocarditis (PVE) successfully treated with oral levofloxacin. Heart and Lung 2015;44(4):317-20. [PMID: 25998992]

\section{Daga 2011}

Daga S, Shepherd J, Callaghan G, Hung R, Dawson D, Padfield G, et al. Platelet receptor polymorphisms do not influence
Staphylococcus aureus-platelet interactions or infective endocarditis. Microbes and Infection 2011;13(3):216-25. [PMID: 21044892]

\section{Damasco 2019}

Damasco PV, Correal JCD, Cruz-Campos ACD, Wajsbrot BR, Cunha RGD, Fonseca AGD, et al. Epidemiological and clinical profile of infective endocarditis at a Brazilian tertiary care center: an eight-year prospective study. Revista da Sociedade Brasileira de Medicina Tropical 2019;52:e2018375. [PMID: 31188916]

\section{de Jong 2019}

de Jong NWM, van Kessel KPM, van Strijp JAG. Immune evasion by Staphylococcus aureus. Microbiology Spectrum 2019;7(2):GPP3-0061-2019. [PMID: 30927347]

\section{Delahaye 2019}

Delahaye F, De Gevigney G. Infective endocarditis and specific situations: right heart, valve prosthesis, cardiac implantable electronic device [Endocardites infectieuses: formes particulieres (coeur droit, prothese valvulaire, dispositif electronique intracardiaque)]. Presse Medicale 2019;48(5):549-55. [PMID: 31109767]

\section{Delorme 2016}

Delorme P, de Micheaux PL, Liquet B, Riou J. Type-II generalized family-wise error rate formulas with application to sample size determination. Statistics in Medicine 2016;35(16):2687-714. [PMID: 26914402]

\section{Dhotre 2018}

Dhotre S, Jahagirdar V, Suryawanshi N, Davane M, Patil R, Nagoba B. Assessment of periodontitis and its role in viridans streptococcal bacteremia and infective endocarditis. Indian Heart Journal 2018;70(2):225-32. [PMID: 29716699]

\section{Drees 2006}

Drees M, Boucher H. New agents for Staphylococcus aureus endocarditis. Current Opinion in Infectious Diseases 2006;19(6):544-50. [PMID: 17075329]

\section{Dryden 2011}

Dryden MS. Linezolid pharmacokinetics and pharmacodynamics in clinical treatment. Journal of Antimicrobial Chemotherapy 2011;66(Suppl 4):iv7-15. [PMID: 21521707]

\section{Durack 1994}

Durack DT, Lukes AS, Bright DK. New criteria for diagnosis of infective endocarditis: utilization of specific echocardiographic findings. Duke Endocarditis Service. American Journal of Medicine 1994;96(3):200-9. [PMID: 8154507]

\section{Egbe 2019}

Egbe AC, Vallabhajosyula S, Akintoye E, Connolly HM. Trends and outcomes of infective endocarditis in adults with tetralogy of Fallot: a review of the national inpatient sample database. Canadian Journal of Cardiology 2019;35(6):721-6. [PMID: 31151707] 


\section{El Rafei 2016}

El Rafei A, DeSimone DC, DeSimone CV, Lahr BD, Steckelberg JM, Sohail MR, et al. Beta-haemolytic streptococcal endocarditis: clinical presentation, management and outcomes. Infectious Diseases (London, England) 2016;48(5):373-8. [PMID: 26950685]

\section{Elbatarny 2019}

Elbatarny M, Bahji A, Bisleri G, Hamilton A. Management of endocarditis among persons who inject drugs: a narrative review of surgical and psychiatric approaches and controversies. General Hospital Psychiatry 2019;57:44-9. [PMID: 30908961]

\section{Elmistekawy 2016}

Elmistekawy E, Chan V, Mesana T. Surgical management: indications, timing and surgical techniques. In: Chan K-L, Embil JM, editors(s). Endocarditis: Diagnosis and Management. London: Springer-Verlag, 2016:153-79. [DOI: 10.1007/978-3-319-27784-4_8]

\section{Erdem 2019}

Erdem H, Puca E, Ruch Y, Santos L, Ghanem-Zoubi N, Argemi X, et al. Portraying infective endocarditis: results of multinational ID-IRI study. European Journal of Clinical Microbiology and Infectious Diseases 2019;38(9):1753-63. [PMID: 31187307]

\section{Falagas 2006}

Falagas ME, Matthaiou DK, Bliziotis IA. The role of aminoglycosides in combination with a beta-lactam for the treatment of bacterial endocarditis: a meta-analysis of comparative trials. Journal of Antimicrobial Chemotherapy 2006;57(4):639-47. [PMID: 16501057]

\section{Falagas 2007}

Falagas ME, Giannopoulou KP, Ntziora F, Vardakas KZ. Daptomycin for endocarditis and/or bacteraemia: a systematic review of the experimental and clinical evidence. Journal of Antimicrobial Chemotherapy 2007;60(1):7-19. [PMID: 17550889]

\section{Flemming 2010}

Flemming HC, Wingender J. The biofilm matrix. Nature Reviews. Microbiology 2010;8(9):623-33. [PMID: 20676145]

\section{Flemming 2016}

Flemming HC, Wingender J, Szewzyk U, Steinberg P, Rice SA, Kjelleberg S. Biofilms: an emergent form of bacterial life. Nature Reviews. Microbiology 2016;14(9):563-75. [PMID: 27510863]

\section{Frank 2009}

Frank $\mathrm{U}$, Tacconelli E. Treatment of the most frequent types of bacterial endocarditis. In: Frank U, Tacconelli E, editors(s). The Daschner Guide to In-Hospital Antibiotic Therapy. Heidelberg: Springer Medizin Verlag, 2009:211-4. [ISBN: 978-3-540-48347-2]

\section{Gabriel 2012}

Gabriel SE, Normand SL. Getting the methods right - the Foundation of Patient-Centered Outcomes Research. New England Journal of Medicine 2012;367(9):787-90. [PMID: 22830434]

\section{Giacobbe 2019}

Giacobbe DR, Corcione S, Salsano A, Del Puente F, Mornese Pinna S, De Rosa FG, et al. Current and emerging pharmacotherapy for the treatment of infections following open-heart surgery. Expert Opinion on Pharmacotherapy 2019;20(6):751-72. [PMID: 30785333]

\section{Gould 2011}

Gould FK. Linezolid: safety and efficacy in special populations. Journal of Antimicrobial Chemotherapy 2011;66(Suppl 4):iv3-6. [PMID: 21521705]

\section{GRADEpro 2008 [Computer program]}

The GRADE Working Group GRADEpro. Brozek J, Oxman A, Schünemann H, Version 3.2 for Windows. The GRADE Working Group, 2008.

\section{Granowitz 2008}

Granowitz EV, Brown RB. Antibiotic adverse reactions and drug interactions. Critical Care Clinics 2008;24(2):421-42. [PMID: 18361954]

\section{Grisoli 2014}

Grisoli D, Million M, Edouard S, Thuny F, Lepidi H, Collart F, et al. Latent $Q$ fever endocarditis in patients undergoing routine valve surgery. Journal of Heart Valve Disease 2014;23(6):735-43. [PMID: 25790621]

\section{Guerra 2017}

Guerra FE, Borgogna TR, Patel DM, Sward EW, Voyich JM. Epic immune battles of history: neutrophils vs. Staphylococcus aureus. Frontiers in Cellular and Infection Microbiology 2017;7:286. [PMID: 28713774]

\section{Gupta 2011}

Gupta A, Biyani M, Khaira A. Vancomycin nephrotoxicity: myths and facts. Netherlands Journal of Medicine 2011;69(9):379-83. [PMID: 21978980]

\section{Guyatt 2008}

Guyatt GH, Oxman AD, Kunz R, Vist GE, Falck-Ytter Y, Schünemann HJ. What is "quality of evidence" and why is it important to clinicians? BMJ 2008;336(7651):995-8. [PMID: 18456631]

\section{Guyatt 2011a}

Guyatt GH, Oxman AD, Kunz R, Brozek J, Alonso-Coello P, Rind $D$, et al. GRADE guidelines 6 . Rating the quality of evidence - imprecision. Journal of Clinical Epidemiology 2011;64(12):1283-93. [PMID: 21839614]

\section{Guyatt 2011b}

Guyatt GH, Oxman AD, Kunz R, Woodcock J, Brozek J, Helfand M, et al. GRADE guidelines: 7. Rating the quality of evidence - inconsistency. Journal of Clinical Epidemiology 2011;64(12):1294-302. [PMID: 21803546]

\section{Guyatt 2011c}

Guyatt GH, Oxman AD, Montori V, Vist G, Kunz R, Brozek J, et al. GRADE guidelines: 5 . Rating the quality of evidence 
- publication bias. Journal of Clinical Epidemiology 2011;64(12):1277-82. [PMID: 21802904]

\section{Guyatt 2011d}

Guyatt GH, Oxman AD, Kunz R, Woodcock J, Brozek J, Helfand M, et al. GRADE guidelines: 8 . Rating the quality of evidence - indirectness. Journal of Clinical Epidemiology 2011;64(12):1303-10. [PMID: 21802903]

\section{Guyatt 2011e}

Guyatt GH, Oxman AD, Sultan S, Glasziou P, Akl EA, AlonsoCoello P, et al. GRADE guidelines: 9. Rating up the quality of evidence. Journal of Clinical Epidemiology 2011;64(12):1311-6. [PMID: 21802902]

\section{Guyatt 2011 f}

Guyatt GH, Oxman AD, Vist G, Kunz R, Brozek J, Alonso-Coello P, et al. GRADE guidelines: 4. Rating the quality of evidence study limitations (risk of bias). Journal of Clinical Epidemiology 2011;64(4):407-15. [PMID: 21247734]

\section{Guyatt 2011g}

Guyatt G, Oxman AD, Akl EA, Kunz R, Vist G, Brozek J, et al. GRADE guidelines: 1. Introduction - GRADE evidence profiles and summary of findings tables. Journal of Clinical Epidemiology 2011;64(4):383-94. [PMID: 21195583]

\section{Guyatt 2011h}

Guyatt GH, Oxman AD, Kunz R, Atkins D, Brozek J, Vist G, et al. GRADE guidelines: 2 . Framing the question and deciding on important outcomes. Journal of Clinical Epidemiology 2011;64(4):395-400. [PMID: 21194891]

\section{Habib 2015}

Habib G, Lancellotti P, Antunes MJ, Bongiorni MG, Casalta JP, Del Zotti F, ESC Scientific Document Group. 2015 ESC guidelines for the management of infective endocarditis: the task force for the management of infective endocarditis of the European Society of Cardiology (ESC). Endorsed by: European Association for Cardio-Thoracic Surgery (EACTS), the European Association of Nuclear Medicine (EANM). European Heart Journal 2015;36(44):3075-128. [PMID: 26320109]

\section{Habib 2019}

Habib G, Erba PA, lung B, Donal E, Cosyns B, Laroche C, et al. Clinical presentation, aetiology and outcome of infective endocarditis. Results of the ESC-EORP EURO-ENDO (European infective endocarditis) registry: a prospective cohort study. European Heart Journal 2019;40(39):3222-32. [PMID: 31504413]

\section{Higgins 2003}

Higgins JP, Thompson SG, Deeks JJ, Altman DG. Measuring inconsistency in meta-analyses. BMJ 2003;327(7414):557-60. [PMID: 12958120]

\section{Higgins 2011}

Higgins JPT, Green S, editor(s). Cochrane Handbook for Systematic Reviews of Interventions. Version 5.1.0 (updated March 2011). The Cochrane Collaboration, 2011. Available from handbook.cochrane.org.

\section{Hitzenbichler 2019}

Hitzenbichler F, Olic J, Hanses F, Salzberger B, Fischer M, Baessler A. Current treatment of endocarditis: innovations and controversies [Aktuelle therapie der endokarditis: neuerungen und kontroversen]. Der Internist 2019;60(10):1111-17. [PMID: 31444523]

\section{Hoen 2006}

Hoen B. Epidemiology and antibiotic treatment of infective endocarditis: an update. Heart 2006;92(11):1694-700. [PMID: 17041124]

\section{Holland 2016}

Holland TL, Baddour LM, Bayer AS, Hoen B, Miro JM, Fowler VG Jr. Infective endocarditis. Nature Reviews. Disease Primers 2016;2:16059. [PMID: 27582414]

\section{Hollis 1999}

Hollis S, Campbell F. What is meant by intention to treat analysis? Survey of published randomised controlled trials. BMJ 1999;319(7211):670-4. [PMID: 10480822]

\section{Humphries 2013}

Humphries RM, Pollett S, Sakoulas G. A current perspective on daptomycin for the clinical microbiologist. Clinical Microbiology Reviews 2013;26(4):759-80. [PMID: 24092854]

\section{Ioannidis 2004}

Ioannidis JP, Evans SJ, Gotzsche PC, O'Neill RT, Altman DG, Schulz $\mathrm{K}$, et al. Better reporting of harms in randomized trials: an extension of the CONSORT statement. Annals of Internal Medicine 2004;141(10):781-8. [PMID: 15545678]

\section{loannidis 2010}

Ioannidis JP. Meta-research: the art of getting it wrong. Research Synthesis Methods 2010;10(3-4):169-84.

\section{lung 2019a}

lung B, Duval X. Infective endocarditis: innovations in the management of an old disease. Nature Reviews. Cardiology 2019;16(10):623-35. [PMID: 31175343 ]

\section{lung 2019b}

lung B. Infective endocarditis. Epidemiology, pathophysiology and histopathology [Endocardite infectieuse. Epidemiologie, physiopathologie et anatomopathologie]. Presse Medicale 2019;48(5):513-21. [PMID: 31056234]

\section{Jakuska 2019}

Jakuska P, Ereminiene E, Muliuolyte E, Kosys V, Pavlavicius L, Zukovas G, et al. Predictors of early mortality after surgical treatment of infective endocarditis: a single-center experience. Perfusion 2019;Sep 4:Online ahead of print.. [DOI: 10.1177/0267659119872345] [PMID: 31480970]

\section{Jung 2015}

Jung CJ, Yeh CY, Hsu RB, Lee CM, Shun CT, Chia JS. Endocarditis pathogen promotes vegetation formation by inducing intravascular neutrophil extracellular traps through activated platelets. Circulation 2015;131(6):571-81. [PMID: 25527699] 


\section{Karchmer 2009}

Karchmer AW. Infective endocarditis. In: Fauci AS, Braunwald E, Kasper DL, Hauser SL, Longo DL, Jameson JL, et al, editors(s). Harrison's Principles of Internal Medicine. 17th edition. New York: McGraw-Hill, 2009:440-7. [ISBN: 978-0-07-147743-7]

\section{Keynan 2013}

Keynan Y, Rubinstein E. Pathophysiology of infective endocarditis. Current Infectious Disease Reports 2013;15(4):342-6. [PMID: 23737237]

\section{Khan 2017}

Khan ZA, Hollenberg SM. Valvular heart disease in adults: infective endocarditis. FP Essentials 2017;457:30-8. [PMID: 28671807]

\section{Kobayashi 2019}

Kobayashi T, Ando T, Streit J, Sekar P. Current evidence on oral antibiotics for infective endocarditis: a narrative review. Cardiology and Therapy 2019;8(2):167-77. [PMID: 31535282]

\section{Krčméry 2019}

Krčméry V, Hricak V, Fischer V, Mrazova M, Brnova J, Hulman M, et al. Etiology, risk factors and outcome of 1003 cases of infective endocarditis from a 33-year National Survey in the Slovak Republic: an increasing proportion of elderly patients. Neuro Endocrinology Letters 2019;39(8):544-9. [PMID: 30927759]

\section{Kumar 2019}

Kumar M, Anstadt EJ, Lopetegui Lia N, Siddiqi MH.

Streptococcus viridans endocarditis affecting all four valves. Cureus 2019;11(5):e4635. [PMID: 31312561]

\section{Lagace-Wiens 2012}

Lagace-Wiens P, Rubinstein E. Adverse reactions to beta-lactam antimicrobials. Expert Opinion on Drug Safety 2012;11(3):381-99. [PMID: 22220627]

\section{Leach 2011}

Leach KL, Brickner SJ, Noe MC, Miller PF. Linezolid, the first oxazolidinone antibacterial agent. Annals of the New York Academy of Sciences 2011;1222:49-54. [PMID: 21434942]

\section{Leahey 2019}

Leahey PA, LaSalvia MT, Rosenthal ES, Karchmer AW, Rowley CF. High morbidity and mortality among patients with sentinel admission for injection drug use-related infective endocarditis. Open Forum Infectious Diseases 2019;6(4):ofz089. [PMID: 30949535]

\section{Leekha 2011}

Leekha S, Terrell CL, Edson RS. General principles of antimicrobial therapy. Mayo Clinic Proceedings 2011;86:156-67. [PMID: 21282489]

\section{Lefebvre 2011}

Lefebvre C, Manheimer E, Glanville J. Chapter 6: Searching for studies. In: Higgins JPT, Green S, editor(s). Cochrane Handbook for Systematic Reviews of Interventions Version 5.1.0 (updated March 2011). The Cochrane Collaboration, 2011. Available from handbook.cochrane.org.

\section{Leyva 2008}

Leyva S, Leyva E. Fluoroquinolonas. Mecanismos de acción y resistencia, estructura, sintesis y reacciones fisicoquímicas importantes para propiedades medicinales. Boletín de la Sociedad Química de México 2008;2(1):1-13.

\section{Li 2000}

Li JS, Sexton DJ, Mick N, Nettles R, Fowler VG Jr, Ryan T, et al. Proposed modifications to the Duke criteria for the diagnosis of infective endocarditis. Clinical Infectious Diseases 2000;30(4):633-8. [PMID: 10770721]

\section{Liberati 2009}

Liberati A, Altman DG, Tetzlaff J, Mulrow C, Gotzsche PC, Ioannidis JP, et al. The PRISMA statement for reporting systematic reviews and meta-analyses of studies that evaluate health care interventions: explanation and elaboration. Journal of Clinical Epidemiology 2009;62(10):e1-34. [PMID: 19631507]

\section{Lin 2019}

Lin CJ, Chua S, Chung SY, Hang CL, Tsai TH. Diabetes mellitus: an independent risk factor of in-hospital mortality in patients with infective endocarditis in a new era of clinical practice. International Journal of Environmental Research and Public Health 2019;16(12):2248. [PMID: 31242695]

\section{Liu 2010}

Liu HH. Safety profile of the fluoroquinolones: focus on levofloxacin. Drug Safety 2010;33(5):353-69. [PMID: 20397737]

\section{Lluri 2018}

Lluri G, Levi DS, Miller E, Hageman A, Sinha S, Sadeghi S, et al. Incidence and outcome of infective endocarditis following percutaneous versus surgical pulmonary valve replacement. Catheterization and Cardiovascular Interventions 2018;91(2):277-84. [PMID: 28895275]

\section{Long 2018}

Long B, Koyfman A. Infectious endocarditis: an update for emergency clinicians. American Journal of Emergency Medicine 2018;36(9):1686-92. [PMID: 30001813]

\section{Mascha 2018}

Mascha EJ, Vetter TR. Significance, errors, power, and sample size: the blocking and tackling of statistics. Anesthesia and Analgesia 2018;126(2):691-8. [PMID: 29346210]

\section{McKinney 2012}

McKinney M. 'Time is of the essence'. PCORI moves to implement comparative effectiveness research, funding. Modern Healthcare 2012;42(5):12-3. [PMID: 22356074]

\section{Melehani 2016}

Melehani JH, Duncan JA. Inflammasome activation can mediate tissue-specific pathogenesis or protection in Staphylococcus aureus infection. Current Topics in Microbiology and Immunology 2016;397:257-82. [PMID: 27460814]

\section{Meshaal 2018}

Meshaal MS, Labib D, Said K, Hosny M, Hassan M, Abd Al Aziz S, et al. Aspergillus endocarditis: diagnostic criteria and 
predictors of outcome, a retrospective cohort study. PLOS ONE 2018;13(8):e0201459. [PMID: 30092074]

\section{Mgbojikwe 2019}

Mgbojikwe N, Jones SR, Leucker TM, Brotman DJ. Infective endocarditis: beyond the usual tests. Cleveland Clinic Journal of Medicine 2019;86(8):559-67. [PMID: 31385793]

\section{Moher 2010}

Moher D, Hopewell S, Schulz KF, Montori V, Gotzsche PC, Devereaux PJ. CONSORT 2010 explanation and elaboration: updated guidelines for reporting parallel group randomised trials. BMJ 2010;340:c869. [PMID: 20332511]

\section{Moriyama 2019}

Moriyama N, Laakso T, Biancari F, Raivio P, Jalava MP, Jaakkola J, et al. Prosthetic valve endocarditis after transcatheter or surgical aortic valve replacement with a bioprosthesis: results from the FinnValve Registry. Eurolntervention 2019;15(6):e500-7. [PMID: 31113766]

\section{Moser 2017}

Moser C, Elming H, Helweg-Larsen J, Christensen JJ, Jensen KT, Smerup MH, et al. Infectious endocarditis. Danish guidelines [Infektiøs endocarditis]. www.nbv.cardio.dk/endocarditis (accessed 28 February 2019).

\section{Murphy 2019}

Murphy DJ, Din M, Hage FG, Reyes E. Guidelines in review: Comparison of ESC and AHA guidance for the diagnosis and management of infective endocarditis in adults. Journal of Nuclear Cardiology 2019;26(1):303-8. [PMID: 29923105]

\section{Muñoz 2007}

Muñoz P, Rodriguez-Creixems M, Moreno M, Marin M, Ramallo V, Bouza E. Linezolid therapy for infective endocarditis. Clinical Microbiology and Infection 2007;13(2):211-5. [PMID: 17328738]

\section{Muñoz-Moreno 2019}

Muñoz-Moreno MF, Ryan P, Alvaro-Meca A, Valencia J, Tamayo E, Resino S. National temporal trend analysis of infective endocarditis among patients infected with HIV in Spain (1997-2014): a retrospective study. Journal of Clinical Medicine 2019;8(8):E1167. [PMID: 31382658]

\section{Naber 2001}

Naber CK, Bartel T, Eggebrecht H, Erbel R. Diagnosis of endocarditis today: Duke criteria or clinical judgment? [Endokarditisdiagnostik Heute: Duke-Kriterien oder klinische Einschatzung?]. Herz 2001;26(6):379-90. [PMID: 11683068]

\section{Nagy 2018}

Nagy M, Alkady H, Abo Senna W, Abdelhay S. Predictors of surgical outcome in isolated prosthetic mitral valve endocarditis. Asian Cardiovascular and Thoracic Annals 2018;26(7):517-23. [PMID: 30185074]

\section{Nailor 2009}

Nailor MD, Sobel JD. Antibiotics for Gram-positive bacterial infections: vancomycin, teicoplanin, quinupristin/dalfopristin, oxazolidinones, daptomycin, dalbavancin, and telavancin.
Infectious Diseases Clinics of North America 2009;23(4):965-82. [PMID: 19909893 ]

\section{Nascimento 2019}

Nascimento CA. Embolic complications in infective endocarditis: how can we predict using a Risk Evaluator Score (SORTIE or ABCDE) [Complicações embólicas na endocardite infecciosa: como poderemos prever usando Escore Avaliador do Risco (ABCDE ou SORTIE)]. ABC Imagem Cardiovascular 2019;32(4):251-3. [PMID: biblio-1023850]

\section{Nasser 2019}

Nasser A, Moradi M, Jazireian P, Safari H, Alizadeh-Sani M, Pourmand MR, et al. Staphylococcus aureus versus neutrophil: scrutiny of ancient combat. Microbial Pathogenesis 2019;131:259-69. [PMID: 31002964]

\section{Nebeker 2004}

Nebeker JR, Barach P, Samore MH. Clarifying adverse drug events: a clinician's guide to terminology, documentation, and reporting. Annals of Internal Medicine 2004;140(10):795-801. [PMID: 15148066]

\section{Ogura 2019}

Ogura N, Tomari K, Takayama T, Tonegawa N, Okawa T, Matsuoka T, et al. Group A streptococcus endocarditis in children: 2 cases and a review of the literature. BMC Infectious Diseases 2019;19(1):102. [PMID: 30704409]

\section{Olaison 1996}

Olaison L, Hogevik H. Comparison of the von Reyn and Duke criteria for the diagnosis of infective endocarditis: a critical analysis of 161 episodes. Scandinavian Journal of Infectious Diseases 1996;28(4):399-406. [PMID: 8893406]

\section{Pabilona 2015}

Pabilona C, Gitler B, Lederman JA, Miller D, Keltz TN. Prosthetic valve endocarditis with valvular obstruction after transcatheter aortic valve replacement. Texas Heart Institute Journal 2015;42(2):172-4. [PMID: 25873834]

\section{Paterson 2013}

Paterson DL. Determining research priorities for clinicianinitiated trials in infectious diseases. Medical Journal of Australia 2013;198(5):270-2. [PMID: 23496404]

\section{Petri 2001a}

Petri WA Jr. Penicillins, cephalosporins, and other $\beta$-lactam antibiotics. In: Hardman JG, Limbird LE, editors(s). Goodman \& Gilman's. The Pharmacological Basis of Therapeutics. 10th edition. New York: McGraw Hill, 2001:1189-218. [ISBN: 0-07-135469-7]

\section{Petri 2001b}

Petri WA Jr. Drug used in the chemotherapy of tuberculosis, Mycobacterium avium complex disease, and leprosy. In: Hardman JG, Limbird LE, editors(s). Goodman \& Gilman's. The Pharmacological Basis of Therapeutics. 10th edition. New York: McGraw Hill, 2001:1273-94. [ISBN: 0-07-135469-7] 


\section{R 2018}

R M, V R, Nambi PS, Ramakrishnan B, Gopalakrishnan R, Sathyamurthy. Profile of infective endocarditis: at a tertiary care referral centre. Journal of the Association of Physicians of India 2018;66(6):60-5. [PMID: 31331138]

\section{Review Manager 2014 [Computer program]}

The Nordic Cochrane Centre, The Cochrane Collaboration Review Manager (RevMan). Version 5.3. Copenhagen: The Nordic Cochrane Centre, The Cochrane Collaboration, 2014.

\section{Sadeghi 2019}

Sadeghi S, Wadia S, Lluri G, Tarabay J, Fernando A, Salem M, et al. Risk factors for infective endocarditis following transcatheter pulmonary valve replacement in patients with congenital heart disease. Catheterization and Cardiovascular Interventions 2019;94(4):625-35. [PMID: 31471941]

\section{Salvador 2017}

Salvador VB, Chapagain B, Joshi A, Brennessel DJ. Clinical risk factors for infective endocarditis in Staphylococcus aureus bacteremia. Texas Heart Institute Journal 2017;44(1):10-5. [PMID: 28265207]

\section{Saraste 2019}

Saraste A, Knuuti J. Guidelines in review: Comparison of ESC and AHA guidance for the diagnosis and management of infective endocarditis in adults. Are the differences clinically relevant? The European perspective. Journal of Nuclear Cardiology 2019;26(1):309-12. [PMID: 30132186]

\section{Selton-Suty 2019}

Selton-Suty C, Goehringer F, Venner C, Thivilier C, Huttin O, Hoen B. Complications and prognosis of infective endocarditis [Complications et pronostic de l'endocardite infectieuse]. Presse Medicale 2019;48(5):532-8. [PMID: 31056233]

\section{Senn 2007}

Senn S, Bretz F. Power and sample size when multiple endpoints are considered. Pharmaceutical Statistics 2007;6(3):161-70. [PMID: 17674404]

\section{Shannon 2010}

Shannon O, Morgelin M, Rasmussen M. Platelet activation and biofilm formation by Aerococcus urinae, an endocarditiscausing pathogen. Infection and Immunity 2010;78(10):4268-75. [PMID: 20696834]

\section{Shao 2019}

Shao IY, Elkind MSV, Boehme AK. Risk factors for stroke in patients with sepsis and bloodstream infections. Stroke 2019;50(5):1046-51. [PMID: 30896327]

\section{Shrestha 2014}

Shrestha NK, Mason P, Gordon SM, Neuner E, Nutter B, O'Rourke C, et al. Adverse events, healthcare interventions and healthcare utilization during home infusion therapy with daptomycin and vancomycin: a propensity scorematched cohort study. Journal of Antimicrobial Chemotherapy 2014;69(5):1407-15. [PMID: 24398341]

\section{Singer 2017}

Singer M, Alkady H, Mohsen T, Roushdy A, Akl AK, Mashaal M. Predictors of surgical outcome in isolated tricuspid valve endocarditis: single center experience of 60 patients. Thoracic and Cardiovascular Surgeon 2017;65(8):634-8. [PMID: 28922673]

\section{Skinner 2016}

Skinner S, Wudel B, Sanche SE. Microbiology of infective endocarditis and microbiologic diagnosis. In: Chan KL, Embil JM, editors(s). Endocarditis: Diagnosis and Management. London: Springer-Verlag, 2016:49-66. [DOI: 10.1007/978-3-319-27784-4_9]

\section{Slipczuk 2013}

Slipczuk L, Codolosa JN, Davila CD, Romero-Corral A, Yun J, Pressman GS, et al. Infective endocarditis epidemiology over five decades: a systematic review. PLOS ONE 2013;8(12):e82665. [PMID: 24349331]

\section{Song 2015}

Song JK. Infective endocarditis involving an apparently structurally normal valve: new epidemiological trend? Korean Journal of Internal Medicine 2015;30(4):434-42. [PMID: 26175567]

\section{Sormani 2017}

Sormani MP. The most frequently asked question to a statistician: the sample size. Multiple Sclerosis 2017;23(5):644-6. [PMID: 28273773]

\section{Sotero 2019}

Sotero FD, Rosario M, Fonseca AC, Ferro JM. Neurological complications of infective endocarditis. Current Neurology and Neuroscience Reports 2019;19(5):23. [PMID: 30927133]

\section{Sterne 2011}

Sterne JA, Sutton AJ, Ioannidis JP, Terrin N, Jones DR, Lau J, et al. Recommendations for examining and interpreting funnel plot asymmetry in meta-analyses of randomised controlled trials. BMJ 2011;343:d4002. [PMID: 21784880]

\section{Sun 2015}

Sun BJ, Choi SW, Park KH, Jang JY, Kim DH, Song JM, et al. Infective endocarditis involving apparently structurally normal valves in patients without previously recognized predisposing heart disease. Journal of the American College of Cardiology 2015;65(3):307-9. [PMID: 25614430]

\section{Süzük 2016}

Süzük S, Kaskatepe B, Cetin M. Antimicrobial susceptibility against penicillin, ampicillin and vancomycin of viridans group Streptococcus in oral microbiota of patients at risk of infective endocarditis. Le Infezioni in Medicina 2016;24(3):190-3. [PMID: 27668898]

\section{Tam 2016}

Tam JW, Shaikh N, Bybel B, Jassal DS. Diagnostic approach to endocarditis. In: Chan K-L, Embil JM, editors(s). Endocarditis: Diagnosis and Management. London: Springer-Verlag, 2016:91-116. [DOI: 10.1007/978-3-319-27784-4] 


\section{Tao 2017}

Tao E, Wan L, Wang W, Luo Y, Zeng J, Wu X. The prognosis of infective endocarditis treated with biological valves versus mechanical valves: a meta-analysis. PLOS ONE 2017;12(4):e0174519. [PMID: 28407024]

\section{Thiene 2006}

Thiene G, Basso C. Pathology and pathogenesis of infective endocarditis in native heart valves. Cardiovascular Pathology 2006;15(5):256-63. [PMID: 16979032]

\section{Thornhill 2015}

Thornhill MH, Dayer MJ, Prendergast B, Baddour LM, Jones S, Lockhart PB. Incidence and nature of adverse reactions to antibiotics used as endocarditis prophylaxis. Journal of Antimicrobial Chemotherapy 2015;70(8):2382-8. [PMID: 25925595]

\section{Thurlow 2010}

Thurlow LR, Thomas VC, Narayanan S, Olson S, Fleming SD, Hancock LE. Gelatinase contributes to the pathogenesis of endocarditis caused by Enterococcus faecalis. Infection and Immunity 2010;78(11):4936-43. [PMID: 20713628]

\section{Tissot-Dupont 2017}

Tissot-Dupont H, Casalta JP, Gouriet F, Hubert S, Salaun E, Habib G, et al. International experts' practice in the antibiotic therapy of infective endocarditis is not following the guidelines. Clinical Microbiology and Infection 2017;23(10):736-9. [PMID: 28323194]

\section{Torres 2010}

Torres MJ, Blanca M. The complex clinical picture of beta-lactam hypersensitivity: penicillins, cephalosporins, monobactams, carbapenems, and clavams. Medical Clinics of North America 2010;94(4):805-20. [PMID: 20609864]

\section{Tran 2019}

Tran PM, Feiss M, Kinney KJ, Salgado-Pabon W. фSa3mw prophage as a molecular regulatory switch of Staphylococcus aureus beta-toxin production. Journal of Bacteriology 2019;201(14):e00766-18. [PMID: 30962356]

\section{Ursi 2019}

Ursi MP, Durante Mangoni E, Rajani R, Hancock J, Chambers JB, Prendergast $\mathrm{B}$. Infective endocarditis in the elderly: diagnostic and treatment options. Drugs and Aging 2019;36(2):115-24. [PMID: 30488173]

\section{Varela 2019}

Varela Barca L, Navas Elorza E, Fernendez-Hidalgo N, Moya Mur JL, Muriel Garcia A, Fernandez-Felix BM, et al. Prognostic factors of mortality after surgery in infective endocarditis: systematic review and meta-analysis. Infection 2019;47(6):879-95. [PMID: 31254171]

\section{Vilhena 2012}

Vilhena C, Bettencourt A. Daptomycin: a review of properties, clinical use, drug delivery and resistance. Mini Reviews in Medicinal Chemistry 2012;12(3):202-9. [PMID: 22356191]

\section{Vinh 2016}

Vinh DC, Embil JM. Treatment of endocarditis. In: Chan K-L, Embil JM, editors(s). Endocarditis: Diagnosis and Management. London: Springer-Verlag, 2016:181-280. [DOI: 10.1007/978-3-319-27784-4_9]

\section{Vogkou 2016}

Vogkou CT, Vlachogiannis NI, Palaiodimos L, Kousoulis AA. The causative agents in infective endocarditis: a systematic review comprising 33,214 cases. European Journal of Clinical Microbiology and Infectious Diseases 2016;35(8):1227-45. [PMID: 27170145]

\section{Von Reyn 1981}

Von Reyn CF, Levy BS, Arbeit RD, Friedland G, Crumpacker CS. Infective endocarditis: an analysis based on strict case definitions. Annals of Internal Medicine 1981;94(4 Part 1):505-18. [PMID: 7011141]

\section{Wang 2014}

Wang SZ, Hu JT, Zhang C, Zhou W, Chen XF, Jiang LY, et al. The safety and efficacy of daptomycin versus other antibiotics for skin and soft-tissue infections: a meta-analysis of randomised controlled trials. BMJ Open 2014;4(6):e004744. [PMID: 24961714]

\section{Warren 2008}

Warren RE. Daptomycin in endocarditis and bacteraemia: a British perspective. Journal of Antimicrobial Chemotherapy 2008;62 Suppl 3:iii25-33. [PMID: 18829722]

\section{Wei 2019}

Wei XB, Su Z, Liu YH, Wang Y, Huang JL, Yu DQ, et al. Age, creatinine, and ejection fraction (ACEF) score: a simple riskstratified method for infective endocarditis. QJM: Monthly Journal of the Association of Physicians 2019;112(12):900-6. [PMID: 31359051]

\section{Werdan 2014}

Werdan K, Dietz S, Loffler B, Niemann S, Bushnaq H, Silber RE, et al. Mechanisms of infective endocarditis: pathogenhost interaction and risk states. Nature Reviews. Cardiology 2014;11(1):35-50. [PMID: 24247105]

\section{Widmer 2006}

Widmer E, Que YA, Entenza JM, Moreillon P. New concepts in the pathophysiology of infective endocarditis. Current Infectious Disease Reports 2006;8(4):271-9. [PMID: 16822370]

\section{Wong-Beringer 2011}

Wong-Beringer A, Joo J, Tse E, Beringer P. Vancomycinassociated nephrotoxicity: a critical appraisal of risk with highdose therapy. International Journal of Antimicrobial Agents 2011;37(2):95-101. [PMID: 21130609]

\section{Yoshioka 2018}

Yoshioka D, Toda K, Yokoyama JY, Matsuura R, Miyagawa S, Kainuma S, et al. Diabetes mellitus adversely affects mortality and recurrence after valve surgery for infective endocarditis. Journal of Thoracic and Cardiovascular Surgery 2018;155(3):1021-9.e5. [PMID: 28992971] 


\section{Yung 2007}

Yung D, Kottachchi D, Neupane B, Haider S, Loeb M. Antimicrobials for right-sided endocarditis in intravenous drug users: a systematic review. Journal of Antimicrobial Chemotherapy 2007;60(5):921-8. [PMID: 17881630]

\section{Şimşek-Yavuz 2020}

Şimşek-Yavuz S, Akar AR, Aydoğdu S, Berzeg-Deniz D, Demir H, Hazırolan T, et al. Diagnosis, treatment and prevention of infective endocarditis: Turkish consensus report-2019. Türk Kardiyoloji Derneği arşivi 2020;48(2):187-226. [PMID: 32147661]

\section{CHARACTERISTICS OF STUDIES}

Characteristics of included studies [ordered by study ID]

\section{References to other published versions of this review Marti-Carvajal 2016}

Marti-Carvajal AJ, Dayer M, Conterno LO, Gonzalez Garay AG, Marti-Amarista CE, Simancas-Racines D. A comparison of different antibiotic regimens for the treatment of infective endocarditis. Cochrane Database of Systematic Reviews 2016, Issue 4. [DOI: 10.1002/14651858.CD009880.pub2] [PMID: 27092951]

* Indicates the major publication for the study

\section{FINLEVO Trial 2006}

\section{Study characteristics}

Design: parallel (2 groups)
Multicentre study: yes
Country: Finland
Follow-up period: at 28 days and 3 months
Unit of randomisation: participants
Unit of analysis: participants
Duke's criteria for diagnosis of infective endocarditis: yes

Participants

People with Staphylococcus aureus bacteraemia with or without endocarditis

Enrolled: 1226

Randomised: 381

- Levofloxacin: 191

- Standard treatment: 190

People with endocarditis: 70

- Levofloxacin: 31

- Standard treatment: 39

Age (mean) for overall participants

- Levofloxacin: 58 (SD 19) years

- Standard treatment: 58 (SD 17) years

Gender (male) for overall participants

- Levofloxacin: $61 \%$

- Standard treatment: $64 \%$

There was no information related solely to the baseline demographics of participants with endocarditis. 
FINLEVO Trial 2006 (Continued)

Interventions

Experimental: levofloxacin ( $500 \mathrm{mg}$ once daily for participants weighing $<60 \mathrm{~kg}$ and $500 \mathrm{mg}$ twice daily for participants weighing $>60 \mathrm{~kg}$, both IV and orally + standard treatment

Control: standard treatment (cloxacillin or dicloxacillin (2 g every 4 hours), IV. Participants with a contraindication to penicillin use: cefuroxime ( $1.5 \mathrm{~g}$ every 6 hours), clindamycin (600 mg every 6 to 8 hours), or vancomycin ( $1 \mathrm{~g}$ twice daily). When oral treatment was indicated, cloxacillin ( $500 \mathrm{mg}$ every 6 hours), cephalexin or cefadroxil (500 mg every 6 hours), or clindamycin (300 mg every 6 hours). Doses were adjusted according to renal function when required. Furthermore, aminoglycosides (tobramycin or netilmicin at $1 \mathrm{mg} / \mathrm{kg} /$ body weight 3 times daily) and rifampicin (450 mg once daily for participants weighing $<50 \mathrm{~kg}$ and $600 \mathrm{mg}$ once daily for participants weighing $>50 \mathrm{~kg}$, oral or IV) were used.

Treatment duration: 14 days

Primary
- Case fatality rate at 28 days and 3 months
Secondary
- Number of complications (e.g. deep infections) observed after the first week
- Decrease in serum C-reactive protein concentration
- Length of antibiotic treatment
- Need for surgical intervention
- Time to apyrexia (days until axillary temperature $<37.5^{\circ} \mathrm{C}$ )

Notes

Conduction date: January 2000 to August 2002

A priori sample size estimation: yes

Sponsor: Aventis Pharma, and Finnish governmental grant

Role of sponsor: supplied experimental medication, but was not involved in the trial at any stage

Conflict of interest: many primary researchers have been consulted by trial sponsor

Identification number clinical trial: not reported

The FINLEVO Trial 2006 specified treatment regimens for patients under 60/50 kg and patients over $60 / 50 \mathrm{~kg}$, but does not specify the exact treatment pattern for people who are either 60 or $50 \mathrm{~kg}$. We contacted the main author for clarification, but as of yet have received no answer.

\section{Risk of bias}

\begin{tabular}{lll}
\hline Bias & Authors' judgement & Support for judgement \\
\hline $\begin{array}{ll}\text { Random sequence genera- } \\
\text { tion (selection bias) }\end{array}$ & Unclear risk & $\begin{array}{l}\text { Quote: "Randomization was done blindly and separately at each study loca- } \\
\text { tion..." (page 180) }\end{array}$ \\
& $\begin{array}{l}\text { Comment: insufficient information about the sequence generation process to } \\
\text { permit judgement of 'low risk' or 'high risk' }\end{array}$
\end{tabular}

\begin{tabular}{lll}
\hline $\begin{array}{l}\text { Allocation concealment } \\
\text { (selection bias) }\end{array}$ & Unclear risk & $\begin{array}{l}\text { Insufficient information about the sequence generation process to permit } \\
\text { judgement of 'low risk' or 'high risk' }\end{array}$ \\
\hline $\begin{array}{l}\text { Blinding of participants } \\
\text { and personnel (perfor- } \\
\text { mance bias) }\end{array}$ & High risk & $\begin{array}{l}\text { Quote: "...the treatments were open for the investigator and the patient" (page } \\
\text { All outcomes }\end{array}$ \\
\end{tabular}

$\begin{array}{lll}\begin{array}{l}\text { Blinding of outcome as- } \\ \text { sessment (detection bias) }\end{array} & \text { Unclear risk } & \begin{array}{l}\text { Trial was designed to assess the efficacy of antibiotics in Staphylococcus au- } \\ \text { reus bacteraemia. There was no separate information on this outcome in peo- }\end{array}\end{array}$




\section{FINLEVO Trial 2006 (Continued)}

Cure ple with endocarditis; insufficient information to permit judgement of 'low risk' or 'high risk'.

\author{
Blinding of outcome as- Low risk \\ sessment (detection bias) \\ All-cause mortality
}

No blinding of outcome assessment, but the review authors judged that the outcome measurements were not likely to be influenced by lack of blinding.

\begin{tabular}{|c|c|c|}
\hline $\begin{array}{l}\text { Blinding of outcome as- } \\
\text { sessment (detection bias) } \\
\text { Adverse events }\end{array}$ & Unclear risk & $\begin{array}{l}\text { Insufficient information about blinding outcome assessment process to permit } \\
\text { judgement of 'low risk' or 'high risk' in participants with endocarditis. }\end{array}$ \\
\hline
\end{tabular}

Adverse events

\begin{tabular}{|c|c|c|}
\hline $\begin{array}{l}\text { Blinding of outcome as- } \\
\text { sessment (detection bias) } \\
\text { Incidence of septic em- } \\
\text { bolism }\end{array}$ & Unclear risk & $\begin{array}{l}\text { Trial was designed to assess the efficacy of antibiotics in Staphylococcus au- } \\
\text { reus bacteraemia. There was no separate information on the incidence of sep- } \\
\text { tic embolism in participants with endocarditis; insufficient information to per- } \\
\text { mit judgement of 'low risk' or 'high risk'. }\end{array}$ \\
\hline
\end{tabular}

bolism mit judgement of 'low risk' or 'high risk'.

Blinding of outcome as- $\quad$ Unclear risk
sessment (detection bias)
Incidence of congestive
heart failure

Insufficient information about the sequence generation process to permit judgement of 'low risk' or 'high risk'

\begin{tabular}{|c|c|c|}
\hline $\begin{array}{l}\text { Blinding of outcome as- } \\
\text { sessment (detection bias) } \\
\text { Quality of life }\end{array}$ & Unclear risk & $\begin{array}{l}\text { Trial was designed for assessing efficacy of antibiotic in Staphylococcus aureus } \\
\text { bacteraemia. There was no information on quality of life in participants with } \\
\text { endocarditis; insufficient information to permit judgement of 'low risk' or 'high } \\
\text { risk'. }\end{array}$ \\
\hline
\end{tabular}

\begin{tabular}{lll}
\hline $\begin{array}{l}\text { Blinding of outcome as- } \\
\text { sessment (detection bias) } \\
\begin{array}{l}\text { Need for cardiac surgical } \\
\text { interventions }\end{array}\end{array}$ & Unclear risk & $\begin{array}{l}\text { Insufficient information about the sequence generation process to permit } \\
\text { judgement of 'low risk' or 'high risk' }\end{array}$ \\
\hline $\begin{array}{l}\text { Blinding of outcome as- } \\
\text { sessment (detection bias) } \\
\text { Indication of cardiac }\end{array}$ & Unclear risk & $\begin{array}{l}\text { Trial was designed to assess the efficacy of antibiotics in Staphylococcus au- } \\
\text { reus bacteraemia. There was no information on indication of cardiac surgery in } \\
\text { surgery }\end{array}$ \\
$\begin{array}{l}\text { participants with endocarditis; insufficient information to permit judgement of } \\
\text { 'low risk' or 'high risk'. }\end{array}$
\end{tabular}

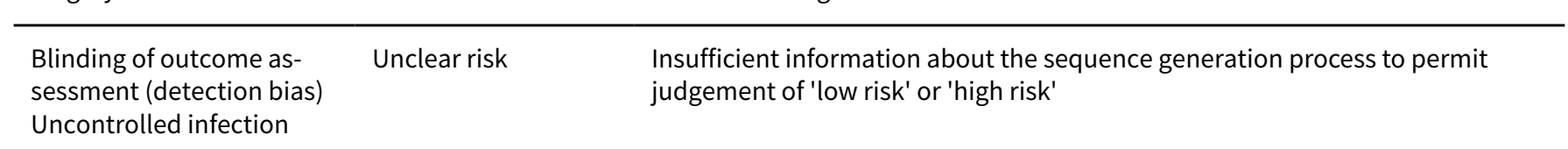

\begin{tabular}{|c|c|c|}
\hline $\begin{array}{l}\text { Blinding of outcome as- } \\
\text { sessment (detection bias) } \\
\text { Relapse }\end{array}$ & Unclear risk & $\begin{array}{l}\text { Trial was designed to assess the efficacy of antibiotics in Staphylococcus au- } \\
\text { reus bacteraemia. There was no information on relapse in participants with } \\
\text { endocarditis; insufficient information to permit judgement of 'low risk' or 'high } \\
\text { risk'. }\end{array}$ \\
\hline
\end{tabular}

\begin{tabular}{|c|c|c|}
\hline $\begin{array}{l}\text { Incomplete outcome data } \\
\text { (attrition bias) } \\
\text { All outcomes }\end{array}$ & Unclear risk & $\begin{array}{l}\text { Trial was designed to assess the efficacy of antibiotics in Staphylococcus au- } \\
\text { reus bacteraemia rather than in infective endocarditis, therefore there was in- } \\
\text { sufficient information to permit judgement of 'low risk' or 'high risk'. }\end{array}$ \\
\hline
\end{tabular}

\begin{tabular}{ll}
$\begin{array}{l}\text { Selective reporting (re- } \\
\begin{array}{l}\text { porting bias) } \\
\text { Unclear risk }\end{array}\end{array}$ & $\begin{array}{l}\text { Trial was designed to assess the efficacy of antibiotics in Staphylococcus au- } \\
\text { reus bacteraemia. There was no information on selective reporting in partici- } \\
\text { pants with endocarditis; insufficient information to permit judgement of 'low } \\
\text { risk' or 'high risk'. }\end{array}$ \\
\hline
\end{tabular}

\begin{tabular}{ll}
\hline Other bias $\quad$ High risk & Design bias \\
\hline
\end{tabular}


Fortún 2001

\section{Study characteristics}

Methods

Design: parallel (3 groups)

Multicentre study: no

Country: Spain

Follow-up period: at least 12 weeks after completion of therapy

Unit of randomisation: participants

Unit of analysis: participants

Duke's criteria for diagnosis of infective endocarditis: yes

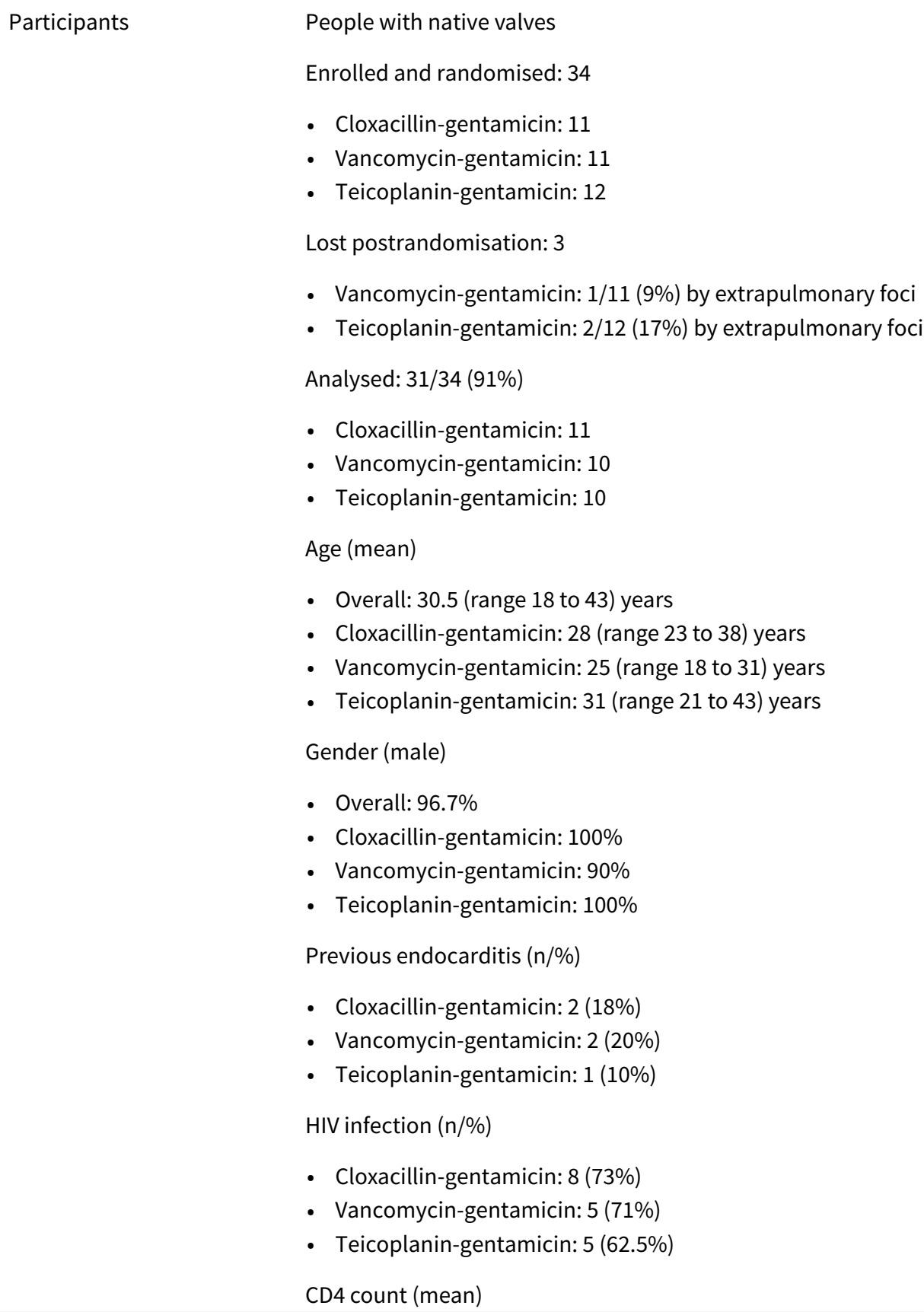


Fortún 2001 (Continued)

- Cloxacillin-gentamicin: 300 (range 129 to 600 ) cells $/ \mathrm{mm}^{3}$

- Vancomycin-gentamicin: 210 (range 120 to 500) cells $/ \mathrm{mm}^{3}$

- Teicoplanin-gentamicin: 243 (range 130 to 378 ) cells $/ \mathrm{mm}^{3}$

White blood cells count (mean)

- Cloxacillin-gentamicin: 7775 (range 3800 to 10,300 ) cells $/ \mathrm{mm}^{3}$

- Vancomycin-gentamicin: 6730 (range 2300 to 14,500 ) cells $/ \mathrm{mm}^{3}$

- Teicoplanin-gentamicin: 8160 (range 5400 to 16,300 ) cells $/ \mathrm{mm}^{3}$

Neutrophil count (mean)

- Cloxacillin-gentamicin: 5998 (range 4200 to 8100 ) cells $/ \mathrm{mm}^{3}$

- Vancomycin-gentamicin: 5040 (range 1400 to 11,730 ) cells $/ \mathrm{mm}^{3}$

- Teicoplanin-gentamicin: 6800 (range 4060 to 14,100 ) cells $/ \mathrm{mm}^{3}$

Inclusion criteria

- Parenteral drug abusers

- Fever

- Isolation of methicillin-susceptible Staphylococcus aureus from $\geq 2$ cultures of blood samples

- Septic pulmonary embolisation

- Tricuspid regurgitation murmur

- Echocardiographic evidence of endocarditis (intracardiac mass on valve or supporting structures, abscess, or nodular tricuspid thickening)

Exclusion criteria

- Isolation of methicillin-resistant Staphylococcus aureus from cultures of blood samples

- Allergy to the antibiotics used

- Extrapulmonary metastatic focus at enrolment or developed within the first 48 hours of therapy

- Serum creatinine level $>220 \mathrm{nmol} / \mathrm{L}(>2.5 \mathrm{mg} / \mathrm{dL})$

- Left-side endocarditis observed on an echocardiogram

- Presence of non-biological valvular prosthesis or long-term catheter

- Polymicrobial infections

- Pregnancy

- Receipt of effective antimicrobial treatment during the 72 hours prior to the study period

Treatment duration: 14 days

- Efficacy (response to therapy) by:

* cure;

* clinical failure: definition;

* microbiological failure;

* microbiological relapse;

* duration of fever while receiving therapy.

- Adverse effects 
Fortún 2001 (Continued)

\author{
A priori sample size estimation: no \\ Sponsor: not reported \\ Role of sponsor: not reported \\ Conflict of interest: not declared \\ Identification number clinical trial: not reported
}

\title{
Risk of bias
}

\begin{tabular}{|c|c|c|}
\hline Bias & Authors' judgement & Support for judgement \\
\hline \multirow{2}{*}{$\begin{array}{l}\text { Random sequence genera- } \\
\text { tion (selection bias) }\end{array}$} & Unclear risk & Quote: " ...randomized ..." (page 120) \\
\hline & & $\begin{array}{l}\text { Comment: insufficient information about the sequence generation process to } \\
\text { permit judgement of 'low risk' or 'high risk' }\end{array}$ \\
\hline $\begin{array}{l}\text { Allocation concealment } \\
\text { (selection bias) }\end{array}$ & Unclear risk & $\begin{array}{l}\text { Insufficient information about the allocation concealment process to permit } \\
\text { judgement of 'low risk' or 'high risk' }\end{array}$ \\
\hline $\begin{array}{l}\text { Blinding of participants } \\
\text { and personnel (perfor- } \\
\text { mance bias) } \\
\text { All outcomes }\end{array}$ & High risk & Quote: "...open..." (pages 120 and 123) \\
\hline
\end{tabular}

\begin{tabular}{|c|c|c|}
\hline $\begin{array}{l}\text { Blinding of outcome as- } \\
\text { sessment (detection bias) }\end{array}$ & Low risk & $\begin{array}{l}\text { No blinding of outcome assessment, but the review authors judged that the } \\
\text { outcome measure (cure) was not likely to be influenced by lack of blinding. }\end{array}$ \\
\hline
\end{tabular}

\begin{tabular}{|c|c|c|}
\hline $\begin{array}{l}\text { Blinding of outcome as- } \\
\text { sessment (detection bias) } \\
\text { All-cause mortality }\end{array}$ & Low risk & $\begin{array}{l}\text { No blinding of outcome assessment, but the review authors judged that the } \\
\text { outcome measure (all-cause mortality) was not likely to be influenced by lack } \\
\text { of blinding. }\end{array}$ \\
\hline $\begin{array}{l}\text { Blinding of outcome as- } \\
\text { sessment (detection bias) } \\
\text { Adverse events }\end{array}$ & Low risk & $\begin{array}{l}\text { No blinding of outcome assessment, but the review authors judged that the } \\
\text { outcome measure (adverse events) was not likely to be influenced by lack of } \\
\text { blinding. }\end{array}$ \\
\hline $\begin{array}{l}\text { Blinding of outcome as- } \\
\text { sessment (detection bias) } \\
\text { Incidence of septic em- } \\
\text { bolism }\end{array}$ & Unclear risk & Trial did not assess incidence of septic embolism. \\
\hline
\end{tabular}

\begin{tabular}{|c|c|c|}
\hline $\begin{array}{l}\text { Blinding of outcome as- } \\
\text { sessment (detection bias) } \\
\text { Incidence of congestive } \\
\text { heart failure }\end{array}$ & Unclear risk & Trial did not assess incidence of congestive heart failure. \\
\hline
\end{tabular}

$\begin{array}{ll}\text { Blinding of outcome as- } & \text { Unclear risk }\end{array}$ Trial did not assess quality of life.

Quality of life

\begin{tabular}{lll}
\hline $\begin{array}{l}\text { Blinding of outcome as- } \\
\text { sessment (detection bias) } \\
\begin{array}{l}\text { Need for cardiac surgical } \\
\text { interventions }\end{array}\end{array}$ & Unclear risk & Trial did not assess need for cardiac surgical interventions. \\
\hline $\begin{array}{l}\text { Blinding of outcome as- } \\
\text { sessment (detection bias) }\end{array}$ & Unclear risk & Trial did not assess indication of cardiac surgery. \\
\hline
\end{tabular}


Fortún 2001 (Continued) Indication of cardiac surgery

\begin{tabular}{lll}
\hline $\begin{array}{l}\text { Blinding of outcome as- } \\
\text { sessment (detection bias) } \\
\text { Uncontrolled infection }\end{array}$ & Unclear risk & Trial did not assess uncontrolled infection. \\
\hline $\begin{array}{l}\text { Blinding of outcome as- } \\
\text { sessment (detection bias) } \\
\text { Relapse }\end{array}$ & Low risk & $\begin{array}{l}\text { No blinding of outcome assessment, but the review authors judged that the } \\
\text { outcome measure (relapse) was not likely to be influenced by lack of blinding. }\end{array}$ \\
\hline $\begin{array}{l}\text { Incomplete outcome data } \\
\text { (attrition bias) } \\
\text { All outcomes }\end{array}$ & Low risk & $\begin{array}{l}\text { Data for primary outcome available for 31/34 (91\%) of the randomised sample, } \\
\text { with balanced reasons for withdrawals or losses to follow-up. }\end{array}$ \\
\hline $\begin{array}{l}\text { Selective reporting (re- } \\
\text { porting bias) }\end{array}$ & Unclear risk & $\begin{array}{l}\text { All the outcomes listed in the Methods section were described in the Results } \\
\text { section. } \\
\text { Trial authors did not mention data of clinical key outcomes such as mortality } \\
\text { and heart failure. }\end{array}$ \\
\hline $\begin{array}{l}\text { Other bias } \\
\text { Migh risk }\end{array}$ & \begin{tabular}{l} 
Design bias \\
\hline
\end{tabular}
\end{tabular}

\section{Fowler 2006}

\section{Study characteristics}

$\begin{array}{ll}\text { Methods } & \text { Design: parallel ( } 2 \text { arms) } \\ \text { Multicentre: yes (44 sites) } \\ \text { Countries: USA } \\ \text { Follow-up period: } 42 \text { days } \\ \text { Unit of randomisation: participants } \\ \text { Unit of analysis: participants } \\ \text { Duke's criteria for diagnosis of infective endocarditis: yes }\end{array}$

Participants

People with native and prosthetic valve

Enrolled and randomised: 246

- Daptomycin: 126

- Standard therapy: 120

Lost postrandomisation: 10

- Daptomycin: 6

- Standard therapy: 4

Analysed: 235/246 (96\%)

- Daptomycin: 120

- Standard therapy: 115

Age: not reported separately for the endocarditis group 
Fowler 2006 (Continued)

Gender (male): not reported separately for the endocarditis group

Definitive endocarditis (baseline diagnosis) ( $\mathrm{n} / \%)$

- Daptomycin: 17 (14.2\%)

- Standard therapy: 20 (61.7\%)

Left-sided endocarditis (final diagnosis) (n/\%)

- Daptomycin: 9 (7.5\%)

- Standard therapy: 9 (7.8\%)

Inclusion criteria:

- $\geq 18$ years of age

- $\geq 1$ blood cultures that were positive for Staphylococcus aureus within 2 calendar days before initiating study medication

Exclusion criteria:

- Known osteomyelitis

- Polymicrobial bacteraemia

- Pneumonia

- Renal failure with creatinine clearance $<30 \mathrm{~mL} /$ minute

- Initial Staphylococcus aureus blood culture outside the 2-day window

- Inability to provide consent or unlikely to comply with study-related procedures

- Presence of an intravascular material (excluding cardiac stents) not intended to be removed within 4 calendar days

- Receipt of non-study antibiotics potentially effective against Staphylococcus aureus

- High likelihood of death or valve replacement surgery in the first 3 days following randomisation

- Refractory shock, significant hepatic insufficiency, or severe leukopenia

- Weight $<50 \mathrm{~kg}$ or $>150 \mathrm{~kg}$

- Allergy to vancomycin or penicillin

- Infection with Staphylococcus aureus with reduced susceptibility to vancomycin (minimum inhibitory concentration $>4 \mu \mathrm{g} / \mathrm{mL}$ )

Interventions

Experimental: daptomycin: $6 \mathrm{mg} / \mathrm{kg}$ body weight, once daily, IV (1 participant also received gentamicin $1 \mathrm{mg} / \mathrm{kg}$ given every 8 hours for the first 4 days)

Control: standard treatment with either:

- vancomycin $1 \mathrm{~g}$, every 12 hours with appropriate dose adjustment with gentamicin $1 \mathrm{mg} / \mathrm{kg}$ given every 8 hours for the first 4 days; OR

- antistaphylococcal penicillin (nafcillin, oxacillin, or flucloxacillin) $2 \mathrm{~g}$ given every 4 hours, depending on the susceptibility of the causative strain to methicillin with gentamicin $1 \mathrm{mg} / \mathrm{kg}$ given every 8 hours for the first 4 days.

Treatment duration: 4 to 6 weeks was determined by the investigator on the basis of the working group. Mean treatment durations were 14 days in daptomycin group and 15 days in standard treatment group. 
Fowler 2006 (Continued)

- receipt of potentially effective non-study antibiotics (any antibiotic received during or after study drug therapy that may have influenced the outcome);

- premature discontinuation of the study medication because of clinical failure, microbiological failure, or an adverse event.

- Adverse events: coded using the Medical Dictionary for Regulatory Activities (MedDRA) (Version 6.0)
Conduction date: 28 August 2002 to 16 February 2005

A priori sample size estimation: yes (page 655)

Sponsor: Cubist Pharmaceuticals

Role of sponsor: study was designed and analysed by the sponsor (page 656)

Conflict of interest: many trials authors were consultants or employees of Cubist Pharmaceuticals (pages 654, 656)

Identifier number: ClinicalTrials.gov ID NCT00093067 (page 653)

\section{Risk of bias}

\begin{tabular}{|c|c|c|}
\hline Bias & Authors' judgement & Support for judgement \\
\hline $\begin{array}{l}\text { Random sequence genera- } \\
\text { tion (selection bias) }\end{array}$ & Low risk & $\begin{array}{l}\text { Quote: "... this centralized computer-generated schedule was designed to } \\
\text { achieve a 1:1 ratio of patients, stratified according to investigative site" (page } \\
655)\end{array}$ \\
\hline $\begin{array}{l}\text { Allocation concealment } \\
\text { (selection bias) }\end{array}$ & Low risk & Quote: "... this centralized computer-generated schedule ..." (page 655) \\
\hline $\begin{array}{l}\text { Blinding of participants } \\
\text { and personnel (perfor- } \\
\text { mance bias) } \\
\text { All outcomes }\end{array}$ & High risk & Quote: "open-label" (page 654) \\
\hline
\end{tabular}

\section{Blinding of outcome as- Low risk} sessment (detection bias) Cure

Blinding of outcome as- Unclear risk sessment (detection bias)

All-cause mortality
No blinding of outcome assessment, but the review authors judged that the outcome measure (cure) was not likely to be influenced by lack of blinding.

\begin{tabular}{lll}
\hline $\begin{array}{l}\text { Blinding of outcome as- } \\
\text { sessment (detection bias) } \\
\text { Adverse events }\end{array}$ & Unclear risk & Trial did not assess adverse events. \\
\hline $\begin{array}{l}\text { Blinding of outcome as- } \\
\text { sessment (detection bias) }\end{array}$ & Unclear risk & Trial did not assess incidence of septic embolism. \\
$\begin{array}{l}\text { Incidence of septic em- } \\
\text { bolism }\end{array}$ & \\
\hline
\end{tabular}

Blinding of outcome as- Unclear risk $\quad$ Trial did not assess incidence of congestive heart failure.
sessment (detection bias) Incidence of congestive heart failure

$\begin{array}{lll}\text { Blinding of outcome as- } & \text { Unclear risk } & \text { Trial did not assess quality of life. }\end{array}$


Fowler 2006 (Continued)

Quality of life

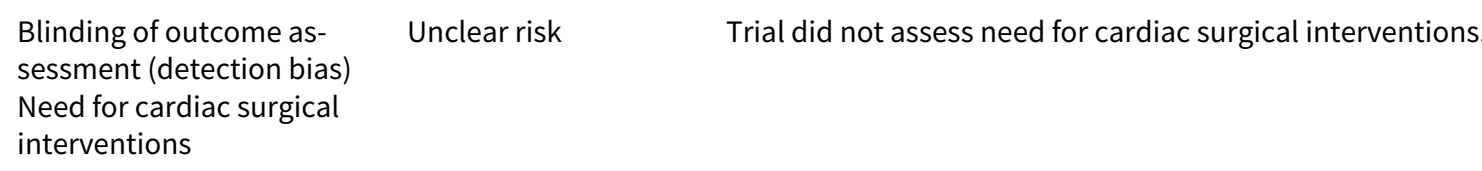

Blinding of outcome as- $\quad$ Unclear risk
sessment (detection bias)
Indication of cardiac

\begin{tabular}{|c|c|c|}
\hline $\begin{array}{l}\text { Blinding of outcome as- } \\
\text { sessment (detection bias) } \\
\text { Uncontrolled infection }\end{array}$ & Low risk & $\begin{array}{l}\text { No blinding of outcome assessment, but the review authors judged that the } \\
\text { outcome measure (uncontrolled infection) was not likely to be influenced by } \\
\text { lack of blinding. }\end{array}$ \\
\hline
\end{tabular}

\begin{tabular}{lll}
\hline $\begin{array}{l}\text { Blinding of outcome as- } \\
\text { sessment (detection bias) } \\
\text { Relapse }\end{array}$ & Unclear risk & Trial did not assess relapse. \\
\hline $\begin{array}{l}\text { Incomplete outcome data } \\
\text { (attrition bias) } \\
\text { All outcomes }\end{array}$ & Low risk & Participants lost postrandomisation not receiving treatment: 10/246 (4\%) \\
\hline $\begin{array}{l}\text { Selective reporting (re- } \\
\text { porting bias) }\end{array}$ & High risk & Participants lost receiving treatment: 1/236 (0.4\%) \\
\hline Other bias & High risk & Trial did no report all-cause mortality and adverse events. \\
\hline
\end{tabular}

Pericas 2018

\section{Study characteristics}

\begin{tabular}{ll}
\hline Methods & Design: parallel (2 arms) \\
Multicentre: yes (10 sites) \\
Countries: Spain \\
Follow-up period: 6 weeks \\
Unit of randomisation: participants \\
Unit of analysis: participants \\
- Type: complicated bacteraemia and endocarditis due to methicillin-resistant Staphylococcus aureus \\
- Randomised: 15 \\
(The following data relate only to those participants with infective endocarditis (IE): 8) \\
Fosfomycin plus imipenem: 4 (2 native valve IE, 2 prosthetic valve IE) \\
Vancomycin: 4 (1 native valve IE, 3 pacemaker IE) \\
Age (years, mean (SD)) \\
- Fosfomycin plus imipenem: 84 (3.3) \\
- Vancomycin: 78 (6.34)
\end{tabular}


Pericas 2018 (Continued)

Sex (male):

- Fosfomycin plus imipenem: $75 \%(3 / 4)$

- Vancomycin: $25 \%(1 / 4)$

Source

- Fosfomycin plus imipenem: vascular (1), urinary (1), cutaneous (1), unknown (1)

- Vancomycin: vascular (2) and unknown (2)

Acquisition

- Fosfomycin plus imipenem: non-nosocomial healthcare-associated (2) and nosocomial (2)

- Vancomycin: non-nosocomial healthcare-associated (2) and nosocomial (2)

Days of bacteraemia until study initiation (media)

- Fosfomycin plus imipenem: 3.25 (0.95)

- Vancomycin: 1 (all participants had 1 day)

Days of study treatment (mean (SD), median)

- Fosfomycin plus imipenem: 18.25 (22.02), 9

- Vancomycin: 35.75 (7.5), 37

Inclusion criteria: adults with suspected or confirmed methicillin-resistant Staphylococcus aureus infective endocarditis (IE; native or prosthetic valve, pacemaker/defibrillator) according to the modified Duke criteria, prosthetic vascular graft infection or complicated bacteraemia (septic thrombophlebitis, soft tissue-skin infection, pneumonia, osteomyelitis, or unknown source)

Excusion criteria:

- Aged under 18 years

- Antibiotics with anti-methicillin-resistant Staphylococcus aureus activity received for $>72 \mathrm{~h}$

- Shock or hypotension

- Urgent surgery needed

- Active intravenous drug use

- Vancomycin trough levels $>15 \mu \mathrm{g} / \mathrm{mL}$ at $72 \mathrm{~h}$ in participants with chronic renal insufficiency or haemodialysis

- Methicillin-resistant Staphylococcus aureus strains with fosfomycin minimum inhibitory concentration (MIC) $>64 \mathrm{mg} / \mathrm{L}$ or vancomycin MIC $\geq 2 \mathrm{mg} / \mathrm{L}$

- Known allergy to vancomycin, fosfomycin, or imipenem

Note: if the participant developed either treatment failure or renal failure with vancomycin, he/she was switched to the other comparison group.

- Treatment duration:

- Complicated bacteraemia with rapid control of the source and negative first control complicated bacteraemia: 2 weeks

- Non-complicated native valve infective endocarditis and pacemaker/defibrillator infective endocarditis or non-rapidly controlled complicated bacteraemia: 4 weeks

- Prosthetic valve infective endocarditis, complicated native infective endocarditis, and complicated bacteraemia with osteomyelitis: 6 weeks

Outcomes

Trial authors did not classify the outcomes as primary or secondary. However, the trial reported data on death, cure, adverse events including treatment-related adverse events, cardiac surgical interventions, uncontrolled infection, and relapse of endocarditis. 
Pericas 2018 (Continued)

Notes
Conduction date: October 2009 to December 2014

A priori sample size estimation: yes

This trial was stopped early due to difficulties in recruiting participants.

Support: Ministerio de Sanidad y Consumo of Spain (Fondo de Investigaciones Sanitarias, Instituto de Salud Carlos III, Madrid, Spain, several grants from public Spanish entities).

Role of support: not stated

Conflict of interest: 1 author has received consulting honoraria or research grants, or both, from Abb-

Vie, Bristol-Myers Squibb, Cubist, Novartis, Gilead Sciences, and Viiv.

Identifier number: ClinicalTrials.gov ID NCT00871104

\section{Risk of bias}

\begin{tabular}{lll}
\hline Bias & Authors' judgement & Support for judgement \\
\hline $\begin{array}{l}\text { Random sequence genera- } \\
\text { tion (selection bias) }\end{array}$ & Unclear risk & $\begin{array}{l}\text { Quote "...randomized clinical trial..." (page 673) } \\
\text { Comment: insufficient information to permit judgement of 'low risk' or 'high } \\
\text { risk' }\end{array}$ \\
\hline $\begin{array}{l}\text { Allocation concealment } \\
\text { (selection bias) }\end{array}$ & Unclear risk & $\begin{array}{l}\text { Quote "...randomized clinical trial..." (page 673) } \\
\text { Comment: insufficient information to permit judgement of 'low risk' or 'high } \\
\text { risk' }\end{array}$ \\
\hline $\begin{array}{l}\text { Blinding of participants } \\
\text { and personnel (perfor- } \\
\text { mance bias) }\end{array}$ & High risk & Quote "open-label" (page 673) \\
All outcomes & &
\end{tabular}

\begin{tabular}{|c|c|c|}
\hline $\begin{array}{l}\text { Blinding of outcome as- } \\
\text { sessment (detection bias) } \\
\text { Cure }\end{array}$ & Unclear risk & $\begin{array}{l}\text { Comment: insufficient information to permit judgement of 'low risk' or 'high } \\
\text { risk' }\end{array}$ \\
\hline
\end{tabular}

\begin{tabular}{lll}
\hline $\begin{array}{l}\text { Blinding of outcome as- } \\
\text { sessment (detection bias) } \\
\text { All-cause mortality }\end{array}$ & Unclear risk & $\begin{array}{l}\text { Comment: insufficient information to permit judgement of 'low risk' or 'high } \\
\text { risk' }\end{array}$ \\
\hline
\end{tabular}

All-cause mortality

\begin{tabular}{|c|c|c|}
\hline $\begin{array}{l}\text { Blinding of outcome as- } \\
\text { sessment (detection bias) }\end{array}$ & Unclear risk & $\begin{array}{l}\text { Comment: insufficient information to permit judgement of 'low risk' or 'high } \\
\text { risk' }\end{array}$ \\
\hline
\end{tabular}

Adverse events

Blinding of outcome as- $\quad$ Unclear risk
sessment (detection bias)
Incidence of septic em-
bolism

Comment: insufficient information to permit judgement of 'low risk' or 'high risk'

\begin{tabular}{|c|c|c|}
\hline $\begin{array}{l}\text { Blinding of outcome as- } \\
\text { sessment (detection bias) } \\
\text { Incidence of congestive } \\
\text { heart failure }\end{array}$ & Unclear risk & $\begin{array}{l}\text { Comment: insufficient information to permit judgement of 'low risk' or 'high } \\
\text { risk' }\end{array}$ \\
\hline
\end{tabular}

Blinding of outcome as-

Unclear risk

Trial did not assess quality of life.

sessment (detection bias)

Quality of life 
Pericas 2018 (Continued)

Blinding of outcome as- Unclear risk Comment: insufficient information to permit judgement of 'low risk' or 'high sessment (detection bias) risk'

Need for cardiac surgical interventions

\begin{tabular}{|c|c|c|}
\hline $\begin{array}{l}\text { Blinding of outcome as- } \\
\text { sessment (detection bias) } \\
\text { Indication of cardiac }\end{array}$ & Unclear risk & $\begin{array}{l}\text { Comment: insufficient information to permit judgement of 'low risk' or 'high } \\
\text { risk' }\end{array}$ \\
\hline
\end{tabular}
surgery

\begin{tabular}{lll}
\hline $\begin{array}{l}\text { Blinding of outcome as- } \\
\text { sessment (detection bias) } \\
\text { Uncontrolled infection }\end{array}$ & Unclear risk & $\begin{array}{l}\text { Comment: insufficient information to permit judgement of 'low risk' or 'high } \\
\text { risk' }\end{array}$ \\
\hline $\begin{array}{l}\text { Blinding of outcome as- } \\
\text { sessment (detection bias) } \\
\text { Relapse }\end{array}$ & Unclear risk & $\begin{array}{l}\text { Comment: insufficient information to permit judgement of 'low risk' or 'high } \\
\text { risk' }\end{array}$ \\
\hline $\begin{array}{l}\text { Incomplete outcome data } \\
\text { (attrition bias) } \\
\begin{array}{l}\text { All outcomes } \\
\text { Selective reporting (re- }\end{array}\end{array}$ & Low risk & Trial authors reported data from 8 participants with IE. \\
\hline porting bias) & High risk & Trial authors reported relevant clinical endpoints. \\
\hline \begin{tabular}{l} 
Other bias \\
\hline
\end{tabular} & Bias in the presentation of the data \\
\hline
\end{tabular}

\section{POET 2019}

\section{Study characteristics}

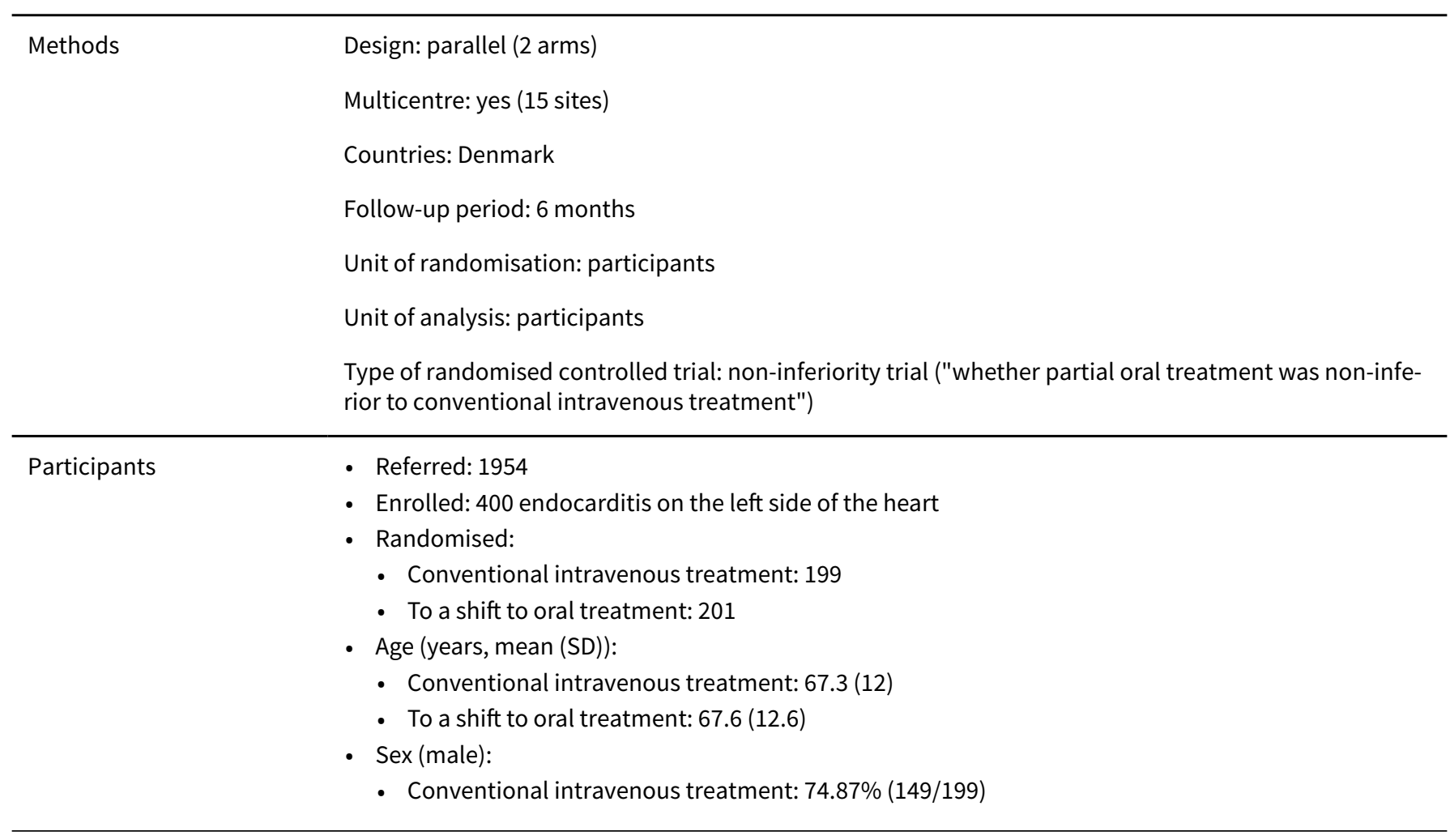


- Pathogen:

- Conventional intravenous treatment: Streptococcus (52.3\%), Enterococcus faecalis (23.1\%), Staphylococcus aureus (20.1\%), and coagulase-negative staphylococci (5.0\%)

- To a shift to oral treatment: Streptococcus (45.8\%), Enterococcus faecalis (25.4\%), Staphylococcus aureus (23.4\%), and coagulase-negative staphylococci (6.5\%)

- Pre-existing prosthesis, implant, or cardiac disease:

- Conventional intravenous treatment: prosthetic heart valve $(26.6 \%)$, pacemaker $(7.5 \%)$, other known valve disease $(41.2 \%)$

- To a shift to oral treatment: prosthetic heart valve $(26.9 \%)$, pacemaker $(10 \%)$, other known valve disease $(44.8 \%)$

- Cardiac involvement at randomisation:

- Conventional intravenous treatment: mitral-valve endocarditis (32.7\%), aortic-valve endocarditis $(54.8 \%)$, mitral-valve and aortic-valve endocarditis (11.6\%), pacemaker endocarditis (3.0\%), and vegetation size $>9 \mathrm{~mm}(3.5 \%)$

- To a shift to oral treatment: mitral-valve endocarditis (35.8\%), aortic-valve endocarditis (54.2\%), mitral-valve and aortic-valve endocarditis (10.0\%), pacemaker endocarditis (4.0\%), and vegetation size $>9 \mathrm{~mm}(5.5 \%)$

- Coexisting condition or risk factor:

- Conventional intravenous treatment: diabetes (18.1\%), renal failure (12.6\%), dialysis (6.5\%), COPD $(8.5 \%)$, liver disease (3.5\%), cancer (7.0\%), and intravenous drug use (1.5\%)

- To a shift to oral treatment: diabetes (15.4\%), renal failure (10.4\%), dialysis (7.5\%), COPD (4.5\%), liver disease (3.0\%), cancer (9.0\%), and intravenous drug use (1.0\%)

- Inclusion criteria:

- Left-sided endocarditis based on the Duke criteria

- Infected with 1 of the following micro-organisms: streptococci, Enterococcus faecalis, Staphylococcus aureus, coagulase-negative staphylococci

- Adult participants ( $\geq 18$ years)

- At least $\geq 10$ days of appropriate parenteral antibiotic treatment overall, and at least 1 week of appropriate parenteral treatment after valve surgery

- Temperature $<38.0^{\circ} \mathrm{C}>2$ days

- C-reactive protein dropped to less than $25 \%$ of peak value or $<20 \mathrm{mg} / \mathrm{L}$, and white blood cell count less than $15 \times 10^{9} / \mathrm{L}$ during antibiotic treatment

- No sign of abscess formation revealed by echocardiography

- Transthoracic and trans-oesophageal echocardiography performed within 48 hours of randomisation

- Exclusion criteria:

- Body mass index $>40$

- Concomitant infection requiring intravenous antibiotic therapy

- Inability to give informed consent to participation

- Suspicion of reduced absorption of oral treatment due to abdominal disorder

- Reduced compliance

- Oral treatment: the composition, doses, and duration of different oral regimens is shown in Appendix 6.

- Conventional intravenous treatment: based on the guidelines of the European Society of Cardiology (Habib 2015), with modifications endorsed by the Danish Society of Cardiology (Moser 2017)

No details were provided regarding the conventional intravenous therapy regimens.

Outcomes

Primary: composite of all-cause mortality, unplanned cardiac surgery, clinically evident embolic events, or relapse of bacteraemia with the primary pathogen (detected in blood cultures obtained during follow-up or for clinical reasons) from randomisation through 6 months after antibiotic treatment was completed 
Trial assessed and reported adverse events.

Notes

Identifier number: ClinicalTrials.gov ID NCT01375257

Conduction date: 15 July 2011 to 30 August 2017

A priori sample size estimation: yes

Support: the Danish Heart Foundation and the Capital Regions Research Council, the Hartmann's

Foundation, Svend Aage Andersens Foundation, and the Novo Nordisk Foundation

Role of support: not stated

Conflict of interest: 1 author has received consulting honoraria or research grants, or both, from Bayer.

\section{Risk of bias}

\begin{tabular}{|c|c|c|}
\hline Bias & Authors' judgement & Support for judgement \\
\hline $\begin{array}{l}\text { Random sequence genera- } \\
\text { tion (selection bias) }\end{array}$ & Low risk & $\begin{array}{l}\text { Quote "Randomization was performed with the use of a Web-based system, } \\
\text { in permuted blocks of } 2 \text { to } 6 \text {, with stratification according to randomization } \\
\text { site." (page 417) }\end{array}$ \\
\hline $\begin{array}{l}\text { Allocation concealment } \\
\text { (selection bias) }\end{array}$ & Low risk & $\begin{array}{l}\text { Quote "Randomization was performed with the use of a Web-based system, } \\
\text { in permuted blocks of } 2 \text { to } 6 \text {, with stratification according to randomization } \\
\text { site." (page 417) }\end{array}$ \\
\hline $\begin{array}{l}\text { Blinding of participants } \\
\text { and personnel (perfor- } \\
\text { mance bias) } \\
\text { All outcomes }\end{array}$ & High risk & Quote "...unblinded..." (page 416) \\
\hline
\end{tabular}

\begin{tabular}{lll}
\hline $\begin{array}{l}\text { Blinding of outcome as- } \\
\text { sessment (detection bias) } \\
\text { Cure }\end{array}$ & Unclear risk & This outcome was not mentioned. \\
\hline $\begin{array}{l}\text { Blinding of outcome as- } \\
\text { sessment (detection bias) }\end{array}$ & Low risk & $\begin{array}{l}\text { Quote "A clinical-event adjudication committee, whose members were un- } \\
\text { aware of the treatment assignments, adjudicated the prespecified clinical out- } \\
\text { comes. The committee consisted of experienced cardiologists and a specialist } \\
\text { in infectious diseases." (page 417) }\end{array}$ \\
\hline
\end{tabular}

\begin{tabular}{|c|c|c|}
\hline $\begin{array}{l}\text { Blinding of outcome as- } \\
\text { sessment (detection bias) } \\
\text { Adverse events }\end{array}$ & Low risk & $\begin{array}{l}\text { Quote "A clinical-event adjudication committee, whose members were un- } \\
\text { aware of the treatment assignments, adjudicated the prespecified clinical out- } \\
\text { comes. The committee consisted of experienced cardiologists and a specialist } \\
\text { in infectious diseases." (page 417) }\end{array}$ \\
\hline
\end{tabular}

\begin{tabular}{|c|c|c|}
\hline $\begin{array}{l}\text { Blinding of outcome as- } \\
\text { sessment (detection bias) } \\
\text { Incidence of septic em- } \\
\text { bolism }\end{array}$ & Low risk & $\begin{array}{l}\text { Quote "A clinical-event adjudication committee, whose members were un- } \\
\text { aware of the treatment assignments, adjudicated the prespecified clinical out- } \\
\text { comes. The committee consisted of experienced cardiologists and a specialist } \\
\text { in infectious diseases." (page 417) }\end{array}$ \\
\hline
\end{tabular}

\begin{tabular}{ll}
\hline $\begin{array}{l}\text { Blinding of outcome as- } \\
\text { sessment (detection bias) }\end{array}$ & Low risk \\
$\begin{array}{l}\text { Incidence of congestive } \\
\text { heart failure }\end{array}$ & $\begin{array}{l}\text { Quote "A clinical-event adjudication committee, whose members were un- } \\
\text { aware of the treatment assignments, adjudicated the prespecified clinical out- } \\
\text { comes. The committee consisted of experienced cardiologists and a specialist } \\
\text { in infectious diseases." (page 417) }\end{array}$ \\
\hline
\end{tabular}

Blinding of outcome as- Unclear risk This outcome was not mentioned.

sessment (detection bias)

Quality of life 
POET 2019 (Continued)

Blinding of outcome as- Low risk Quote "A clinical-event adjudication committee, whose members were unsessment (detection bias) Need for cardiac surgical interventions aware of the treatment assignments, adjudicated the prespecified clinical outcomes. The committee consisted of experienced cardiologists and a specialist in infectious diseases." (page 417)

$\begin{array}{ll}\begin{array}{l}\text { Blinding of outcome as- } \\ \text { sessment (detection bias) }\end{array} & \text { Low risk } \\ \begin{array}{l}\text { Indication of cardiac } \\ \text { surgery }\end{array} & \begin{array}{l}\text { Quote "A clinical-event adjudication committee, whose members were un- } \\ \text { aware of the treatment assignments, adjudicated the prespecified clinical out- } \\ \text { comes. The committee consisted of experienced cardiologists and a specialist } \\ \text { in infectious diseases." (page 417) }\end{array}\end{array}$

Unclear risk

This outcome was not mentioned.

sessment (detection bias)

Uncontrolled infection

Blinding of outcome as- Low risk

sessment (detection bias)

Relapse
Quote "A clinical-event adjudication committee, whose members were unaware of the treatment assignments, adjudicated the prespecified clinical outcomes. The committee consisted of experienced cardiologists and a specialist in infectious diseases." (page 417)

Incomplete outcome data Low risk No participants were lost to follow-up.
(attrition bias)

All outcomes

Selective reporting (re- Low risk Trial reported relevant clinical outcomes. porting bias)

Other bias Low risk -

Sexton 1998

\section{Study characteristics}

\begin{tabular}{ll}
\hline Methods & Design: parallel (2 groups) \\
Multicentre study: yes (9 sites) \\
Country: USA \\
Follow-up period: 3 months \\
Unit of randomisation: participants \\
Unit of analysis: participants \\
Duke's criteria for diagnosis of infective endocarditis: yes \\
People with ceftriaxone-susceptible Streptococcus viridans or Streptococcus bovis endocarditis \\
People with native valve \\
Enrolled and randomised: 67 \\
- Ceftriaxone: 33 \\
- Ceftriaxone + gentamicin: 3 \\
Analysed for clinical efficacy: 51 \\
- Ceftriaxone: 26 \\
- Ceftriaxone + gentamicin: 25
\end{tabular}


Sexton 1998 (Continued)

$$
\text { Age (mean) }
$$

- Ceftriaxone: 52.5 (SD 17.8) (range 18 to 87) years

- Ceftriaxone + gentamicin: 59.5 (SD 15.5) (range 27 to 92) years

Gender (male)

- Ceftriaxone: not reported

- Ceftriaxone + gentamicin: not reported

- Total group: 41 (80.3\%)

Previous endocarditis

- Ceftriaxone: 4 (15.3\%)

- Ceftriaxone + gentamicin: $1(4 \%)$

History of rheumatic heart disease

- Ceftriaxone: 3 (11.5\%)

- Ceftriaxone + gentamicin: $3(12 \%)$

Inclusion criteria

- Aged $\geq 18$ years

- Received $<72$ hours of parenteral antibiotic therapy before enrolment

- Provided written informed consent

Exclusion criteria

- Presence of aetiological agents other than ceftriaxone-susceptible viridans streptococci or S bovis

- Hypersensitivity to cephalosporins or aminoglycosides

- Prior treatment with antibiotics for $>72$ hours

- New York Heart Association class IV heart failure

- Need for therapy for $>2$ weeks

- Moderate-to-severe renal dysfunction (serum creatinine clearance of $<20 \mathrm{~mL} /$ minute)

- Prosthetic valve endocarditis

- Clinically apparent moderate-to-severe hearing loss or vestibular dysfunction

- Neutropenia (absolute neutrophil count $<1000 / \mathrm{mm}^{3}$ )

Interventions

Experimental: ceftriaxone $2 \mathrm{~g}$ once daily for 4 weeks, IV + gentamicin $3 \mathrm{mg} / \mathrm{kg}$ IV once daily for 2 weeks

Control: ceftriaxone 2 g once daily, IV

Infusion time: 30 to 60 minutes

Co-intervention: not reported

Treatment duration: 2 to 4 weeks

\begin{tabular}{ll}
\hline Outcomes & Outcomes were not classified as primary or secondary. \\
- Cure with or without surgery \\
- Re-infection \\
- Treatment failure \\
\hline Notes & Conduction date: 29 January 1992 to 22 December 1996 \\
A priori sample size estimation: no \\
Sponsor: Roche
\end{tabular}

A comparison of different antibiotic regimens for the treatment of infective endocarditis (Review) 
Sexton 1998 (Continued)

Role of sponsor: not reported

Conflict of interest: not declared

Identification number clinical trial: not reported

\section{Risk of bias}

\begin{tabular}{lll}
\hline Bias & Authors' judgement & Support for judgement \\
\hline $\begin{array}{l}\text { Random sequence genera- } \\
\text { tion (selection bias) }\end{array}$ & Unclear risk & $\begin{array}{l}\text { Quote: "Patients were assigned randomly" (page 1471) } \\
\text { Comment: insufficient information to permit judgement of 'low risk' or 'high } \\
\text { risk' }\end{array}$ \\
\hline $\begin{array}{l}\text { Allocation concealment } \\
\text { (selection bias) }\end{array}$ & Unclear risk & Insufficient information to permit judgement of 'low risk' or 'high risk' \\
\hline
\end{tabular}

Blinding of participants High risk Quote: "This randomised, multicenter, open-label study" (page 1470)
and personnel (perfor-
mance bias)
All outcomes

Blinding of outcome as- Low risk sessment (detection bias) Cure
The review authors judged that the outcome measure (cure) was not likely to be influenced by lack of blinding.

\begin{tabular}{lll}
\hline $\begin{array}{l}\text { Blinding of outcome as- } \\
\text { sessment (detection bias) } \\
\text { All-cause mortality }\end{array}$ & Unclear risk & The trial did not assess all-cause mortality. \\
\hline $\begin{array}{l}\text { Blinding of outcome as- } \\
\text { sessment (detection bias) }\end{array}$ & Low risk & $\begin{array}{l}\text { The review authors judged that the outcome measure (adverse events) was } \\
\text { not likely to be influenced by lack of blinding. }\end{array}$
\end{tabular}

Adverse events

Blinding of outcome as-
sessment (detection bias)
Incidence of septic em-
bolism

bolism

\begin{tabular}{|c|c|c|}
\hline $\begin{array}{l}\text { Blinding of outcome as- } \\
\text { sessment (detection bias) } \\
\text { Incidence of congestive } \\
\text { heart failure }\end{array}$ & Unclear risk & The trial did not assess incidence of congestive heart failure. \\
\hline $\begin{array}{l}\text { Blinding of outcome as- } \\
\text { sessment (detection bias) } \\
\text { Quality of life }\end{array}$ & Unclear risk & The trial did not assess quality of life. \\
\hline $\begin{array}{l}\text { Blinding of outcome as- } \\
\text { sessment (detection bias) } \\
\text { Need for cardiac surgical } \\
\text { interventions }\end{array}$ & Low risk & $\begin{array}{l}\text { The review authors judged that the outcome measure (need for cardiac surgi- } \\
\text { cal interventions) was not likely to be influenced by lack of blinding. }\end{array}$ \\
\hline $\begin{array}{l}\text { Blinding of outcome as- } \\
\text { sessment (detection bias) } \\
\text { Indication of cardiac } \\
\text { surgery }\end{array}$ & Low risk & $\begin{array}{l}\text { The review authors judged that the outcome measure (indication of cardiac } \\
\text { surgery) was not likely to be influenced by lack of blinding. }\end{array}$ \\
\hline
\end{tabular}


Sexton 1998 (Continued)

Blinding of outcome as- Low risk The review authors judged that the outcome measure (uncontrolled infection) sessment (detection bias) was not likely to be influenced by lack of blinding.

Uncontrolled infection

\begin{tabular}{lll}
\hline $\begin{array}{l}\text { Blinding of outcome as- } \\
\text { sessment (detection bias) } \\
\text { Relapse }\end{array}$ & Unclear risk & $\begin{array}{l}\text { The review authors judged that the outcome measure (relapse) was not likely } \\
\text { to be influenced by lack of blinding. }\end{array}$ \\
\hline $\begin{array}{l}\text { Incomplete outcome data } \\
\text { (attrition bias) } \\
\begin{array}{l}\text { All outcomes } \\
\text { Sigh risk }\end{array}\end{array}$ & $\begin{array}{l}\text { Loss postrandomisation: } 51 / 67(24 \%) \\
-\quad \text { Ceftriaxone: } 7(21.2 \%) \\
\text { Ceftriaxone + gentamicin: } 9(26.47 \%)\end{array}$ \\
\hline $\begin{array}{l}\text { Selective reporting (re- } \\
\text { porting bias) }\end{array}$ & High risk & $\begin{array}{l}\text { Trial did not mention all-cause mortality and other clinically relevant out- } \\
\text { comes. }\end{array}$ \\
\hline Other bias & High risk & Design bias \\
\hline
\end{tabular}

COPD: chronic obstructive pulmonary disease

IV: intravenous

$\mathrm{n}$ : number of participants

SD: standard deviation

Characteristics of excluded studies [ordered by study ID]

\begin{tabular}{ll}
\hline Study & Reason for exclusion \\
\hline Abrams 1979 & $\begin{array}{l}\text { Randomised clinical trial did not use Duke's criteria for diagnosis of infective endocarditis. It used } \\
\text { Von Reyn } 1981 \text { criteria. }\end{array}$ \\
\hline Fortún 1995 & Randomised clinical trial that did not use Duke's criteria for diagnosis of infective endocarditis \\
\hline Gilbert 1991 & Randomised clinical trial that did not use Duke's criteria for diagnosis of infective endocarditis \\
\hline Greenman 1984 & Randomised clinical trial that did not use Duke's criteria for diagnosis of infective endocarditis \\
\hline Heldman 1996 & Randomised clinical trial that did not use Duke's criteria for diagnosis of infective endocarditis \\
\hline Korzeniowski 1982 & Randomised clinical trial that did not use Duke's criteria for diagnosis of infective endocarditis \\
\hline Levine 1991 & Randomised clinical trial that did not use Duke's criteria for diagnosis of infective endocarditis \\
\hline Markowitz 1992 & Randomised clinical trial that did not use Duke's criteria for diagnosis of infective endocarditis \\
\hline Ribera 1996 & Randomised clinical trial that did not use Duke's criteria for diagnosis of infective endocarditis \\
\hline Stamboulian 1991 & Randomised clinical trial that did not use Duke's criteria for diagnosis of infective endocarditis \\
\hline
\end{tabular}

Characteristics of ongoing studies [ordered by study ID] 


$\begin{array}{ll}\text { Study name } & \begin{array}{l}\text { An open labelled, double arm, randomized, multicentric, prospective and comparative, phase-III } \\ \text { trial to evaluate the safety and efficacy of fixed dose combination of ceftriaxone and vancomycin } \\ \text { injection versus vancomycin injection in subjects with various bacterial infections }\end{array}\end{array}$

Methods Randomised, parallel-group, active-controlled trial

Method of generating randomisation sequence: computer-generated randomisation

Method of allocation concealment: not applicable

Blinding and masking: not applicable

Phase 3
Interventions

Outcomes
- Age minimum: not reported

- Age maximum: not reported

- Gender: not reported

- Inclusion criteria: all participants aged between 18 and 70 years

- Diagnosed participants of infectious disease (on clinical evaluation)

- Participants willing to give informed consent

- Participant suffering from any of the following infections: lower respiratory tract infections, skin and skin structure infections, endocarditis, bacterial meningitis, and bone infection

- Exclusion criteria:

- History of hypersensitivity reaction or any specific contraindication to penicillin group of drugs or ceftriaxone or vancomycin

- Presence of hepatic or renal disorder

- Pregnancy and/or lactation

- Intervention: vancomycin ( $2 \mathrm{~g}$ divided either as $500 \mathrm{mg}$ every 6 hours or $1 \mathrm{~g}$ every 12 hours) and ceftriaxone combined ( $6 \mathrm{~g}$ IV in 2 equally divided slow doses, depending on the severity of disease)

- Control intervention: vancomycin (2 g divided either as 500 mg every 6 hours or 1 g every 12 hours)

Primary: efficacy of a $3.0 \mathrm{~g}$ ceftriaxone and vancomycin injection versus $1.0 \mathrm{~g}$ vancomycin injection in participants with mild-to-severe bacterial infections

Secondary: safety of the test and comparative product

Note: the protocol authors did not report primary outcomes, instead reporting a primary objective rather than a measurement of efficacy.

\begin{tabular}{|c|c|}
\hline Starting date & 7 May 2008 \\
\hline \multirow[t]{2}{*}{ Contact information } & $\begin{array}{l}\text { Dr Namit Saraf (Senior Doctor) (drnamitsaraf@rediffmail.com). Orthopaedics Department, Ansari } \\
\text { Road AlIMS 110029, New Delhi, DELHI, India }\end{array}$ \\
\hline & Mahesh Mudgal: Flat No: 90, Pocket A Sector - 14, Dwarka 110029 New Delhi, DELHI, India \\
\hline Notes & $\begin{array}{l}\text { Primary sponsor: Venus Remedies Limited (Venus Remedies Limited 51-52, Industrial Area, Phase 1, } \\
\text { Panchkula, } 134112 \text { Haryana) }\end{array}$ \\
\hline
\end{tabular}

\section{EUCTR 2016-003059-31}

Study name

A multicenter, double-blind, randomized, comparative study of the safety, tolerability, efficacy, and pharmacokinetics of CF-301 versus placebo in addition to standard-of-care antibacterial therapy for the treatment of adult patients with Staphylococcus aureus bloodstream infections (bacteremia) including endocarditis 
EUCTR 2016-003059-31 (Continued)

Arms: 2

Phase: phase II

\begin{tabular}{ll}
\hline Participants & Male or female \\
& - Age: $\geq 18$ years or older \\
- Inclusion criteria: known or suspected endocarditis by modified Duke criteria and/or known or & suspected complicated Staphylococcus aureus, and several other inclusion criteria \\
& - Exclusion criteria: several
\end{tabular}

Interventions

CF-301, solution for infusion

Placebo: solution for infusion, intravenous use

Standard-of-care antibacterial therapy

\begin{tabular}{|c|c|}
\hline Outcomes & $\begin{array}{l}\text { Primary: } \\
\text { - Safety and tolerability of CF-301 versus placebo in addition to standard-of-care antibacterial ther- } \\
\text { apy } \\
\text { - Clinical outcome at Day } 14 \text { after CF-301/placebo administration } \\
\text { - Pharmacokinetic parameters of CF-301 } \\
\text { Secondary endpoint(s): } \\
\text { - Clinical outcome at Day } 7 \text { after CF301/placebo administration } \\
\text { - Clinical outcome at the end of standard-of-care antibacterial therapy, and at test of cure, and } 28 \\
\text { days after test of cure } \\
\text { - Microbiological response } \\
\text { - Microbiological outcome }\end{array}$ \\
\hline Starting date & 27 Octuber 2017 \\
\hline Contact information & Clinical Development Corporation \\
\hline Notes & $\begin{array}{l}\text { Primary sponsor: ContraFect Corporation ( } 28 \text { Wells Ave } 10701 \text { Yonkers, NY, USA) } \\
\text { clinicalstudies@contrafect.com }\end{array}$ \\
\hline
\end{tabular}

EUCTR 2017-001699-43

Study name

A randomized, double-blind, multi-center study to establish the efficacy and safety of ceftobiprole medocaril compared to daptomycin in the treatment of Staphylococcus aureus bacteremia, including infective endocarditis

\begin{tabular}{ll}
\hline Methods & Controlled, randomised, double-blind, parallel group \\
& Phase: phase III \\
& International multicentre \\
\hline Participants & Age minimum: 18 years \\
& Age maximum: not reported \\
& Female: yes \\
Male: yes & Several inclusion and exclusion criteria \\
\hline
\end{tabular}


EUCTR 2017-001699-43 (Continued)

Interventions Ceftobiprole medocaril: infusion

Daptomycin: infusion

Aztreonam: infusion

Doses: not reported

Outcomes

- Primary endpoint(s): overall success at the PTE visit (Day $70 \pm 5$ days postrandomisation): the primary endpoint will be tested for the non-inferiority of ceftobiprole versus daptomycin using a non-inferiority margin of $15 \%$. Several criteria for assessing overall success.

- Secondary objective: to compare ceftobiprole with daptomycin with respect to several criteria

\section{December 2018}

Alain Bobillier (alain.bobillier@basilea.com)

Affiliation: Basilea Pharmaceutica International Ltd

Notes Primary sponsor: Basilea Pharmaceutica International Ltd

\section{EudraCT 2008-008683-28}

\begin{tabular}{ll}
\hline Study name & $\begin{array}{l}\text { Evaluación de la eficacia y la seguridad de la combinación de fosfomicina (F) e imipenem (I) para el } \\
\text { tratamiento de la endocarditis infecciosa (EI) sobre válvula nativa o protésica por Staphylococcus } \\
\text { aureus resistente a meticilina (SARM) }\end{array}$ \\
\hline Methods & Not reported \\
\hline Participants & Age: adults, elderly \\
Sex: male or female
\end{tabular}

\section{JPRN-UMIN 000032006}

\begin{tabular}{ll}
\hline Study name & $\begin{array}{l}\text { An open-label randomized controlled trial of ampicillin/cloxacillin and ceftriaxone for empirical } \\
\text { treatment of infective endocarditis }\end{array}$ \\
\hline Methods & Interventional \\
& Parallel, randomised \\
\hline Participants & Inclusion criteria: \\
& Patients with confirmed or suspected diagnosis of infective endocarditis based on modified \\
Duke's criteria, who need to start empirical treatment waiting for the result of blood cultures
\end{tabular}


- Causative micro-organism already confirmed

- History of allergy or contraindication of penicillin, cephalosporins, and aminoglycoside

- History of prosthetic valve replacement within 1 year

- eGFR less than $50 \mathrm{~mL} / \mathrm{min}$

- White blood cells less than $1000 / \mu \mathrm{L}$, when physicians in charge chose another treatment regimen

- Age minimum: 20 years

- Age maximum: not applicable

- Gender: male and female

Interventions
- Intervention: ampicillin/cloxacillin $4 \mathrm{~g}$ every 4 hours IV maximum for 6 weeks plus gentamicin 3 $\mathrm{mg} / \mathrm{kg}$ every 4 hours IV maximum for 2 weeks

- Control: ceftriaxone $2 \mathrm{~g}$ every 4 hours IV maximum for 6 weeks plus gentamicin $3 \mathrm{mg} / \mathrm{kg}$ every 4 hours IV maximum for 2 weeks

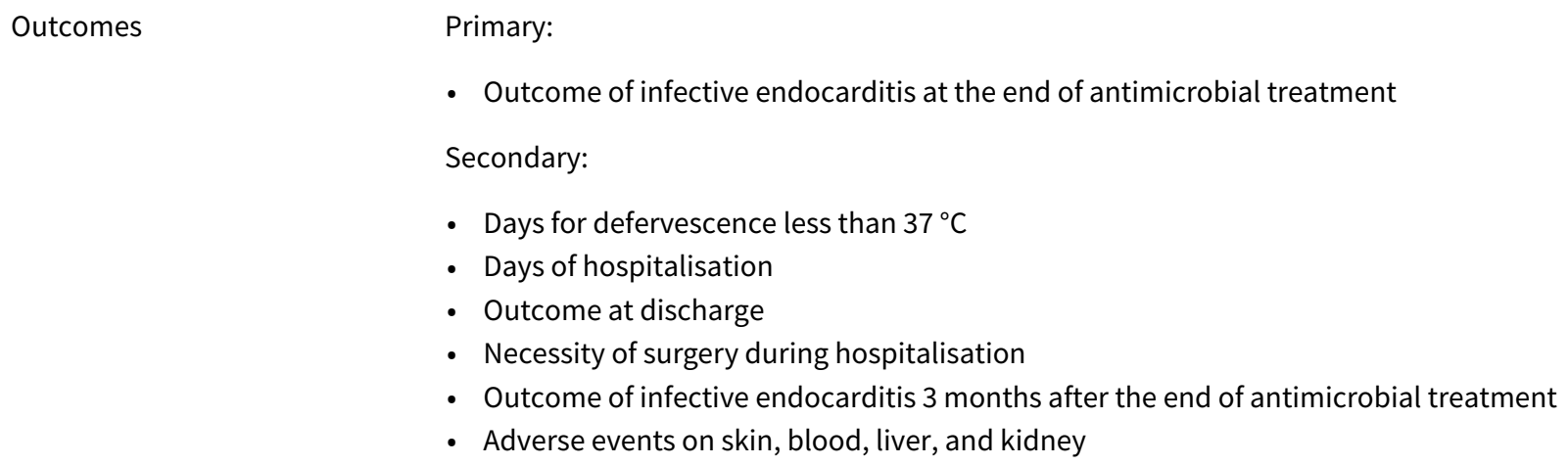

- Outcome of infective endocarditis at the end of antimicrobial treatment

Secondary:

- Days for defervescence less than $37^{\circ} \mathrm{C}$

- Days of hospitalisation

- Outcome at discharge

- Necessity of surgery during hospitalisation

- Outcome of infective endocarditis 3 months after the end of antimicrobial treatment

- Adverse events on skin, blood, liver, and kidney

\begin{tabular}{ll} 
Starting date & 2 April 2018 \\
\hline Contact information & Primary sponsor: Juntendo University \\
& Contacts: Toshio Naito (naito@juntendo.ac.jp) and Yuki Uehara (yuuehara@juntendo.ac.jp) \\
& Affiliation Juntendo University Faculty of Medicine Department of General Medicine
\end{tabular}

Notes

upload.umin.ac.jp/cgi-open-bin/ctr_e/ctr_view.cgi?recptno=R000036524

Date of first enrolment: 2 April 2018

\section{NCT00638157}

Study name

A phase 4 multicenter, randomized, double blind study to describe the efficacy and safety of cubicin (Daptomycin for Injection) with and without initial gentamicin combination therapy in the treatment of Staphylococcus aureus infective endocarditis

\section{Methods}

Interventional, randomised, parallel assignment, and double-blind (participant, investigator)

Phase IV

Estimated enrolment: 24
Inclusion criteria:
- Written informed consent has been obtained
- Men or women $\geq 18$ years
- History of drug abuse within the past 3 months or recent needle track marks
- Definite or possible infective endocarditis according to the modified Duke's criteria


NCT00638157 (Continued)

- 2 blood cultures positive for Staphylococcus aureus obtained within 96 hours prior to first dose of study medication acquired by fresh venepuncture using aseptic technique and analysed at the local laboratory

Exclusion criteria:

- Intravascular foreign material in place at the time that the positive blood culture was drawn

- High likelihood of left infective endocarditis as indicate

- Prosthetic heart valve

- Baseline creatinine clearance of $<30 \mathrm{~mL} /$ minute

- Baseline creatinine phosphokinase value $5 \mathrm{x}$ upper limit of normal in conjunction with symptoms of myalgia or baseline creatine phosphokinase value $10 \mathrm{x}$ upper limit of normal without symptoms

- Alanine aminotransferase $>5 x$ upper limit of normal

- Aspartate aminotransferase $>5 \times$ upper limit of normal

- Moribund clinical condition

- Shock or hypotension

- Known pneumonia or osteomyelitis

- Polymicrobial infection or bacteraemia due to a pathogen other than Staphylococcus aureus

- Neutropenia (absolute neutrophil count $<0.5 \times 10^{3} / \mu \mathrm{L}$ ) or lymphopenia (CD4 lymphocytes $<0.2$ $\left.\times 10^{3} / \mu \mathrm{L}\right)$, or both

- Anticipated to require non-study antibiotics that may potentially be effective against Staphylococcus aureus

- Prior gentamicin therapy $>1$ day

- Documented history of significant allergy or intolerance to any of the study medications

- Unlikely to comply with study procedures

- Pregnant or nursing

- Female of childbearing potential and not willing to practice barrier methods of contraception

Interventions

Experimental: daptomycin $6 \mathrm{mg} / \mathrm{kg}$ every 24 hours with concomitant initial gentamicin dosed for the first 2 days of therapy

Control: daptomycin $6 \mathrm{mg} / \mathrm{kg}$ every 24 hours

Treatment duration: daptomycin will be 28 days. The duration of treatment for gentamicin will be 3 days.

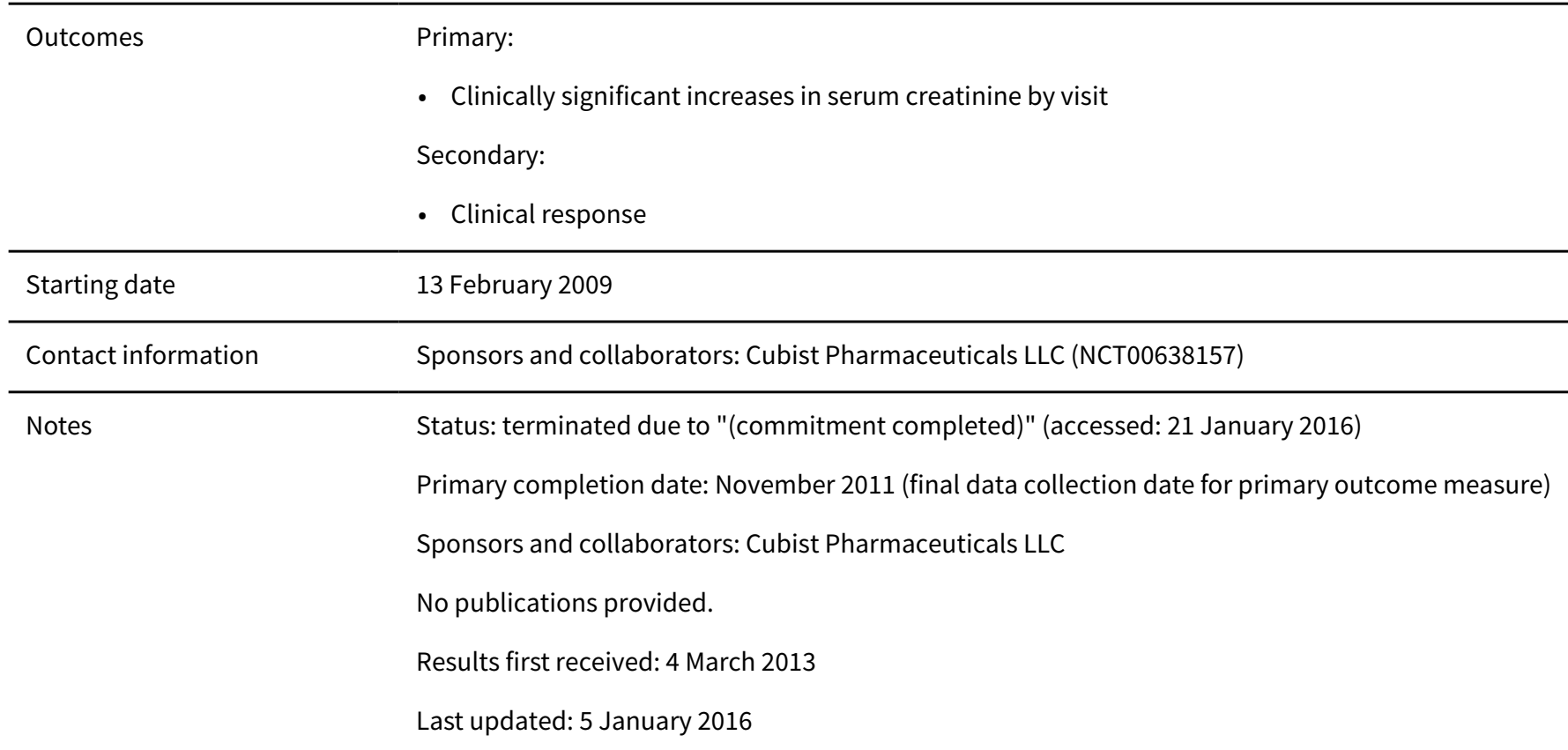

A comparison of different antibiotic regimens for the treatment of infective endocarditis (Review) 
NCT00638157 (Continued)

\section{Organisation: Cubist Pharmaceuticals}

Telephone: 781-860-8318

Email: ed.campanaro@cubist.com ficacy, and pharmacokinetics of daptomycin $10 \mathrm{mg} / \mathrm{kg} /$ day and vancomycin for the treatment of methicillin-resistant Staphylococcus aureus bacteraemia

Methods Interventional, randomised, parallel assignment, and double-blind (participant, investigator)

Phase II

Participants

Enrolment: 38

Inclusion criteria:

- Written informed consent has been obtained

- $\geq 18$ years

- Suspected methicillin-resistant Staphylococcus aureus bacteraemia determined by clinical judgement or 2 sets of positive blood cultures

- Increased risk for a methicillin-resistant Staphylococcus aureus infection

Exclusion criteria:

- Received $>48$ hours of vancomycin therapy in the 7 days prior to enrolment

- Received any systemic antibacterial agents potentially effective against methicillin-resistant Staphylococcus aureus in the 7 days prior to enrolment

- Anticipated requirement of antibiotics potentially effective against methicillin-resistant Staphylococcus aureus

- High likelihood of left-sided infective endocarditis

- Known/suspected polymicrobial bacteraemia or infection including gram-negative infections

- Known pneumonia, osteomyelitis, or meningitis

- Intravascular foreign material unless material intended removed within 3 days

- Prosthetic heart valve

- Cardiac decompensation, valve damage, or both, such that high likelihood of valve replacement surgery within first 3 days of study drug treatment

- Moribund clinical condition such that death likely within first 3 days of study drug treatment

- Shock or hypotension or oliguria unresponsive to fluids after 4 hours

- Received investigational drug within 30 days of study entry

- Received statins or other therapy associated with rhabdomyolysis within 2 days of study entry

- History of significant allergy or intolerance to vancomycin or daptomycin

- Infecting pathogen with confirmed reduced susceptibility to vancomycin

- Infecting pathogen with confirmed reduced susceptibility to daptomycin

- Creatinine clearance $<30 \mathrm{~mL} /$ minute

- Serum creatine phosphokinase $\geq 500 \mathrm{U} / \mathrm{L}$

- Alanine transaminase or aspartate aminotransferase $>5 x$ upper limit of normal

- Total bilirubin $\geq 3.0 \mathrm{mg} / \mathrm{dL}$

- Severe neutropenia or expected development of severe neutropenia during study

- Known or suspected HIV infection with a CD4+ T-cell count $<200 / \mu \mathrm{L}$

- Unlikely to comply with study procedures or return for evaluations

- Body mass index $\geq 40 \mathrm{~kg} / \mathrm{m}^{2}$ 
NCT00695903 (Continued)

- Pregnant or nursing

- Woman of childbearing potential not willing to practice barrier methods of contraception
Experimental: daptomycin $10 \mathrm{mg} / \mathrm{kg}$ IV every 24 hours

Control: vancomycin $15 \mathrm{mg} / \mathrm{kg} \mathrm{IV}$, dosed to maintain trough serum concentrations of 15 to $20 \mu \mathrm{g} /$ $\mathrm{mL}$

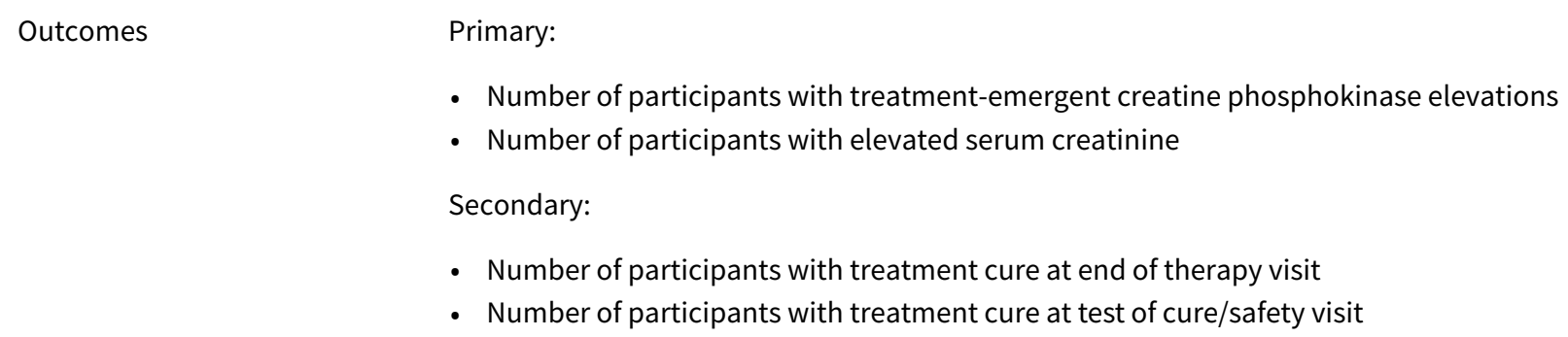

- Number of participants with treatment-emergent creatine phosphokinase elevations

- Number of participants with elevated serum creatinine

Secondary:

- Number of participants with treatment cure at end of therapy visit

- Number of participants with treatment cure at test of cure/safety visit

\begin{tabular}{ll}
\hline Starting date & 17 September 2008 \\
\hline Contact information & Sponsors and collaborators: Cubist Pharmaceuticals LLC \\
& Study director: Peter Pertel, MD; Cubist Pharmaceuticals LLC \\
& Organisation: Cubist Pharmaceuticals \\
& Email: ellie.hershberger@cubist.com \\
\hline
\end{tabular}

Notes Status: terminated due to lack of enrolment (accessed: 21 January 2016)

Study completion date: October 2010

\section{NCT02208063}

Study name

A Phase 3 multicenter, randomized, open-label, clinical trial of telavancin versus standard intravenous therapy in the treatment of subjects with Staphylococcus aureus bacteremia Including Staphylococcus aureus right-sided infective endocarditis

\section{Methods}

Interventional, randomised, parallel assignment and open-label

Phase III

\section{Participants}

\section{Estimated enrolment: 248}

Age: $\geq 18$ years

Gender: men and women

Inclusion criteria:

- $\geq 18$ years with $\geq 1$ blood culture positive for $\mathrm{S}$. aureus within 48 hours before randomisation

- $\geq 1$ of the following signs or symptoms of bacteraemia: temperature $\geq 38.0^{\circ} \mathrm{C}$, white blood cells $>10,000$ or $<4000$ cells $/ \mu \mathrm{L}$ or $>10 \%$ immature neutrophils (bands), tachycardia (heart rate $>90$ beats/minute), tachypnoea (respiratory rate $>20$ breaths/minute), hypotension (systolic blood pressure $<90 \mathrm{mmHg}$ ), signs or symptoms of localised catheter-related infection 
- At enrolment, participants must have:

* known right-sided infective endocarditis by modified Duke's criteria;

* known complicated bacteraemia, demonstrated as signs or symptoms of metastatic foci of Staphylococcus aureus infection; or

* $\geq 1$ risk factor for complicated bacteraemia.

Exclusion criteria:

- Treatment with any potentially effective (antistaphylococcal) systemic antibiotic for $>48$ hours within 7 days before randomisation. Exception: documented resistance to the prior systemic antibacterial therapy

- Presence of any removable infection source (e.g. IV line, abscess) that will not be removed or debrided within 3 days after randomisation

- Presence of prosthetic joint or cardiac device (e.g. implantable cardioverter defibrillator, permanent pacemaker, or prosthetic valve or cardiac valve support ring)

- Known or suspected left-sided infective endocarditis, by modified Duke's criteria

- Known or suspected osteomyelitis (primary or embolic), or meningitis (primary). Note: evidence of metastatic complications related to the primary infection such as right-sided endocarditis, septic arthritis, and septic pulmonary infarcts will be allowed.

Interventions

Experimental: telavancin

Control: standard of care (vancomycin, daptomycin, synthetic penicillin or cefazolin)

\begin{tabular}{ll}
\hline Outcomes & Primary: \\
& - Clinical response (success or failure) \\
Secondary: \\
- Development of new metastatic foci of infection \\
- Clearance of bacteraemia
\end{tabular}

Starting date December 2014

Contact information Peter St Wecker, email: PStwecker@theravance.com; telephone: 650-808-6000

USA

Notes Estimated study completion date: April 2017

Sponsors: Theravance Biopharma Antibiotics Inc

NCT02701595

\begin{tabular}{ll}
\hline Study name & Oral switch during treatment of left-sided endocarditis due to multi-susceptible Streptococcus \\
\hline Methods & Interventional (clinical trial) \\
& Randomised \\
& Parallel assignment \\
& Open-label
\end{tabular}

Participants

Male or female at least 18 years old

Inclusion criteria: several 
NCT02701595 (Continued)

\section{Exclusion criteria: several}

Experimental: oral switch treatment. Oral switch to amoxicillin

Active comparator: conventional IV treatment according to European guidelines. Conventional IV treatment of streptococci/enterococci infective disease (European guidelines 2015)

\section{Outcomes Primary:}

- Failure is a composite outcome defined by death from all causes and/or symptomatic embolic events and/or unplanned valvular surgery and/or a microbiological relapse (with the primary pathogen).

Secondary: several endpoints

\begin{tabular}{ll}
\hline Starting date & 29 February 2016 \\
\hline Contact information & Louis Bernard (L.BERNARD@chu-tours.fr) \\
& Elodie Mousset (e.mousset@chu-tours.fr) \\
\hline Notes & Sponsor: University Hospital, Tours \\
& Principal Investigator: Louis Bernard, MD, PHD \\
\hline
\end{tabular}

\section{NCT02701608}

\begin{tabular}{ll}
\hline Study name & Oral switch during treatment of left-sided endocarditis due to multi-susceptible Staphylococcus \\
\hline Methods & Interventional (clinical trial) \\
& Randomised \\
& Parallel assignment \\
& Open-label \\
\hline
\end{tabular}

\begin{tabular}{ll}
\hline Participants & Male or female at least 18 years old \\
Inclusion criteria: several \\
Exclusion criteria: several
\end{tabular}

Interventions

Experimental: oral switch treatment. Oral switch to combination levofloxacin and rifampicin

Active comparator: conventional IV treatment according to European guidelines. Conventional IV treatment of staphylococci infective endocarditis (European guidelines 2015)

Outcomes Primary:

- Failure is a composite outcome defined by death from all causes and/or symptomatic embolic events and/or unplanned valvular surgery and/or a microbiological relapse (with the primary pathogen).

Secondary: several endpoints

\begin{tabular}{|c|c|}
\hline Starting date & 29 February 2016 \\
\hline Contact information & Louis Bernard (L.BERNARD@chu-tours.fr) \\
\hline
\end{tabular}


NCT02701608 (Continued)

Elodie Mousset (e.mousset@chu-tours.fr)

Notes

Sponsor: University Hospital, Tours

Principal Investigator: Louis Bernard, MD, PHD

\section{NCT03138733}

Study name

A randomized, double-blind, multi-center study to establish the efficacy and safety of ceftobiprole medocaril compared to daptomycin in the treatment of Staphylococcus aureus bacteremia, including infective endocarditis

Methods

Interventional (clinical trial), randomised, parallel assignment, quadruple masking (participant, care provider, investigator, outcomes assessor)
Inclusion criteria:

- Male or female $\geq 18$ years of age

- Staphylococcus aureus bacteraemia, based on at least 1 positive blood culture obtained within the $72 \mathrm{~h}$ prior to randomisation

- At least 2 of the following signs or symptoms of bacteraemia:

- fever $\geq 38^{\circ} \mathrm{C} / 100.4^{\circ} \mathrm{F}$

- white blood cell count $>10,000$ or $<4000$ cells $/ \mu \mathrm{L}$, or $>10 \%$ immature neutrophils (bands)

- tachycardia (heart rate $>90$ beats per minute)

- hypotension (systolic blood pressure $<90 \mathrm{mmHg}$ )

- At least 1 of the following:

- Staphylococcus aureus bacteraemia in patients undergoing chronic intermittent haemodialysis or peritoneal dialysis

- Persistent Staphylococcus aureus bacteraemia

- Definite native-valve right-sided infective endocarditis by modified Duke's criteria

- Other forms of complicated Staphylococcus aureus bacteraemia

Exclusion criteria:

- Treatment with potentially effective (antistaphylococcal) systemic antibacterial treatment for more than $48 \mathrm{~h}$ within the 7 days prior to randomisation. Exception: documented failure of bloodstream clearance

- Bloodstream or non-bloodstream concomitant infections with gram-negative bacteria that are known to be non-susceptible to either ceftobiprole or aztreonam

- Left-sided infective endocarditis

- Prosthetic cardiac valves or valve support rings, cardiac pacemakers, automatic implantable cardioverter-defibrillator, or left-ventricular assist devices

- Community- or hospital-acquired pneumonia

- Opportunistic infections within 30 days prior to randomisation, where the underlying cause of these infections is still active

- Requirement for continuous renal-replacement therapy

- Women who are pregnant or nursing

- Other exclusion criteria may apply

Experimental: ceftobiprole medocaril (ceftobiprole medocaril $500 \mathrm{mg}$ )

Active comparator: daptomycin (daptomycin $6 \mathrm{mg} / \mathrm{kg}$, with or without aztreonam) 
NCT03138733 (Continued)

- Overall success at the PTE

Secondary outcome measures:

- All-cause mortality at the PTE visit

- Microbiological eradication at the PTE visit

- Overall success at the PTE visit

- Development of new metastatic foci or other complications of Staphylococcus aureus bacteraemia after day 7

- Time to Staphylococcus aureus bloodstream clearance

- Incidence, type, severity, and relationship to study medication of adverse events; and changes in laboratory tests

- Ceftobiprole maximum plasma concentration

Ceftobiprole area under the concentration-time curve

\begin{tabular}{ll}
\hline Starting date & 1 June 2018 \\
\hline Contact information & Kamal Hamed, MD, MPH (+4161567 15 88) (kamal.hamed@basilea.com) \\
& Marc Engelhardt, MD (+4161567 15 46) (marc.engelhardt@basilea.com) \\
& Sponsors and collaborators: Basilea Pharmaceutica \\
\hline Notes & International, multicentre (56 sites) \\
& Estimated study completion date: August 2021 \\
\hline
\end{tabular}

\section{NCT03148756}

Study name Efficacy and safety of dalbavancin compared to standard of care antibiotic therapy for the completion of treatment of patients with complicated bacteremia or infective endocarditis

$\begin{array}{ll}\text { Methods } & \begin{array}{l}\text { Interventional (clinical trial), randomised parallel assignment, single-masking (outcomes assessor), } \\ \text { treatment }\end{array}\end{array}$
treatment

\section{Participants}

$$
\text { Male or female } \geq 18 \text { years of age }
$$

Inclusion criteria:

- Diagnosis of complicated bacteraemia or infective endocarditis

- Gram-positive bacteraemia at screening with MSSA, MRSA, or streptococci

- Treatment with standard-of-care antibiotics for $72 \mathrm{~h}-10$ days

- Defervescence for at least $24 \mathrm{~h}$ and clearance of bacteraemia from screening pathogen

Exclusion criteria:

- Embolic events

- History of prosthetic valve surgery, cardiac device, or prosthetic joint

- Left-sided endocarditis due to Staphylococcus aureus

- Large mobile vegetations (> $10 \mathrm{~mm}$ ) on mitral valves

- Perivalvular abscess

- Several other exclusion criteria: see clinicaltrials.gov/ct2/show/NCT03148756 for details 
NCT03148756 (Continued)

Active comparator: standard of care. Antibiotic consistent with standard of care, based on baseline pathogen, for 4 to 6 weeks

\begin{tabular}{ll}
\hline Outcomes & Primary outcome measures: \\
- Number of participants with clinical response at day 84 in the ITT population \\
Secondary outcome measures: \\
- Clinical outcome of success at day 42 in the ITT population \\
- Clinical outcome of success at day 42 in the clinically evaluable population \\
- Number of participants with day 84 mortality in the safety population \\
- Clinical outcome of success at day 84 in the clinically evaluable population \\
- Clinical outcome of success by pathogen at day 42 in the ITT population \\
- Note: total number of secondary outcome measures: 12. See clinicaltrials.gov/ct2/show/ \\
NCT03148756 for details. \\
\hline Starting date \\
\hline Contact information 2017 \\
Sponsor: Allergan \\
Study Director: Urania Rappo, MD \\
\hline Notes
\end{tabular}

\section{NCT04222257}

Study name

Short-course antibiotic regimen compared to conventional antibiotic treatment for Gram-positive Cocci infective endocarditis: randomized clinical trial

Methods Randomised, parallel assignment, open-label

Phase IV

Participants

Male or female at least 18 years old

Inclusion criteria: several

Exclusion criteria: several

- Participants allocated to this group will receive a short course of antibiotic therapy for 2 weeks.

Control group:

- Those participants allocated to continue with standard parenteral treatment will maintain the same antibiotic treatment for 4 to 6 weeks.

\section{Outcomes}

\section{Primary:}

- Composite endpoint: all-cause mortality, unplanned cardiac surgery, symptomatic embolisms, and relapses within 6 months after inclusion into the study, between participants with infective endocarditis caused by gram-positive cocci receiving a short course of 2 weeks of antibiotic therapy and those participants receiving conventional antibiotic therapy for 4 to 6 weeks

Secondary:

- Perceived quality of life: SF-12 
NCT04222257 (Continued)

- Determination of functional performance according to the short performance physical battery test

- Clinical complications: nosocomial infections, intravascular catheter-related infections

- Total hospital length of stay

RBR-3p8g7n 2016

A phase 3 multicenter, randomized, open-label, clinical trial of telavancin versus standard intra-
venous therapy in the treatment of subjects with Staphylococcus aureus bacteremia including in-
fective endocarditis

\begin{tabular}{ll}
\hline Methods & Randomised controlled, parallel, open-label \\
& Arms: 2 \\
& Phase: III \\
& International multicentre study \\
\hline Participants & Male or female at least 18 years old \\
& Inclusion criteria: several \\
& Exclusion criteria: several \\
\hline
\end{tabular}

Interventions

Experimental group:

- Telavancin, $7.5 \mathrm{mg} / \mathrm{kg}$, IV in 100 to $250 \mathrm{~mL}$ over 60 (+/- 10) minutes, once every 24 hours for 2 to 6 weeks

Control group:

- Standard IV therapy, administered for 2 to 6 weeks: vancomycin (recommended dose of $15 \mathrm{mg} / \mathrm{kg}$ IV every 12 hours); daptomycin (recommended dose of $6 \mathrm{mg} / \mathrm{kg}$ IV every 24 hours); antistaphylococcal penicillin (i.e. nafcillin, oxacillin, or cloxacillin) recommended dose of $2 \mathrm{~g}$ IV every 4 hours or $12 \mathrm{~g}$ IV continuous infusion over 24 hours; or cefazolin (recommended dose of $2 \mathrm{~g}$ IV every 8 hours)

\section{Outcomes}

Primary: clinical success or failure at test of cure

Secondary: reported as "not applicable"

Starting date 03 August 2016

Contact information

Anna Carolina Coimbra (Rua da passagem, 123 / $6^{\circ}$ andar, Botafogo 22290-030 Rio de Janeiro, Brazil)

annacarolina.coimbra@incresearch.com

INC Research BR Serviços de Pesquisas Clínicas Ltda

A comparison of different antibiotic regimens for the treatment of infective endocarditis (Review) 
RBR-3p8g7n 2016 (Continued)

Notes

\begin{abstract}
There is inconsistency regarding 'date of registration' (03 August 2016) and 'date of first enrolment' (01 June 2015).
\end{abstract}

Status: discontinued (27 Feb 2018).

Source: https://adisinsight.springer.com/trials/700248032 (6 May 2020).

eGFR: estimated Glomerular Filtration Rate

ITT: intention-to-treat

IV: intravenous

MIC: minimum inhibitory concentration

MRSA: methicillin-resistant Staphylococcus aureus

MSSA: methicillin-susceptible Staphylococcus aureus

PTE: post-treatment evaluation

SF-12: 12-item Short Form Health Survey

$\mathrm{U}$ : unit

\section{AP P E N D I CES}

\section{Appendix 1. Types of infective endocarditis}

- According to localisation of infection and presence or absence of intracardiac material (left-sided native valve, left-sided prosthetic valve, right-sided and device-related (permanent pacemaker or cardioverter-defibrillator)).

- According to the mode of acquisition (healthcare associated (nosocomial and non-nosocomial), community-acquired, and intravenous drug abusers).

- Active (infective endocarditis with persistent fever, and positive blood culture or active inflammatory morphology found at surgery or person still under antibiotic therapy or histopathological evidence of active infective endocarditis).

- Recurrent (relapse or reinfection).

From Habib 2019.

\section{Appendix 2. Clinical presentation of infective endocarditis}

Infective endocarditis should be suspected in the following situations.

- New regurgitant heart murmur.

- Embolic events of unknown origin.

- Sepsis of unknown origin (especially if it is associated with an organism recognised as causing infective endocarditis).

- Fever: the most frequent sign of infective endocarditis. Fever may be absent in older people, after antibiotic pre-treatment, in immunocompromised people, and in infective endocarditis involving less virulent or atypical organisms.

Infective endocarditis should be suspected if fever is associated with the following.

- Intracardiac prosthetic material (e.g. prosthetic valve, pacemaker or implantable defibrillator, surgical baffle/conduit).

- Previous history of infective endocarditis.

- Known valvular or congenital heart disease.

- Other predisposition for infective endocarditis (e.g. immunocompromised state, intravenous drug abusers).

- Recent intervention with associated bacteraemia.

- Evidence of congestive heart failure.

- New conduction disturbance.

- Positive blood cultures with typical infective endocarditis causative organism or positive serology for chronic Q fever (microbiological findings may precede cardiac manifestations).

- Vascular or immunological phenomena: embolic event, Roth spots, splinter haemorrhages, Janeway lesions, Osler's nodes.

- Focal or non-specific neurological symptoms and signs.

- Evidence of pulmonary embolism/infiltration (right-sided infective endocarditis).

- Peripheral abscesses (renal, splenic, cerebral, vertebral) of unknown cause. 
From Habib 2019.

\section{Appendix 3. Antibiotic therapy for the treatment of infective endocarditis: recommended dosages of the main antibiotics}

- Crystalline penicillin $\mathrm{G} 12$ to 18 million U/24 h IV either continuously or in 4 or 6 equally divided doses.

- Ampicillin sodium $12 \mathrm{~g} / 24 \mathrm{~h}$ IV in 6 equally divided doses.

- Flucloxacillin $12 \mathrm{~g} / 24 \mathrm{~h}$ IV in 6 equally divided doses.

- Nafcillin or oxacillin $12 \mathrm{~g} / 24 \mathrm{~h}$ IV in 6 equally divided doses.

- Ceftriaxone $2 \mathrm{~g} / 24 \mathrm{~h}$ IV/IM in 1 dose.

- Vancomycin $30 \mathrm{mg} / \mathrm{kg}$ per $24 \mathrm{~h}$ IV in 2 equally divided doses.

- Teicoplanin $10 \mathrm{mg} / \mathrm{kg}$ per $24 \mathrm{~h}$.

- Gentamicin $3 \mathrm{mg} / \mathrm{kg}$ per $24 \mathrm{~h}$ IV/IM in 1 dose.

- Daptomycin $6 \mathrm{mg} / \mathrm{kg}$ per $24 \mathrm{~h}$.

- Levofloxacin $500 \mathrm{mg} /$ daily either IV or orally.

Abbreviations: IM: intramuscular; IV: intravenous U: unit

Sources: Baddour 2015; FINLEVO Trial 2006..

A description of the various classes of antibiotics and their adverse reactions follows below.

\section{Clinical pharmacology and microbiological spectrum}

Many antimicrobial drugs have been used alone or in combination in the treatment of infective endocarditis (Vinh 2016). They include beta-lactam antibiotics, aminoglycosides, glycopeptides, oxazolidinones, and complex macrocyclic antibiotics (Drees 2006; Frank 2009).

- Beta-lactam antibiotics: includes penicillins, cephalosporins, and carbapenems (Petri 2001a). The penicillins consist of penicillins $\mathrm{G}$ and $\mathrm{V}$, which are highly active against susceptible gram-positive cocci, and ampicillin and other agents with an improved gramnegative spectrum. This group also includes the cephalosporin antibiotics, which are classified by generation: first-generation agents with excellent gram-positive and modest gram-negative activity; second-generation agents with somewhat better activity against gram-negative organisms and some have additional anti-anaerobe activity; third-generation agents have activity against gram-positive organisms and more activity against the Enterobacteriaceae, with a subset active against Pseudomonas aeruginosa; and fourthgeneration agents encompass the antimicrobial spectrum of all the third-generation agents but have increased stability to hydrolysis by inducible chromosomal beta-lactamases (Petri 2001a).

- Aminoglycosides: gentamicin is the most studied drug of this pharmacological antibiotic class (Chambers 2001a), and was once widely used as a primary agent for treating gram-negative infections. However, because of their toxicity and the availability of newer effective agents, systemic aminoglycosides have been primarily relegated to a role as companion drugs, either to broaden coverage against gram-negative aerobic bacilli, or to provide synergistic effects against gram-positive cocci or certain gram-negative bacilli (Chen 2009). Aminoglycosides are poorly absorbed orally, and the excretion of aminoglycosides is primarily by glomerular filtration; clearance is decreased with renal insufficiency, but increased in children and pregnant women (Chen 2009). In addition to gentamicin, amikacin and streptomycin are aminoglycosides that have been used to treat infective endocarditis.

- Glycopeptides: includes vancomycin and teicoplanin, which have been widely used for treating serious gram-positive infections, particularly those involving methicillin-resistant Staphylococcus aureus (Nailor 2009).

- Oxazolidinones: linezolid is a synthetic class of antimicrobial agent. Linezolid has both parenteral and oral preparations with $100 \%$ bioavailability, and penetrates well into tissues (Dryden 2011). The antimicrobial spectrum of the oxazolidinedione is similar to that of vancomycin, with activity against most gram-positive organisms, including methicillin-resistant $S$ aureus and penicillin-resistant pneumococci (Leach 2011; Muñoz 2007; Nailor 2009).

- Complex macrocyclic antibiotics (rifamycins): rifampicin is highly active against both coagulase-positive and -negative staphylococci and other gram-positive cocci, such as Streptococcus pyogenes and Streptococcus pneumoniae (Chen 2009; Petri 2001b). Enterococci are only moderately susceptible. Among gram-negative organisms, Neisseria meningitidis, Neisseria gonorrhoeae, and Hemophilus influenzae are the most susceptible. Rifampicin is well absorbed when given orally. An intravenous preparation is available when the oral route cannot be used. It penetrates well into body fluids, achieving therapeutic levels in saliva, bile, bone, pleural fluid, prostate, and cerebrospinal fluid. Moreover, rifampicin readily enters phagocytic cells and can kill micro-organisms in the cells (Chen 2009).

- Lipopeptide antibiotics (daptomycin): an antibiotic with bactericidal activity against $S$ aureus bacteraemia and endocarditis, and infections caused by Enterococcus spp., especially if vancomycin-resistant (Warren 2008). There are reports of an increasing of daptomycin non-susceptibility in S aureus, Enterococcus faecium, and Enterococcus faecalis (Humphries 2013).

- Fluoroquinolone (levofloxacin): a synthetic antimicrobial agent of third-generation fluoroquinolone that is quickly absorbed by oral administration (Leyva 2008; Liu 2010). This property is important because the intravenous formulation can be changed to oral route. This drug has a broad-spectrum antibacterial profile (Anderson 2008). 


\section{Antibiotic adverse reactions}

The major antibiotic adverse reactions associated with the main antimicrobial drugs for treating infective endocarditis have been widely described (Granowitz 2008). Briefly, untoward reactions of these drugs are as follows.

- Beta-lactam antibiotics: although this group of antibiotics commonly causes drug hypersensitivity reactions (Chambers 2001b; Torres 2010), beta-lactams are generally safe (Lagace-Wiens 2012; Petri 2001a), and serious adverse events are rare and allergy is overdiagnosed (Lagace-Wiens 2012). One publication suggests that amoxicillin given as endocarditis prophylaxis is associated with a very low rate of adverse events (Thornhill 2015).

- Aminoglycosides: gentamicin: the major adverse effects of the aminoglycosides are nephrotoxicity and oto-vestibular toxicity (Chen 2009). Furthermore, aminoglycosides can cause neuromuscular blockade due to interference with neurotransmission at the neuromuscular junction (Chen 2009; Cosgrove 2009).

- Glycopeptides: vancomycin: there are three major adverse events associated with this drug. First, the 'red man' syndrome is a nonimmunologically mediated histamine release associated with rapid infusion of vancomycin. Clinical signs and symptoms include pruritus, erythema, and flushing of the upper torso, angio-oedema, and occasionally, hypotension (Nailor 2009). Second, nephrotoxicity is well described, but rare when vancomycin is used alone and at conventional dosages (e.g. $1 \mathrm{~g}$ every 12 hours) (Nailor 2009). The risk increases in people who are critically ill and on vasopressor support or when used with concomitant nephrotoxic agents, or both; who have deranged renal function at baseline; who are undergoing prolonged duration of therapy; or who are obese (Gupta 2011; WongBeringer 2011). Third, deafness may occur, usually preceded by tinnitus and high-tone hearing loss (Nailor 2009).

- Oxazolidinones: linezolid: the major adverse events associated with the use of this drug include hepatic dysfunction (Gould 2011), peripheral neuropathies (Gould 2011; Vinh 2016), with or without optic neuropathy in people receiving therapy for more than 28 days (Gould 2011), haematological abnormalities (anaemia and thrombocytopenia) (Gould 2011), gastrointestinal disturbances (Gould 2011; Vinh 2016), and lactic acidosis, generally in people with numerous comorbidities, such as thiamine deficiency or cirrhosis (Gould 2011).

- Complex macrocyclic antibiotics: rifampicin: the administration of this drug frequently results in urine and sweat developing an orange tinge; soft contact lenses may be stained. An influenza-like syndrome can occur in up to $5 \%$ of people who have had prolonged intermittent use of rifampicin. Rash and gastrointestinal adverse effects (e.g. nausea, vomiting, diarrhoea, heartburn) may occur in up to $5 \%$ of people. Abnormal liver function tests are common, but frank hepatitis is uncommon (<1\%) (Chen 2009).

- Lipopeptide antibiotics: daptomycin: Shrestha and colleagues have reported that people receiving daptomycin at home have fewer antimicrobial adverse events than similar people receiving vancomycin (Shrestha 2014). One meta-analysis assessing the safety and efficacy of daptomycin versus other antibiotics for skin and soft-tissue infections showed higher creatine phosphokinase elevation in the daptomycin group than in the control group (Wang 2014), as reported by Falagas and colleagues in people with endocarditis and treated with daptomycin (Falagas 2007).

- Fluoroquinolone: levofloxacin: this drug is relatively well tolerated, with low rates of clinically important adverse events such as central nervous system toxicity (headache and dizziness), cardiovascular toxicity (QT interval prolongation), and metabolism glucose disruption (Liu 2010).

\section{How the intervention might work}

Appropriate antibiotic treatment is important to control local infection, eradicate the organisms from the vegetations, and reduce the risk of complications such as septic embolisation (Baddour 2015).

The pharmacodynamics of the most frequent antimicrobial drugs used for treating infective endocarditis include the following.

- Beta-lactam antibiotics: the beta-lactam antibiotics share a common mechanism of action, i.e. inhibition of synthesis of the bacterial peptidoglycan cell wall (Petri 2001a).

- Aminoglycosides: gentamicin is the most studied aminoglycoside, and acts in part by impairing bacterial protein synthesis through irreversible binding to the $30 \mathrm{~S}$ subunit of the bacterial ribosome (Chen 2009).

- Glycopeptides: vancomycin exhibits concentration-independent bactericidal activity by the inhibition of bacterial cell wall synthesis. Vancomycin requires actively growing bacteria to exert its effect (Nailor 2009).

- Oxazolidinones: linezolid exerts its effect early in protein synthesis by inhibiting the initiation complex at the $30 \mathrm{~S}$ ribosome (Nailor 2009; Vinh 2016).

- Complex macrocyclic antibiotics: rifampicin acts by inhibiting deoxyribonucleic acid-dependent ribonucleic acid polymerase, after binding to the beta subunit of the enzyme. This interaction interferes with protein synthesis by preventing chain initiation (Chen 2009).

- Lipopeptide antibiotics: daptomycin affects the membrane of the micro-organism through a calcium-dependent dissipation of membrane potential that leads to the release of intracellular ions from the cell and bacteria death (Vilhena 2012).

- Fluoroquinolone: levofloxacin acts by inhibition of deoxyribonucleic acid gyrase or topoisomerase IV (Leyva 2008).

\section{Appendix 4. Search strategies}

\section{CENTRAL}

\#1 MeSH descriptor: [Endocarditis] explode all trees 
\#2 endocarditi ${ }^{\star}$

\#3 (infect* near/2 endocard ${ }^{\star}$ )

\#4 \#1 or \#2 or \#3

\#5 MeSH descriptor: [Anti-Infective Agents] explode all trees

\#6 ((antimycobacterial or (anti next mycobacterial) or antibacterial or (anti next bacterial) or antibiotic ${ }^{\star}$ ) near/2 (drug* or agent* or

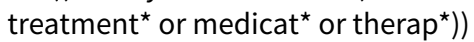

\#7 (((anti next infect $\left.{ }^{\star}\right)$ or antiinfect ${ }^{\star}$ or antimicrobial or (anti next microbial)) near/2 (drug ${ }^{\star}$ or agent or treatment $^{\star}$ or medicat $^{\star}$ or therap m $\left.^{\star}\right)$ \#8 bacteriocid $^{*}$

\#9 ampicillin or amcill or ukapen or polycillin or omnipen or aminobenzylpenicillin or (aminobenzyl next penicillin) or pentrexyl or amoxicillin or azlocillin

\#10 mezlocillin or piperacillin or pivampicillin or talampicillin or aminopenicillin^ or (Penicillin next g) or penilevel or pekamin or penibiot or ursopen or van-pen-g

\#11 pfizerpen or sodiopen or benpen or peniroger or or-pen or pengesod or (sodium next penicillin) or parcillin or unicilina or (benzylpenicillin next potassium)

\#12 sodipen or crystapen or coliriocilina or benzylpenicillin or Sulbenicillin or Carbenicillin or flucloxacillin or floxacillin or fluorochloroxacillin or cefazolin or cephazolin or cephamezine

\#13 cefamedin or totacef or cefamezine or gramaxin or ancef or kefzol or cephalosporin* or ceftriaxon* or terbac or rocefalin or longacef or rocephine or lendacin or rocephin

\#14 cefaxona or ceftrex or longaceph or rocefin or tacex or benaxona

\#15 MeSH descriptor: [Aminoglycosides] explode all trees

\#16 gentam?cin^ or gentavet or genticin or garamycin or gentacycol or gmyticin or (g next myticin) or aminoglycoside* or vancom?cin ${ }^{\star}$ or vanco-saar or (vanco next azupharma)

\#17 diatracin or (vancocin next hcl) or ab-vancomycin or vanco-cell or vancocin* or linezolid* or benemycin or rimactane or tubocin or rifampicin or rimactan or rifadin or rifampin

\#18 MeSH descriptor: [Glycopeptides] explode all trees

\#19 Bleomycin or Peptidoglycan or Ristocetin or Teicoplanin

\#20 MeSH descriptor: [beta-Lactams] this term only

\#21 (beta-lactam near/2 antibiot ${ }^{\star}$ ) or betalactam

$\# 22 \# 5$ or \#6 or \#7 or \#8 or \#9 or \#10 or \#11 or \#12 or \#13 or \#14 or \#15 or \#16 or \#17 or \#18 or \#19 or \#20 or \#21

\#23 \#4 and \#22

\section{MEDLINE Ovid}

1. exp Endocarditis/

2. endocarditi ${ }^{\star}$. tw.

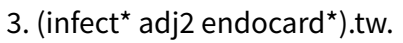

4. or/1-3

5. exp Anti-Infective Agents/

6. ((antimycobacterial or anti mycobacterial or antibacterial or anti bacterial or antibiotic $\left.{ }^{\star}\right)$ adj (drug* or agent ${ }^{\star}$ or treatment $^{\star}$ or medicat ${ }^{\star}$ or therap*)).tw.

7. ((anti infect ${ }^{\star}$ or antiinfect ${ }^{\star}$ or antimicrobial or anti microbial) adj (drug ${ }^{\star}$ or agent ${ }^{\star}$ or treatment ${ }^{\star}$ or medicat ${ }^{\star}$ or therap $\left.\left.^{\star}\right)\right)$.tw. 
8. bacteriocid $^{\star}$. tw.

9. ampicillin.tw.

10. amcill.tw.

11. (ksr1 or ks-r1).tw.

12. ukapen.tw.

13. polycillin.tw.

14. omnipen.tw.

15. (aminobenzylpenicillin or aminobenzyl penicillin).tw.

16. pentrexyl.tw.

17. amoxicillin.tw.

18. azlocillin.tw.

19. mezlocillin.tw.

20. piperacillin.tw.

21. pivampicillin.tw.

22. talampicillin.tw.

23. aminopenicillin*.tw.

24. Penicillin G.tw.

25. penilevel.tw.

26. pekamin.tw.

27. penibiot.tw.

28. ursopen.tw.

29. van-pen-g.tw.

30. pfizerpen.tw.

31. sodiopen.tw.

32. benpen.tw.

33. peniroger.tw.

34. or-pen.tw.

35. pengesod.tw.

36. sodium penicillin.tw.

37. parcillin.tw.

38. unicilina.tw.

39. benzylpenicillin potassium.tw.

40. sodipen.tw.

41. crystapen.tw.

42. coliriocilina.tw.

A comparison of different antibiotic regimens for the treatment of infective endocarditis (Review) 
43. benzylpenicillin.tw.

44. Sulbenicillin.tw.

45. Carbenicillin.tw.

46. flucloxacillin.tw.

47. floxacillin.tw.

48. fluorochloroxacillin.tw.

49. cefazolin.tw.

50. cephazolin.tw.

51. cephamezine.tw.

52. cefamedin.tw.

53. totacef.tw.

54. cefamezine.tw.

55. gramaxin.tw.

56. ancef.tw.

57. kefzol.tw.

58. cephalosporin ${ }^{\star}$. tw.

59. ceftriaxon ${ }^{\star} . t w$.

60. terbac.tw.

61. rocefalin.tw.

62. longacef.tw.

63. rocephine.tw.

64. (ro13 9904 or ro 139904 or ro139904 or ro 139904$). t w$.

65. lendacin.tw.

66. rocephin.tw.

67. cefaxona.tw.

68. ceftrex.tw.

69. longaceph.tw.

70. rocefin.tw.

71. tacex.tw.

72. benaxona.tw.

73. exp Aminoglycosides/

74. gentam? $\operatorname{cin}^{\star} . t w$.

75. gentavet.tw.

76. genticin.tw.

77. garamycin.tw.

A comparison of different antibiotic regimens for the treatment of infective endocarditis (Review) 
78. gentacycol.tw.

79. (g myticin or gmyticin).tw.

80. aminoglycoside $e^{\star}$.tw.

81. vancom?cin*.tw.

82. vanco-saar.tw.

83. vanco azupharma.tw.

84. diatracin.tw.

85. vancocin hcl.tw.

86. ab-vancomycin.tw.

87. vanco-cell.tw.

88. vancocin ${ }^{\star}$. tw

89. linezolid*.tw.

90. benemycin.tw.

91. rimactane.tw.

92. tubocin.tw.

93. rifampicin.tw.

94. rimactan.tw.

95. rifadin.tw.

96. rifampin.tw.

97. exp Glycopeptides/

98. Bleomycin.tw.

99. Peptidoglycan.tw.

100. Ristocetin.tw.

101. Teicoplanin.tw.

102. beta-Lactams/

103. (beta-lactam ${ }^{\star}$ adj2 antibiot $\left.{ }^{\star}\right)$. tw.

104. betalactam.tw.

105. or/5-104

106. 4 and 105

107. randomized controlled trial.pt.

108. controlled clinical trial.pt.

109. randomized.ab.

110. placebo.ab.

111. clinical trials as topic.sh.

112. randomly.ab.

A comparison of different antibiotic regimens for the treatment of infective endocarditis (Review) 
113. trial.ti.

\subsection{7 or 108 or 109 or 110 or 111 or 112 or 113}

115. exp animals/ not humans.sh.

116. 114 not 115

117. 106 and 116

\section{EMBASE Ovid}

1. exp endocarditis/

2. endocarditi ${ }^{\star}$. tw.

3. infect $^{\star}$ adj2 endocard $\left.{ }^{\star}\right)$.tw.

4. or/1-3

5. exp antiinfective agent/

6. ((antimycobacterial or anti mycobacterial or antibacterial or anti bacterial or antibiotic $\left.{ }^{\star}\right)$ adj (drug* or agent ${ }^{\star}$ or treatment $^{\star}$ or medicat ${ }^{\star}$ or therap*)).tw.

7. ((anti infect ${ }^{\star}$ or antiinfect ${ }^{\star}$ or antimicrobial or anti microbial) adj (drug ${ }^{\star}$ or agent ${ }^{\star}$ or treatment ${ }^{\star}$ or medicat ${ }^{\star}$ or therap $\left.\left.^{\star}\right)\right)$.tw.

8. bacteriocid $^{*}$. tw.

9. ampicillin.tw.

10. amcill.tw.

11. (ksr1 or ks-r1).tw.

12. ukapen.tw.

13. polycillin.tw.

14. omnipen.tw.

15. (aminobenzylpenicillin or aminobenzyl penicillin).tw.

16. pentrexyl.tw.

17. amoxicillin.tw.

18. azlocillin.tw.

19. mezlocillin.tw.

20. piperacillin.tw.

21. pivampicillin.tw.

22. talampicillin.tw.

23. aminopenicillin ${ }^{\star} . t w$.

24. Penicillin G.tw.

25. penilevel.tw.

26. pekamin.tw.

27. penibiot.tw.

28. ursopen.tw.

A comparison of different antibiotic regimens for the treatment of infective endocarditis (Review) 
29. van-pen-g.tw.

30. pfizerpen.tw.

31. sodiopen.tw.

32. benpen.tw.

33. peniroger.tw.

34. or-pen.tw.

35. pengesod.tw.

36. sodium penicillin.tw.

37. parcillin.tw.

38. unicilina.tw.

39. benzylpenicillin potassium.tw.

40. sodipen.tw.

41. crystapen.tw.

42. coliriocilina.tw.

43. benzylpenicillin.tw.

44. Sulbenicillin.tw.

45. Carbenicillin.tw.

46. flucloxacillin.tw.

47. floxacillin.tw.

48. fluorochloroxacillin.tw.

49. cefazolin.tw.

50. cephazolin.tw.

51. cephamezine.tw.

52. cefamedin.tw.

53. totacef.tw.

54. cefamezine.tw.

55. gramaxin.tw.

56. ancef.tw.

57. kefzol.tw.

58. cephalosporin*.tw.

59. ceftriaxon ${ }^{\star} . t w$.

60. terbac.tw.

61. rocefalin.tw.

62. longacef.tw.

63. rocephine.tw.

A comparison of different antibiotic regimens for the treatment of infective endocarditis (Review) 
64. (ro13 9904 or ro 139904 or ro139904 or ro 13 9904).tw.

65. lendacin.tw.

66. rocephin.tw.

67. cefaxona.tw.

68. ceftrex.tw.

69. longaceph.tw.

70. rocefin.tw.

71. tacex.tw.

72. benaxona.tw.

73. exp aminoglycoside/

74. gentam? $\operatorname{cin}^{\star}$. tw.

75. gentavet.tw.

76. genticin.tw.

77. garamycin.tw.

78. gentacycol.tw.

79. (g myticin or gmyticin).tw.

80. aminoglycoside ${ }^{\star}$.tw.

81. vancom?cin ${ }^{\star}$.tw.

82. vanco-saar.tw.

83. vanco azupharma.tw.

84. diatracin.tw.

85. vancocin hcl.tw.

86. ab-vancomycin.tw.

87. vanco-cell.tw.

88. vancocin ${ }^{\star}$. tw

89. linezolid ${ }^{\star}$. tw.

90. benemycin.tw.

91. rimactane.tw.

92. tubocin.tw.

93. rifampicin.tw.

94. rimactan.tw.

95. rifadin.tw.

96. rifampin.tw.

97. exp glycopeptide/

98. Bleomycin.tw.

A comparison of different antibiotic regimens for the treatment of infective endocarditis (Review) 
99. Peptidoglycan.tw.

100. Ristocetin.tw.

101. Teicoplanin.tw.

102. beta lactam/

103. (beta-lactam ${ }^{\star}$ adj2 antibiot $\left.{ }^{\star}\right)$.tw.

104. betalactam.tw.

105. or/5-104

106. 4 and 105

107. random\$.tw.

108. factorial\$.tw.

109. crossover\$.tw.

110. cross over\$.tw.

111. cross-over\$.tw.

112. placebo\$.tw.

113. (doubl\$ adj blind\$).tw.

114. (singl\$ adj blind\$).tw.

115. assign\$.tw.

116. allocat\$.tw.

117. volunteer\$.tw.

118. crossover procedure/

119. double blind procedure/

120. randomized controlled trial/

121. single blind procedure/

122. 107 or 108 or 109 or 110 or 111 or 112 or 113 or 114 or 115 or 116 or 117 or 118 or 119 or 120 or 121

123. (animal/ or nonhuman/) not human/

124. 122 not 123

125. 106 and 124

126. limit 125 to embase

\section{LILACS}

"antibiotics" [Subject descriptor] or (antibiotic\$ OR antiinfect\$ OR anti-infect\$ OR antibacter\$ OR anti-bacter\$) [Words] and (endocarditis) or "endocarditis" [Words]

\section{CINAHL}

S51 S32 AND S50

S50 S33 OR S34 OR S35 OR S36 OR S37 OR S38 OR S39 OR S40 OR S41 OR S42 OR S43 OR S44 OR S45 OR S46 OR S47 OR S48 OR S49

S49 cross-over*

A comparison of different antibiotic regimens for the treatment of infective endocarditis (Review) 
S48 crossover ${ }^{\star}$

S47 volunteer*

S46 (MH "Crossover Design")

S45 allocat*

S44 control*

S43 assign *

S42 placebo*

S41 (MH "Placebos")

S40 random*

S39 (doubl ${ }^{\star}$ N1 mask ${ }^{\star}$ )

S38 (singl* N1 mask*)

S37 (doubl* N1 blind ${ }^{\star}$ )

S36 (singl* N1 blind)

S35 (clinic* N1 trial?)

S34 PT clinical trial

S33 (MH "Clinical Trials")

S32 S4 and S31

$\mathrm{S} 31 \mathrm{~S} 5$ or $\mathrm{S} 6$ or $\mathrm{S} 7$ or S8 or S9 or S10 or S11 or S12 or S13 or S14 or S15 or S16 or S17 or S18 or S19 or S20 or S21 or S22 or S23 or S24 or $\mathrm{S} 25$ or $\mathrm{S} 26$ or $\mathrm{S} 27$ or $\mathrm{S} 28$ or $\mathrm{S} 29$ or $\mathrm{S} 30$

S30 AB (gentam?cin* or gentavet or genticin or garamycin or gentacycol or gmyticin or "g myticin" or aminoglycoside* or vancom?cin* or vanco-saar or "vanco azupharma")

S29 TI (gentam?cin* or gentavet or genticin or garamycin or gentacycol or gmyticin or "g myticin" or aminoglycoside* or vancom?cin* or vanco-saar or "vanco azupharma")

$\mathrm{S} 28 \mathrm{AB}$ ((beta-lactam* $\mathrm{N} 2$ antibiot $\left.^{\star}\right)$ or betalactam)

S27 TI ((beta-lactam* N2 antibiot*) or betalactam)

S26 AB (Bleomycin or Peptidoglycan or Ristocetin or Teicoplanin or glycopeptid*)

S25 TI (Bleomycin or Peptidoglycan or Ristocetin or Teicoplanin or glycopeptid*)

S24 AB (diatracin or "vancocin hcl" or ab-vancomycin or vanco-cell or vancocin* or linezolid* or benemycin or rimactane or tubocin or rifampicin or rimactan or rifadin or rifampin)

S23 TI (diatracin or "vancocin hcl" or ab-vancomycin or vanco-cell or vancocin* or linezolid* or benemycin or rimactane or tubocin or rifampicin or rimactan or rifadin or rifampin)

S22 (MH "Aminoglycosides+")

S21 TI (cefaxona or ceftrex or longaceph or rocefin or tacex or benaxona) or AB (cefaxona or ceftrex or longaceph or rocefin or tacex or benaxona)

$\mathrm{S} 20 \mathrm{AB}$ (cefamedin or totacef or cefamezine or gramaxin or ancef or kefzol or cephalosporin* or ceftriaxon* or terbac or rocefalin or longacef or rocephine or lendacin or rocephin)

$\mathrm{S} 19 \mathrm{TI}$ (cefamedin or totacef or cefamezine or gramaxin or ancef or kefzol or cephalosporin* or ceftriaxon* or terbac or rocefalin or longacef or rocephine or lendacin or rocephin) 
S18 AB (sodipen or crystapen or coliriocilina or benzylpenicillin or Sulbenicillin or Carbenicillin or flucloxacillin or floxacillin or fluorochloroxacillin or cefazolin or cephazolin or cephamezine)

S17 TI (sodipen or crystapen or coliriocilina or benzylpenicillin or Sulbenicillin or Carbenicillin or flucloxacillin or floxacillin or fluorochloroxacillin or cefazolin or cephazolin or cephamezine)

S16 AB (pfizerpen or sodiopen or benpen or peniroger or or-pen or pengesod or "sodium penicillin" or parcillin or unicilina or "benzylpenicillin potassium")

S15 TI (pfizerpen or sodiopen or benpen or peniroger or or-pen or pengesod or "sodium penicillin" or parcillin or unicilina or "benzylpenicillin potassium")

S14 AB (mezlocillin or piperacillin or pivampicillin or talampicillin or aminopenicillin* or "Penicillin g" or penilevel or pekamin or penibiot or ursopen or van-pen-g)

S13 TI (mezlocillin or piperacillin or pivampicillin or talampicillin or aminopenicillin* or "Penicillin g" or penilevel or pekamin or penibiot or ursopen or van-pen-g)

S12 AB (ampicillin or amcill or ukapen or polycillin or omnipen or aminobenzylpenicillin or "aminobenzyl penicillin" or pentrexyl or amoxicillin or azlocillin)

S11 TI (ampicillin or amcill or ukapen or polycillin or omnipen or aminobenzylpenicillin or "aminobenzyl penicillin" or pentrexyl or amoxicillin or azlocillin)

S10 TI bacteriocid* or AB bacteriocid*

S9 AB (("anti infect*" or antiinfect* or antimicrobial or "anti microbial") N2 (drug* or agent* or treatment* or medicat* or therap*))

S8 TI (("anti infect*" or antiinfect* or antimicrobial or "anti microbial") N2 (drug* or agent ${ }^{\star}$ or treatment* or medicat ${ }^{\star}$ or therap*))

S7 AB ((antimycobacterial or "anti mycobacterial" or antibacterial or "anti bacterial" or antibiotic*) N2 (drug* or agent* or treatment* or medicat* or therap*))

S6 TI ((antimycobacterial or "anti mycobacterial" or antibacterial or "anti bacterial" or antibiotic $\left.{ }^{\star}\right)$ N2 (drug* or agent ${ }^{\star}$ or treatment* or medicat $^{\star}$ or therap $\left.{ }^{\star}\right)$ )

S5 (MH "Antiinfective Agents+")

S4 S1 or S2 or S3

S3 TI (infect* N2 endocard*) or AB (infect* N2 endocard*)

S2 TI endocarditi* or AB endocarditi*

S1 (MH "Endocarditis+")

\section{Web of Science}

\#14 \#13 AND \#12

\#13 TS=(random ${ }^{\star}$ or blind ${ }^{\star}$ or allocat ${ }^{\star}$ or assign ${ }^{\star}$ or trial ${ }^{\star}$ or placebo ${ }^{\star}$ or crossover ${ }^{\star}$ or $_{\text {cross-over }}^{\star}$ )

\#12 \#11 AND \#1

\#11 \#10 OR \#9 OR \#8 OR \#7 OR \#6 OR \#5 OR \#4 OR \#3 OR \#2

\#10 TS=(Bleomycin or Peptidoglycan or Ristocetin or Teicoplanin or (beta-lactam* NEAR/2 antibiot* ) or betalactam)

\#9 TS=(cefaxona or ceftrex or longaceph or rocefin or tacex or benaxona or Glycopeptide ${ }^{\star}$ )

\#8 TS=(cefamedin or totacef or cefamezine or gramaxin or ancef or kefzol or cephalosporin* or ceftriaxon* or terbac or rocefalin or longacef or rocephine or lendacin or rocephin)

\#7 TS=(sodipen or crystapen or coliriocilina or benzylpenicillin or Sulbenicillin or Carbenicillin or flucloxacillin or floxacillin or fluorochloroxacillin or cefazolin or cephazolin or cephamezine)

\#6 TS=(pfizerpen or sodiopen or benpen or peniroger or or-pen or pengesod or "sodium penicillin" or parcillin or unicilina or "benzylpenicillin potassium") 
\#5 TS=(mezlocillin or piperacillin or pivampicillin or talampicillin or aminopenicillin* or "Penicillin g" or penilevel or pekamin or penibiot or ursopen or van- pen-g)

\#4 TS=(bacteriocid* or ampicillin or amcill or ukapen or polycillin or omnipen or aminobenzylpenicillin or "aminobenzyl penicillin" or pentrexyl or amoxicillin or azlocillin)

\#3 TS=(("anti infect*" or antiinfect* or antimicrobial or "anti microbial") NEAR/2 (drug* or agent* or treatment* or medicat* or therap*))

\#2 TS=((antibiotic ${ }^{\star}$ or antimycobacterial or "anti mycobacterial" or antibacterial or "anti bacterial") NEAR/2 (drug* or agent* or treatment* or medicat* or therap $\left.{ }^{\star}\right)$ )

\#1 TS=endocard*

\section{clinicaltrials.gov}

infective endocarditis plus randomized and recruiting OR not yet recruiting

\section{International Clinical Trials Registry Platform Search Portal}

infective endocarditis AND randomized

\section{ISRCTN registry}

infective endocarditis AND randomized

\section{Appendix 5. Assessment of risk of bias in included studies}

\section{Generation of allocation sequence (checking for possible selection bias)}

We described for each included study the method used to generate the allocation sequence in sufficient detail to allow an assessment of whether it should produce comparable groups.

We assessed the method as:

- low risk (any truly random process, e.g. random number table; computer random number generator);

- high risk (any non-random process, e.g. odd or even date of birth; hospital or clinic record number);

- unclear, if the trial was described as randomised, but the method used for the allocation sequence generation was not described.

\section{Allocation concealment (checking for possible selection bias)}

We described for each included study the method used to conceal the allocation sequence in sufficient detail to determine whether intervention allocation could have been foreseen in advance of, or during recruitment, or changed after assignment.

We assessed the methods as:

- low risk (e.g. telephone or central randomisation; consecutively numbered, sealed, opaque envelopes);

- high risk (open random allocation; unsealed or non-opaque envelopes, alternation; date of birth);

- unclear, if the trial was described as randomised, but the method used to conceal the allocation was not described.

\section{Blinding or masking (checking for possible performance bias)}

We described for each included study the methods used, if any, to blind study participants and personnel from the knowledge of which intervention a participant received. We judged studies to be at low risk of bias if they were blinded, or if we judged that the lack of blinding could not have affected the results. We assessed blinding separately for different outcomes or classes of outcomes.

We assessed the methods as:

- low risk, high risk, or unclear risk for participants;

- low risk, high risk, or unclear risk for personnel;

- low risk, high risk, or unclear risk for outcome assessors.

\section{Incomplete outcome data (checking for possible attrition bias through withdrawals, dropouts, protocol deviations)}

- Low risk (any one of the following): no missing outcome data; reasons for missing outcome data unlikely to be related to true outcome (for survival data, censoring unlikely to be introducing bias); missing outcome data balanced in numbers across intervention groups, with similar reasons for missing data across groups; for dichotomous outcome data, the proportion of missing outcomes compared with observed event risk not enough to have a clinically relevant impact on the intervention effect estimate; for continuous outcome 
data, plausible effect size (difference in means or standardised difference in means) amongst missing outcomes not enough to have a clinically relevant impact on observed effect size; missing data were imputed using appropriate methods.

- High risk (any one of the following): reason for missing outcome data likely to be related to true outcome, with either an imbalance in numbers or reasons for missing data across intervention groups; for dichotomous outcome data, the proportion of missing outcomes compared with observed event risk enough to induce clinically relevant bias in intervention effect estimate; for continuous outcome data, plausible effect size (difference in means or standardised difference in means) amongst missing outcomes enough to induce clinically relevant bias in observed effect size; 'as-treated' analysis done with substantial departure of the intervention received from that assigned at randomisation; potentially inappropriate application of simple imputation.

- Unclear risk (any one of the following): insufficient reporting of attrition/exclusions to permit judgement of 'low risk' or 'high risk' (e.g. number randomised not stated, no reasons for missing data provided); the study did not address this outcome.

\section{Selective reporting bias (reporting bias due to selective outcome reporting)}

We described for each included study how we investigated the possibility of selective outcome reporting bias and what we found.

We assessed the methods as:

- low risk (any one of the following): the study protocol was available, and all of the study's prespecified (primary and secondary) outcomes that were of interest in the review were reported in the prespecified way, or the study protocol was not available but it was clear that the published reports included all expected outcomes, including those that were prespecified (convincing text of this nature may be uncommon);

- high risk (any one of the following): not all of the study's prespecified primary outcomes were reported; one or more primary outcomes were reported using measurements, analysis methods, or subsets of the data (e.g. subscales) that were not prespecified; one or more reported primary outcomes were not prespecified (unless clear justification for their reporting was provided, such as an unexpected adverse effect); one or more outcomes of interest in the review were reported incompletely so that they could not be entered in a metaanalysis; the study report did not include results for a key outcome that would be expected to have been reported for such a study;

- unclear risk: insufficient information to permit judgement of 'low risk' or 'high risk'.

\section{Free of other bias (bias due to problems not covered elsewhere)}

We described for each included study any important concerns we had about other possible sources of bias (sponsorship bias, confirmation bias, bias of the presentation data, etc.).

- Low risk: the trial appears to be free of other components that could put it at risk of bias.

- High risk: there are other factors in the trial that could put it at risk of bias (e.g. no sample size calculation made).

- Unclear risk: the trial may or may not be free of other components that could put it at risk of bias.

\section{Overall risk of bias}

We made explicit judgements about whether studies were at high risk of bias, according to the criteria described in the Cochrane Handbook for Systematic Reviews of Interventions (Higgins 2011). We assessed the likely magnitude and direction of the bias and whether we considered it was likely to impact on the findings.

\section{Appendix 6. Oral regimens recommended in POET 2019}

Penicillin and methicillin-sensitive Staphylococcus aureus and coagulase-negative staphylococci

- Amoxicillin $1 \mathrm{~g} \times 4$ and fusidic acid $0.75 \mathrm{~g} \times 2$

- Amoxicillin $1 \mathrm{~g} \times 4$ and rifampicin $0.6 \mathrm{~g} \times 2$

- Linezolid $0.6 \mathrm{~g} \times 2$ and fusidic acid $0.75 \mathrm{~g} \times 2$

- Linezolid $0.6 \mathrm{~g} \times 2$ and rifampicin $0.6 \mathrm{~g} \times 2$

Methicillin-sensitive Staphylococcus aureus and coagulase-negative staphylococci

- Dicloxacillin $1 \mathrm{~g} \times 4$ and fusidic acid $0.75 \mathrm{~g} \times 2$

- Dicloxacillin $1 \mathrm{~g} \times 4$ and rifampicin $0.6 \mathrm{~g} \times 2$

- Linezolid $0.6 \mathrm{~g} \times 2$ and fusidic acid $0.75 \mathrm{~g} \times 2$

- Linezolid $0.6 \mathrm{~g} \times 2$ and rifampicin $0.6 \mathrm{~g} \times 2$

Methicillin-resistant coagulase-negative staphylococci

- Linezolid $0.6 \mathrm{~g} \times 2$ and fusidic acid

- Linezolid $0.6 \mathrm{~g} \times 2$ and rifampicin $0.6 \mathrm{~g} \times 2$ 
Enterococcus faecalis

- Amoxicillin $1 \mathrm{~g} \times 4$ and rifampicin $0.6 \mathrm{~g} \times 2$

- Amoxicillin $1 \mathrm{~g} \times 4$ and moxifloxacin $0.4 \mathrm{~g} \times 1$

- Linezolid $0.6 \mathrm{~g} \times 2$ and rifampicin $0.6 \mathrm{~g} \times 2$

- Linezolid $0.6 \mathrm{~g} \times 2$ and moxifloxacin $0.4 \mathrm{~g} \times 1$

Streptococci with a minimal inhibitory concentration for penicillin of $<1 \mathrm{mg} / \mathrm{L}$

- Amoxicillin $1 \mathrm{~g} \times 4$ and rifampicin $0.6 \mathrm{~g} \times 2$

- Linezolid $0.6 \mathrm{~g} \times 2$ and rifampicin $0.6 \mathrm{~g} \times 2$

- Linezolid $0.6 \mathrm{~g} \times 2$ and moxifloxacin $0.4 \mathrm{~g} \times 1$

Streptococci with a minimal inhibitory concentration for penicillin of $\geq 1 \mathrm{mg} / \mathrm{L}$

- Linezolid $0.6 \mathrm{~g} \times 2$ and rifampicin $0.6 \mathrm{~g} \times 2$

- Moxifloxacin $0.4 \mathrm{~g} \times 1$ and rifampicin $0.6 \mathrm{~g} \times 2$

- Moxifloxacin $0.4 \mathrm{~g} \times 1$ and clindamycin $0.6 \mathrm{~g} \times 3$

Source: POET 2019 (Supplementary Appendix).

\section{Appendix 7. Oral antibiotic regimens in POET 2019}

\begin{tabular}{lll}
\hline Micro-organism & Regimens & Frequency (\%) \\
\hline Staphylococcus aureus & Dicloxacillin and rifampicin & 29 \\
\cline { 2 - 3 } & Amoxicillin and rifampicin & 47 \\
\hline Enterococcus faecalis & Amoxicillin and moxifloxacin & 25 \\
\cline { 2 - 3 } & Amoxicillin and linezolid & 12 \\
\cline { 2 - 3 } & Amoxicillin and rifampicin & 10 \\
\cline { 2 - 3 } & Moxifloxacin and linezolid & 52 \\
\hline Streptococci & Amoxicillin and rifampicin & 13 \\
\cline { 2 - 3 } & Amoxicillin and moxifloxacin & 38 \\
\hline lococci & Fusidic acid and linezolid & 31
\end{tabular}

Source: POET 2019 (Supplementary Appendix)

WHAT'S NEW

\begin{tabular}{lll}
\hline Date & Event & Description \\
\hline 5 February 2020 & $\begin{array}{l}\text { New citation required but conclusions } \\
\text { have not changed }\end{array}$ & $\begin{array}{l}\text { Conclusion: This first update confirms the findings of the original } \\
\text { version: current evidence does not support or reject any regimen } \\
\text { of antibiotic therapy for the treatment of infective endocarditis. }\end{array}$ \\
\hline
\end{tabular}




\begin{tabular}{|c|c|c|}
\hline Date & Event & Description \\
\hline 6 January 2020 & New search has been performed & $\begin{array}{l}\text { This update is based on a search from } 6 \text { January } 2020 \text { and in- } \\
\text { cludes two new randomised controlled trials. The review has a } \\
\text { total of six included trials. }\end{array}$ \\
\hline
\end{tabular}

\section{HIS T O R Y}

Protocol first published: Issue 5, 2012

Review first published: Issue 4, 2016

\section{CONTRIBUTIONSOF AUTHORS}

Arturo Martí-Carvajal is the lead author of the protocol and review, and acts as guarantor of the review.

Mark Dayer reviewed and contributed to the manuscript.

Lucieni Oliveira Conterno contributed to the review conception and design; screened the studies for inclusion; assessed the risk of bias; interpreted the results providing a clinical perspective; revised and commented on the draft; and approved the final version.

Alejandro González Garay and Cristina Martí-Amarista checked the search results and data, and contributed to the manuscript.

\section{DECLARATIONS OF INTEREST}

Arturo Martí-Carvajal: in 2004 Arturo Martí-Carvajal was employed by Eli Lilly to run a four-hour workshop on 'How to critically appraise clinical trials on osteoporosis and how to teach this'. This activity was not related to his work with Cochrane or any Cochrane Review. In 2007, Arturo Martí-Carvajal was employed by Merck to run a four-hour workshop on 'How to critically appraise clinical trials and how to teach this'. This activity was not related to his work with Cochrane or any Cochrane Review.

Mark Dayer is currently undertaking clinical trials, sponsored by Novartis, in the field of heart failure. He has received no direct funding from Novartis since 2008, when the company sponsored his attendance at the European Society of Cardiology. Novartis is the manufacturer of daptomycin. In 2015, Dr Dayer received educational sponsorship from Bayer. He received advisory board fees from Res-Med (2014 to 2015), Daiichi-Sankyo (2015), and St Jude (2015 to 2016). Between 2007 and 2015, Dr Dayer also received educational sponsorship/speaker fees from Boehringer-Ingelheim, Pfizer, Boston Scientific, Medtronic, Biotronik, and Sorin.

Lucieni Oliveira Conterno, Alejandro González Garay, and Cristina Martí-Amarista have no known conflicts of interest.

None of the authors of this review were authors on the studies considered by this review.

\section{SOURCES OF SUPPORT}

\section{Internal sources}

- Cochrane Ecuador, Ecuador

Financial

\section{External sources}

- Iberoamerican Cochrane Center, Spain Academic

- NIHR Cochrane Infrastructure Funding, UK

This project was supported by the National Institute for Health Research, via Cochrane Infrastructure, Cochrane Programme Grant or Cochrane Incentive funding to the Heart Group. The views and opinions expressed therein are those of the authors and do not necessarily reflect those of the Systematic Reviews Programme, NIHR, NHS or the Department of Health and Social Care.

\section{DIFFERENCES BETWEEN PROTOCOL AND REVIEW}

- We added: 
- lipopeptide antibiotics (daptomycin) into the Background and Types of interventions due to the inclusion of a trial assessing that drug (Fowler 2006);

- quinolone antibiotics (levofloxacin) into the Background and Types of interventions due to the inclusion of a trial assessing that drug (FINLEVO Trial 2006).

- We changed:

- the initial review question, which was to assess the effect of antibiotic treatment versus no antibiotic treatment, as no suitable studies were identified;

- the number of authors who extracted data. We had planned for three review authors to independently extract data, but only two extracted the data, as only two review authors were available at the time of the data extraction;

- the presentation of data. We added a 'Summary of findings' table and GRADE assessments;

- the search strategy. We did not search the Scientific Electronic Library Online (SciELO) because of more recent concerns over the quality of some open access studies;

- we removed the following sentence: "...we will consider there to be substantial statistical heterogeneity if the $I^{2}$ statistic is greater than $50 \%$ (Higgins 2011), and will explore this by pre-specified subgroup analysis". We did this to adapt this Cochrane Review to statistical issues and common analysis queries of the Cochrane Heart Group;

- we removed those studies that were not randomised controlled trials from the Excluded studies section.

\section{IN DEX TERMS}

\section{Medical Subject Headings (MeSH)}

Anti-Bacterial Agents [adverse effects] [*therapeutic use]; Endocarditis, Bacterial [ ${ }^{*}$ drug therapy] [microbiology] [mortality]; Fosfomycin [adverse effects] [therapeutic use]; Imipenem [adverse effects] [therapeutic use]; Levofloxacin [adverse effects] [therapeutic use]; Penicillins [adverse effects] [therapeutic use]; Randomized Controlled Trials as Topic; Vancomycin [adverse effects] [therapeutic use]

\section{MeSH check words}

Female; Humans; Male 